\title{
MAGNETO-RHEOLOGICAL (MR) DAMPER FOR LANDING GEAR SYSTEM
}

\author{
Mahboubeh Khani
}

\author{
A Thesis \\ in \\ the Department \\ of \\ Mechanical and Industrial Engineering
}

Presented in Partial Fulfillment of the Requirements

for the Degree of Master of Applied Science (Mechanical Engineering) at Concordia University

Montreal, Quebec, Canada

June 2010

(C) Mahboubeh Khani, 2010 
Library and Archives

Canada

Published Heritage

Branch

395 Wellington Street

Ottawa ON K1A ON4

Canada
Bibliothèque et

Archives Canada

Direction du

Patrimoine de l'édition

395 , rue Wellington

Ottawa ON K1A ON4

Canada
Your file Votre référence

ISBN: 978-0-494-71048-7

Our file Notre référence

ISBN: 978-0-494-71048-7
NOTICE:

The author has granted a nonexclusive license allowing Library and Archives Canada to reproduce, publish, archive, preserve, conserve, communicate to the public by telecommunication or on the Internet, loan, distribute and sell theses worldwide, for commercial or noncommercial purposes, in microform, paper, electronic and/or any other formats.

The author retains copyright ownership and moral rights in this thesis. Neither the thesis nor substantial extracts from it may be printed or otherwise reproduced without the author's permission.
AVIS:

L'auteur a accordé une licence non exclusive permettant à la Bibliothèque et Archives Canada de reproduire, publier, archiver, sauvegarder, conserver, transmettre au public par télécommunication ou par l'Internet, prêter, distribuer et vendre des thèses partout dans le monde, à des fins commerciales ou autres, sur support microforme, papier, électronique etou autres formats.

L'auteur conserve la propriété du droit d'auteur et des droits moraux qui protège cette thèse. $\mathrm{Ni}$ la thèse ni des extraits substantiels de celle-ci ne doivent être imprimés ou autrement reproduits sans son autorisation.
In compliance with the Canadian Privacy Act some supporting forms may have been removed from this thesis.

While these forms may be included in the document page count, their removal does not represent any loss of content from the thesis.
Conformément à la loi canadienne sur la protection de la vie privée, quelques formulaires secondaires ont été enlevés de cette thèse.

Bien que ces formulaires aient inclus dans la pagination, il n'y aura aucun contenu manquant. 


\title{
ABSTRACT \\ Magneto-Rheological (MR) Damper for Landing Gear System
}

\author{
Mahboubeh Khani
}

Depending on the different sink speeds, angles of attack and masses; aircraft landing gears could face a wide range of impact conditions which may possibly cause structural damage or failure. Thus, in hard landing scenarios, the landing gear must absorb sufficient energy in order to minimize dynamic stress on the aircraft airframe. Semi-active control systems are the recent potential solutions to overcome these limitations. Among semi-active control strategies, those based on smart fluids such as magneto-rheological (MR) fluids have received recent attraction as their rheological properties can be continuously controlled using magnetic or electric field and they are not sensitive to the contaminants and the temperature variation and also require lower powers.

This thesis focuses on modeling of a MR damper for landing gear system and analysis of semi-active controller to attenuate dynamic load and landing impact. First, passive landing gear of a Navy aircraft is modeled and the forces associated with the shock strut are formulated. The passive shock strut is then integrated with a MR valve to design MR shock strut. 
Here, MR shock strut is integrated with the landing gear system modeled as the 2DOF system and governing equations of motion are derived in order to simulate the dynamics of the system under different impact conditions. Subsequently the inverse model of the MR shock strut relating MR yield stress to the MR shock strut force and strut velocity is formulated. Using the developed governing equations and inverse model, a PID controller is formulated to reduce the acceleration of the system. Controlled performance of the simulated MR landing gear system is demonstrated and compared with that of passive system. 


\section{ACKNOWLEDGMENTS}

First, I would like to pay my great appreciation to my supervisors, Dr. Ion Stiharu and Dr. Ramin Sedaghati for their endless amount of moral support and encouragement along with their practical opinions throughout the thesis work.

The financial support by Mechanical and Industrial Engineering Department of Concordia University is acknowledged.

I also would like to extend my thanks to my colleagues, MR. Arash Firoozrai and MR. Amin Changizi, for their collaborations.

Finally, I would like to dedicate this thesis to my beloved husband, Majid Fekri, my parents, Masi Hassan zadeh and Eino Khani and my sisters, Marzi, Leila and Zara Khani who have always been there for me throughout my life with their love, support, advice and encouragement. 


\section{TABLE OF CONTENTS}

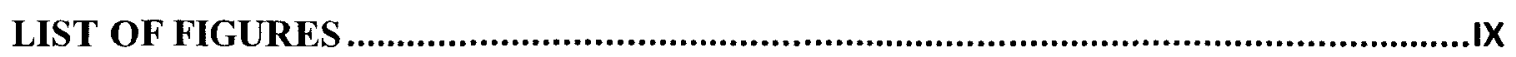

LIST OF TABLES.........................................................................................................III

NOMENCLATURE......................................................................................... XIV

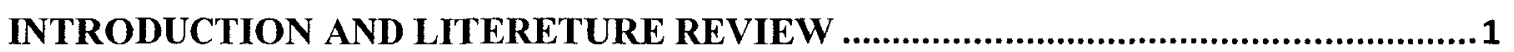

$1.1 \quad$ Motivations and Objectives ............................................................................

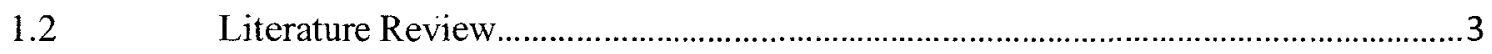

1.2.1 Developments in landing gear design ..............................................................

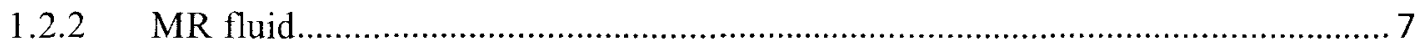

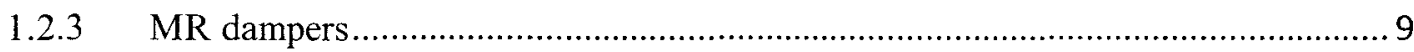

1.2.4 Controller schemes for MR damper applications............................................. 12

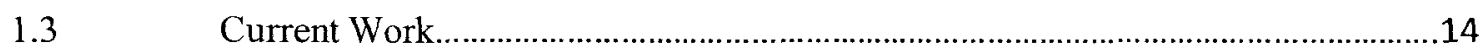

$1.4 \quad$ Thesis Organization..............................................................................................

MODELING OF LANDING GEAR COMPONENTS...........................................................16

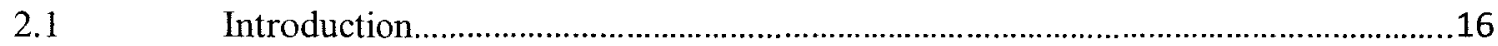

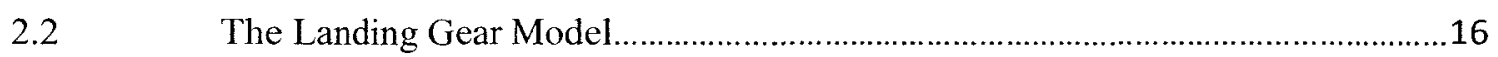

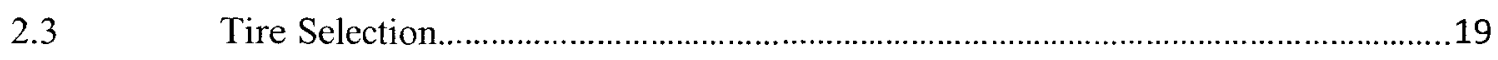

$2.4 \quad$ MR Shock Strut Model.............................................................................................25

2.4.1 Design consideration for a MR shock strut.............................................................28

2.4.2 Formulation of the forces................................................................................. 30 


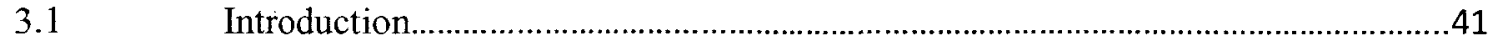

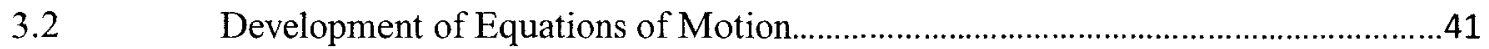

3.2.1 Calculation of the natural frequencies and the normal modes of the system .........45

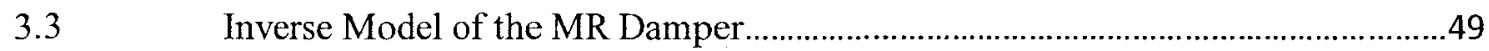

3.3.1 Formulation of an inverse model of the MR damper .......................................5 50

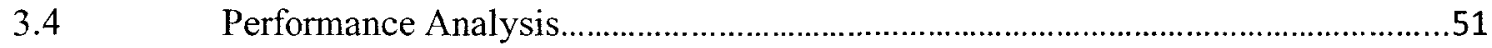

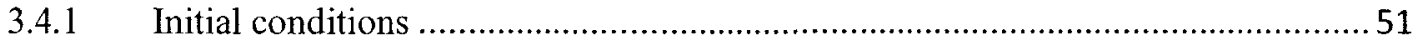

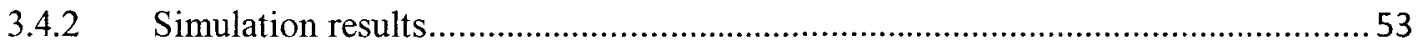

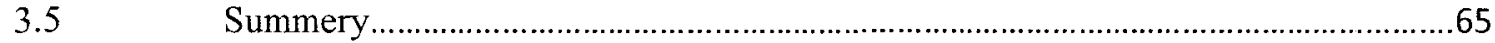

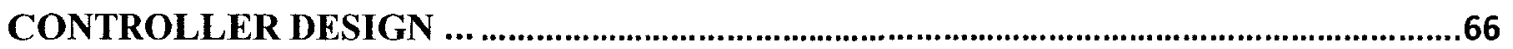

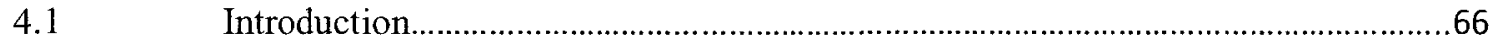

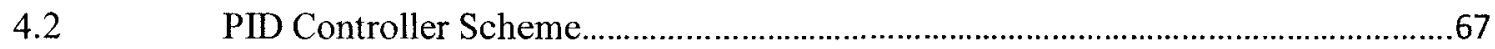

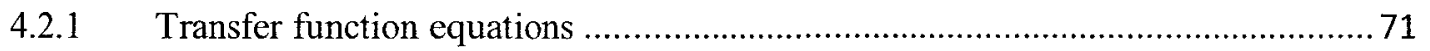

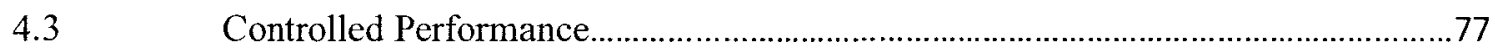

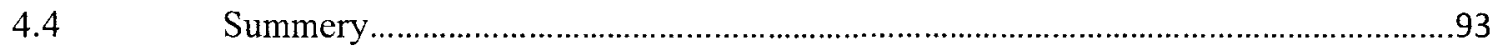

CONCLUSIONS AND FUTURE RECOMMENDATIONS............................................94

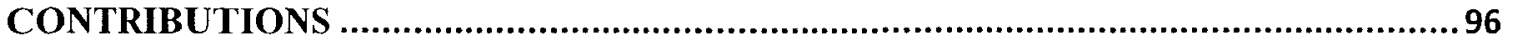

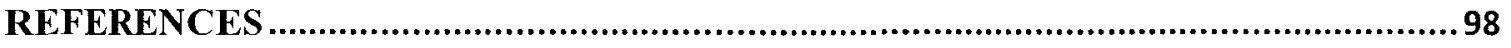


APPENDIX A: Development of the Pressure Drop across the Active Length of the orifice...102 APPENDIX B: Calculation of the Gas Pressure and Volume at Full Extension ....................106

APPENDIX C: Zero-Input Response. .108 


\section{LIST OF FIGURES}

Fig 1.1 Schematics of passive, active and semi-active landing gears.

Fig 1.2 Behaviour of MR fluid without (left) and with electric signal (right) being applied. Note that the particles are aligned in same direction as the magnetic flux........... 8

Fig 2.1 a) Side and b) front view of A6-Intruder aircraft. 17

Fig 2.2 Simplified schematic of the landing gear system. 18

Fig 2.3 Diagram of forces for load calculation. 20

Fig 2.4 Schematic of tire under vertical loading. 21

Fig 2.5 Tire spring force as a function of deflection. 23

Fig 2.6 Approximation to the actual spring force-deflection curve. 24

Fig 2.7 Sketch of a passive shock strut. 26

Fig 2.8 Load-deflection curve and the significant events during the landing cycle [4] $\ldots .28$

Fig 2.9 Schematic of the MR valve and the annular orifice featuring Bingham plastic

$\underline{\operatorname{model}} . .$. 30

Fig 2.10 Schematic of MR shock strut. 31

Fig 2.11 Yield stress as a function of the input current. 37

Fig 2.12 Isothermal and polytropic compression curves.. 40 
Fig 3.1 Two-DOF model of the landing gear system and the free body diagram of the

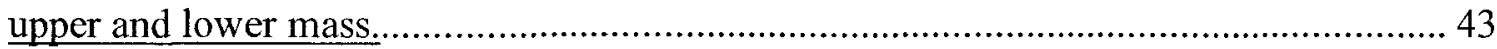

Fig 3.2 Nonlinear and linear lift forces versus time............................................... 45

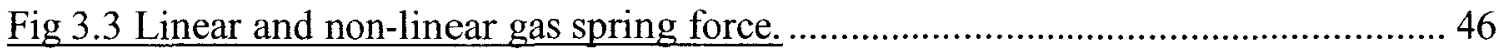

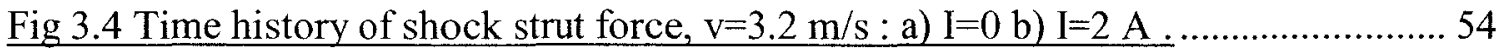

Fig 3.5 Time history of landing gear displacement in case of $\mathrm{I}=2 \mathrm{~A}$ and $\mathrm{v}=3.2 \mathrm{~m} / \mathrm{s} \ldots \ldots . .55$

Fig 3.6 Time history of landing gear velocity in case of $\mathrm{I}=2 \mathrm{~A}$ and $\mathrm{v}=3.2 \mathrm{~m} / \mathrm{s} \ldots \ldots \ldots \ldots . . . .56$

Fig 3.7 Time history of landing gear acceleration in case of $\mathrm{I}=2 \mathrm{~A}$ and $\mathrm{v}=3.2 \mathrm{~m} / \mathrm{s} \ldots \ldots . .57$

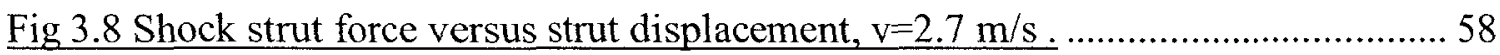

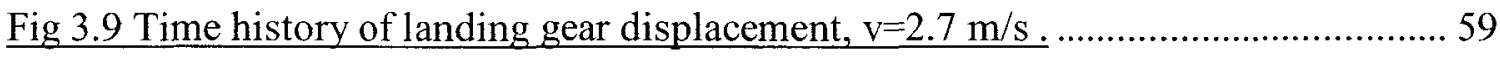

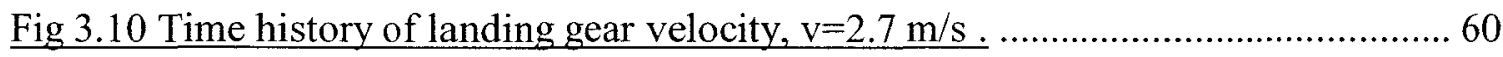

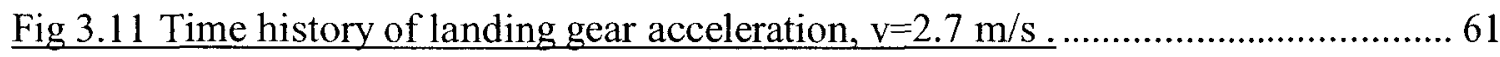

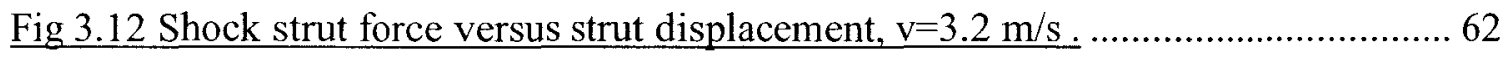

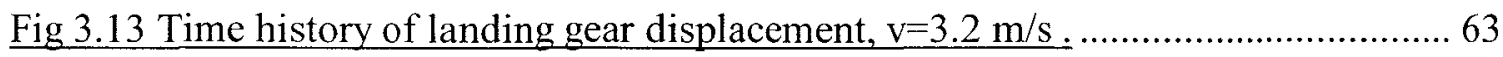

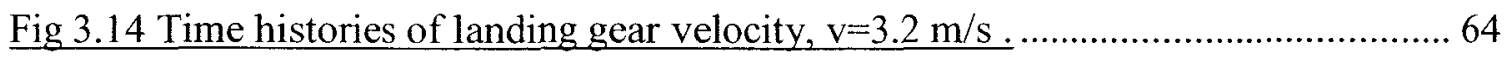

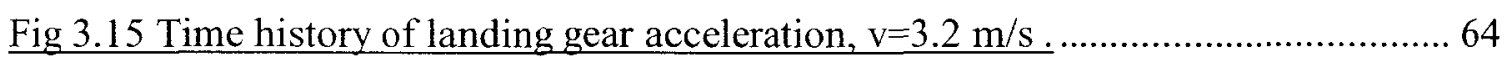

Fig 4.1 Proposed block diagram of the landing gear system. .................................. 68 
Fig 4.2 Time history of reference and passive displacement and acceleration, $v=3.2 \mathrm{~m} / \mathrm{s}$. 69

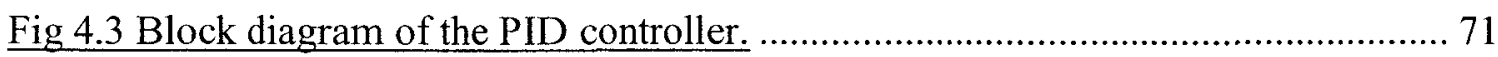

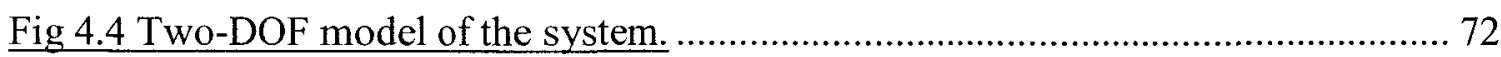

Fig 4.5 Time history of shock strut force in open-loop and control system, v=3.2 m/s. .80

Fig 4.6 Shock strut force vs. shock strut displacement in open-loop and control system, $\underline{v}=3.2 \mathrm{~m} / \mathrm{s}$. .81

Fig 4.7 Time history of energy dissipation in open-loop and control system, v=3.2 m/s

Fig 4.8 Time history of lower and upper mass displacement in open-loop and control system, $v=3.2 \mathrm{~m} / \mathrm{s}$. 83

Fig 4.9 Time history of lower and upper mass velocity in control and open-loop system. $\underline{\mathrm{v}=3.2 \mathrm{~m} / \mathrm{s}}$. 83

Fig 4.10 Time history of lower and upper mass acceleration in open-loop and control system, $v=10.5 \mathrm{ft} / \mathrm{s}$ 85

Fig 4.11 Time history of shock strut displacement and acceleration in open-loop and control system, $v=3.2 \mathrm{~m} / \mathrm{s}$.

Fig 4.12 Time history of control current input, $\mathrm{v}=3.2 \mathrm{~m} / \mathrm{s}$. 86

Fig 4.13 Time history of shock strut force in open-loop and control system, v=3.7 m/s .87 
Fig 4.14 Shock strut force vs. shock strut displacement in open-loop and control system, $\mathrm{v}=3.7 \mathrm{~m} / \mathrm{s}$ 88

Fig 4.15 Time history of energy dissipation in open-loop and control system, $v=3.7 \mathrm{~m} / \mathrm{s}$ .89

Fig 4.16 Time history of lower and upper mass displacement in open-loop and control system, $v=3.7 \mathrm{~m} / \mathrm{s}$. 90

Fig 4.17 Time history of lower and upper mass velocity in control and open-loop system, $\mathrm{v}=3.7 \mathrm{~m} / \mathrm{s}$.

Fig 4.18 Time history of lower and upper mass acceleration in open-loop and control system, $v=3.7 \mathrm{~m} / \mathrm{s}$ .91

Fig 4.19 Time history of shock strut displacement and acceleration in open-loop and control system, $\mathrm{v}=3.7 \mathrm{~m} / \mathrm{s}$. 92

Fig 4.20 Time history of control current input, $v=3.7 \mathrm{~m} / \mathrm{s}$. 92

Fig A.1 Laminar flow between stationary parallel plates. 102 


\section{LIST OF TABLES}

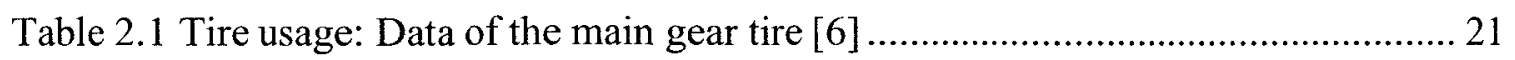

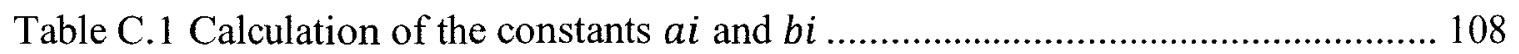




\section{NOMENCLATURE}

$\begin{array}{ll}A_{L} & \text { lower chamber cross-sectional area } \\ A_{u} & \text { upper chamber cross-sectional area } \\ \text { AV } & \text { apparent viscosity } \\ c_{t} & \text { tire damping coefficient } \\ d & \text { mean valve diameter } \\ F_{L_{1}} & \text { displacement } \\ F_{L} & \text { diameter of lower chamber } \\ F_{d} & \text { force due to gas pressure } \\ F_{a} & \text { orifice height } \\ D_{m} & \text { valve diameter } \\ & \end{array}$




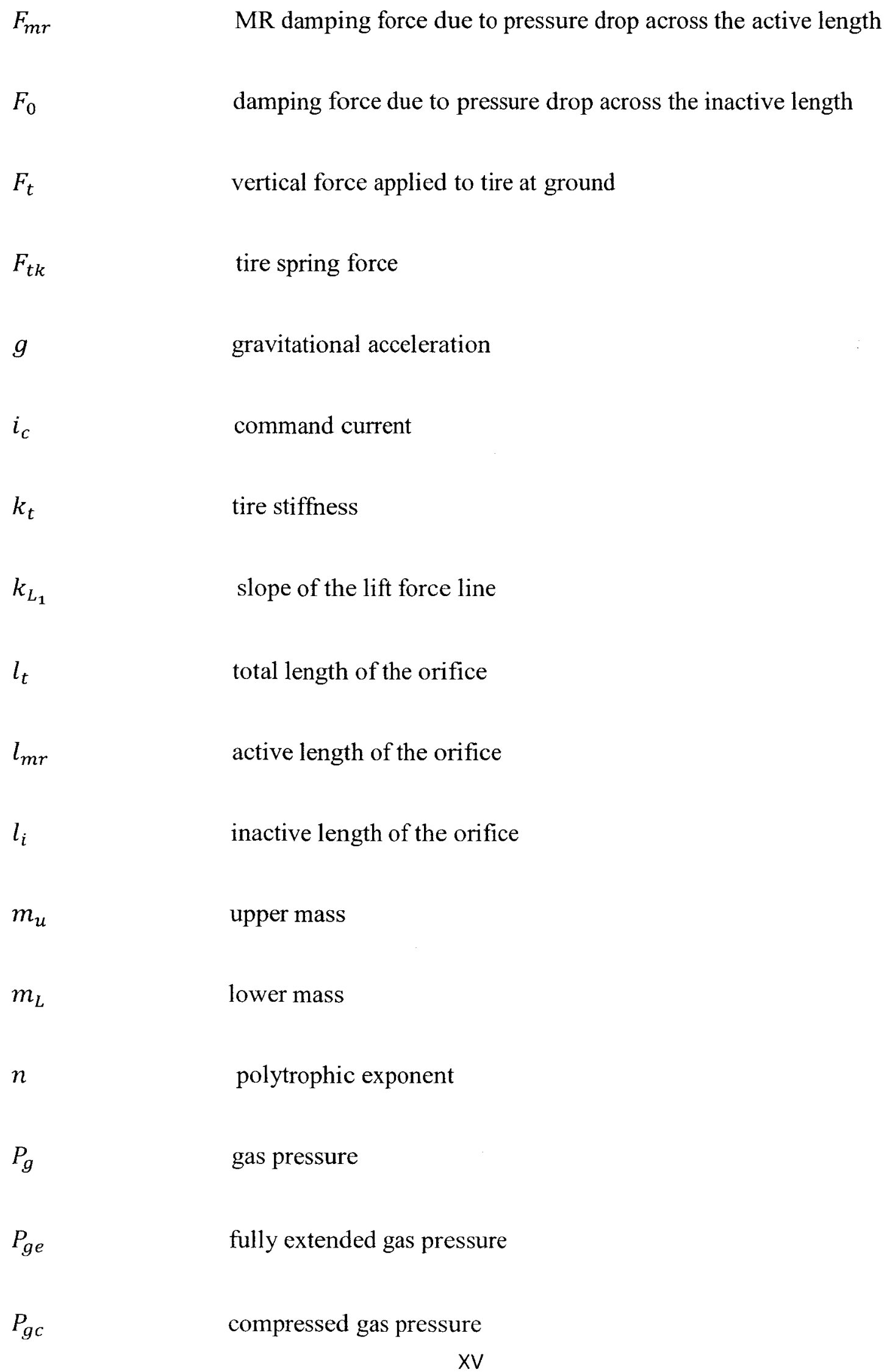




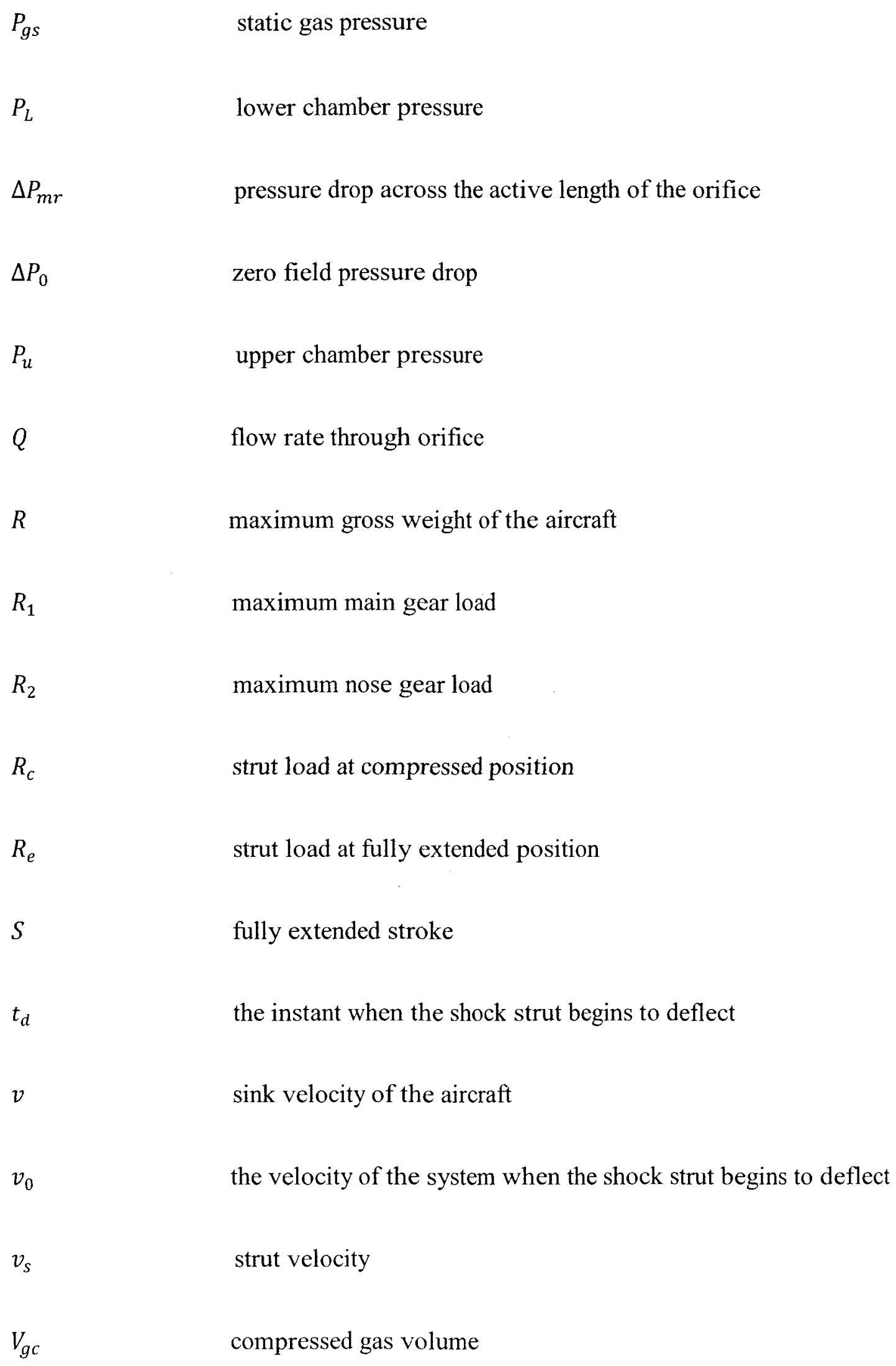




$\begin{array}{ll}V_{g e} & \text { fully extended gas volume } \\ V_{g s} & \text { static gas volume } \\ W_{L} & \text { weight of the wheel tire } \\ W_{u} & \text { weight of the airframe } \\ x_{L} & \text { displacement of the weight of the wheel tire } \\ \tau_{0} & \text { displacement of the system when the shock strut begins to deflect } \\ \tau_{w} & \text { Btrut stroke } \\ \mu_{p} & \text { Ningham plastic viscosity } \\ & \text { displacement of the weight of the airframe } \\ x_{s} & \text { shear stress at the wall } \\ & \end{array}$




\section{CHAPTER 1}

\section{INTRODUCTION AND LITERETURE REVIEW}

\subsection{Motivations and Objectives}

The aircraft is composed of numerous complex components. All systems in an aircraft that are used for taxing, taking off, cruising and landing are vital. Landing gear is one of them. Statistics show that more than $50 \%$ of the not-fatal accidents occur during take-off and landing [1].

During touchdown the shock strut and the associated forces are transmitted from the ground to the fuselage through the landing gear. The impact energy needs to be attenuated to prevent the potential structural damage. When hard landing occurs, fuselage might experience more than allowable value of dynamic stress causing structural damage. During the landing, a transport aircraft is normally approached to carry out the touchdown at a speed of about $6 \mathrm{ft} / \mathrm{s}(1.8 \mathrm{~m} / \mathrm{s})$. However, Navy aircrafts are designed to approach at higher sink speeds. Hard landing situation may occur for sink speed above these values. The effect of hard landing may be ranging from mild passenger discomfort to serious crash landing depending on the level of sink speed. All the potential consequences are associated with various levels of severity impacts which are of very short duration and furthermore yield high level accelerations.

In order to minimize structural damage, energy in hard landing situation should be absorbed as much and as fast as possible. However, the hard landing situations caused by weather conditions, mechanical problems and over-weight aircraft are unavoidable. To mitigate landing impact transmitted from the ground to the aircraft fuselage, several well- 
known types of shock absorbers are employed in the landing gear system and invariably designed to attain satisfactory performance. When the shock absorber is compressing, a soft suspension would be desirable, while in extension it requires stiffer suspension to improve landing performance. Therefore, uncontrollable properties of hydraulic dampers cause restriction to performance characteristic of the aircrafts with passive gears.

In the past four decades, several numbers of the variable damping concept based on active control approach have been developed to improve riding characteristics of the vehicle. This approach has also been experimented for aeronautic applications [2]. Among all variable damping concepts, a new and promising method is to make use of semi-active control and consequently "smart" magneto-rheological (MR) or electrorheological (ER) fluids in the damping system. The main advantage of these fluids is the possible continuous low power control of their rheological properties. It becomes obvious that with a variable and controllable viscosity of the fluid, the force of the damper also becomes variable and controllable. The semi-active approach has been extensively developed in automotive application nevertheless; a few aeronautical applications have been reported [2]. However, use of ER fluids in the aeronautical application is narrowed due to their need to a high voltage source and their narrow operating temperature range [3]. MR fluids are much more appropriate for aerospace applications since they need a low voltage source and can work in the temperature environment ranging from -40 to $150^{\circ} \mathrm{C}[3]$.

Therefore, the main objective of this research thesis is to derive and solve a mathematical model of the MR landing gear in conjunction with the design of a semi- 
active controller for the proposed model to attenuate the acceleration and stroke of the landing gear system.

The specific objectives of the thesis research are provided below:

1. Modeling and simulation of aircraft landing gear attached to a rigid mass under landing impact as a lump mass model and formulation of the forces acting on the landing gear

2. Formulation of a PID controller for a magneto-rheological (MR) fluid based landing gear system with potential application in the commercial aircraft to optimize the acceleration encountered during impact.

3. To prove that an aircraft equipped with a MR landing gear would land normally under a sink speed which would otherwise (in case of passive landing gear) cause hard landing and consequently possible structural damage

\subsection{Literature Review}

The development of a controller for MR-damper landing gear system requires to fully understand the landing gear dynamics, the properties and behaviour of the MR-fluid damper and the control concepts. Therefore several studies related to these subjects are reviewed to gain the required knowledge and organize the scope of the thesis. The studies reported in these areas are presented and discussed in the following sections.

\subsubsection{Developments in landing gear design}

Development of landing gear analysis goes back to 55 years ago [4] when almost all aircrafts had tail wheels or skids and when the very simple oleo-pneumatic shock strut 
was used. Since then, not all aspects of landing gear have been much developed, however, some new materials were developed to assist landing gear designers to increase the efficiency of the shock absorbers with lower weight and cost in a more compact space [4].

Different sink speeds and angles of attack lead to a wide range of impact conditions for aircraft landing gear [2]. The landing gear should attenuate sufficient dynamic load in hard landing conditions in order to minimize structural damage. Fulfilling this requirement, however, causes reduction in the performance of the less severe impact scenarios and consequently may decrease the fatigue life of the aircraft components. To introduce an optimum landing gear design and improve landing performance, it is required to achieve rapid variation in damping force. A range of variable damping concept has been developed to introduce a possible answer to conflicting requirements of the landing gear design. The active and semi-active dampers applied in landing gear system might represent proper solution for these needs. The active control of a landing gear can increase the efficiency of the landing gear system and cause significant reduction in ground loads during touch-down and taxiing. It might also result in improvement of the passenger and crew comfort. The active control system has been widely tested for military aircrafts [4]. Ross and Edson [5] are among the first to design active control system for landing gear of a military aircraft in order to attenuate landing impact during touch-down and while crossing bomb-damaged landing paths. Daniels [6] demonstrated a method for modeling and simulation of a Navy A6-Intruder landing gear system and later, Horta et al. [7] have discussed an extension of the work done by Daniels [6] to include active controls. This work focuses on the modeling of the main gear of a 
Navy A6-Intruder. To respond the U.S. Navy need for an aircraft that could work under any weather condition, day or night and attack targets on the ground and the sea, the A6 was developed. To fulfill these needs, eight design proposals were submitted to U.S. Navy upon their request among which Grumman's design was selected in 1959. A6Intruder could carry both nuclear and conventional weapons, being able to attack in all types of weather. It could deliver twenty-eight 500 pounds weapons. The Intruder battle was first used in the Vietnam conflict with U.S. in 1965 to 1973 while the last one to Iraq in 1993.

To actively control the motion of the landing gear, high and low pressure tanks are used in conjunction with electronically controlled valves to adjust the amount of the hydraulic fluid of the shock absorber. The spring and damper in actively controlled landing gear system are replaced by a high performance hydraulic actuator with a valve and hydraulic power supply. The usage of actively controlled landing gear system can cause complexity in the system and considerable rise in weight which is known to be the most sensitive criteria in aircraft design.

The semi-active control system is extensively used in the automotive applications but also few aeronautical applications have been proposed thus far [8]. This system is less complex, less expensive and lighter than fully active control one since it works using variable metering-pin concept. Metering pin with variable cross-section moves through the orifice and consequently, changes the orifice diameter which is related to damping. Therefore, it can improve the performance of the shock strut by relating damping coefficient to the shock strut motion. 
The semi-active control system offers controllable damping forces with minimal power requirements and combines the reliability and fail-safe features of passive system with adaptability of the active system. The semi-active control system application in the aircrafts has been studied by Choi and Wereley [9]. Choi and Wereley [9] demonstrated the effectiveness of ER and MR landing gear systems on attenuating the landing impact. They showed that the acceleration and displacement of the shock strut can be attenuated by employing a robust sliding mode controller to the ER/MR landing gear system. A design methodology to optimize an MR landing gear both in terms of damping and magnetic circuit performance was presented by Batterbee et. al. [3]. They designed an optimized MR valve in such a way that the semi-active landing gear can achieve an optimal performance and produce desirable behavior for a wide range of impact conditions.

The schematics of passive, active and semi-active landing gear system are illustrated in Fig 1.1 via single DOF modeling not including tire model. The part of the fuselage on each gear can be considered as a rigid mass since the main gears of the aircraft are mostly located near the nodal points of the wing bending modes and consequently landing gear performance is not affected by the elastic deformation of the aircraft structure [10]. As an instance, in landing gear drop tests, the structure of the aircraft is typically substituted by a rigid mass. Since the dynamics of the landing gear is studied in this work, it is assumed that the landing gear is attached to a rigid mass which has single DOF in vertical translation. 

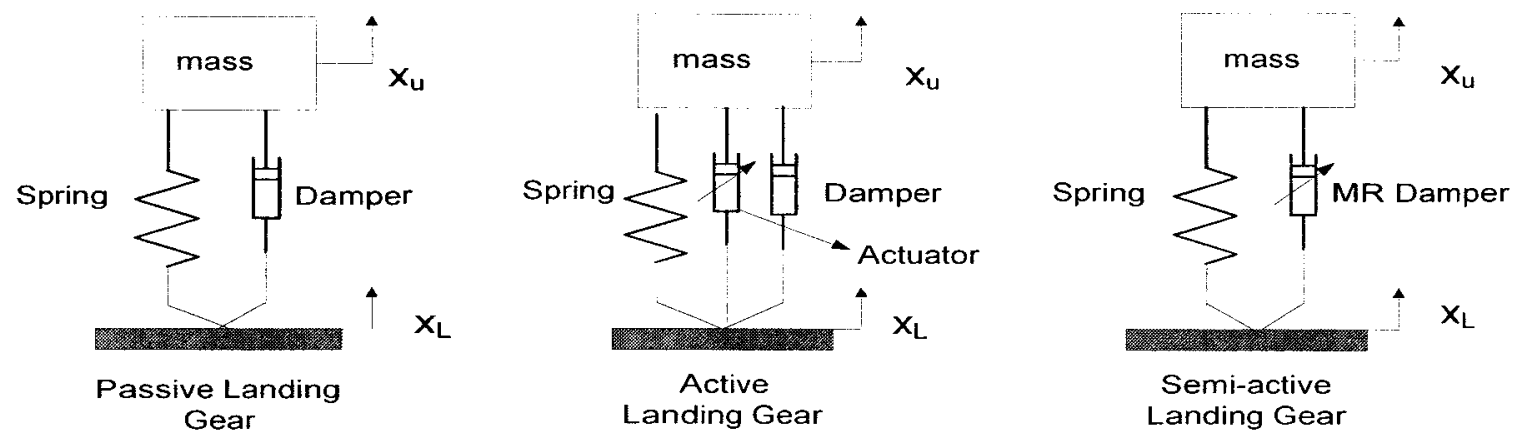

Fig 1.1 Schematics of passive, active and semi-active landing gears.

\subsubsection{MR fluid}

A MR-fluid is a type of "smart" fluid made from magnetic particles in a carrier fluid, usually silicon based oil. These fluids are designed in order to apply controllable forces in practical damping problems, where a low response time, low power consumption and high reliability is needed [11]. The idea of MR fluid itself goes back as early as 1950's, when Rabinow [12] introduced it for the first time. MR fluid is basically a fluid that can be responsive to the magnetic field by a change in its rheological behaviour. A similar but meanwhile different type of fluid can also be responsive to an electric field. In this case the fluid is called ER fluid. The idea of ER-fluid has been proposed by Winslow [13] at almost the same time as MR-fluid is known as smart material. Fig 1.2 shows schematic of a MR-fluid damper.

The MR-fluid contains numerous small particles suspended in carrier oil. The particles inside the MR-fluid are usually coated with an anti-clustering material. Their size must be much smaller than the size of the orifice of the damper to avoid joining of the particles and to prevent particle agglomeration. 


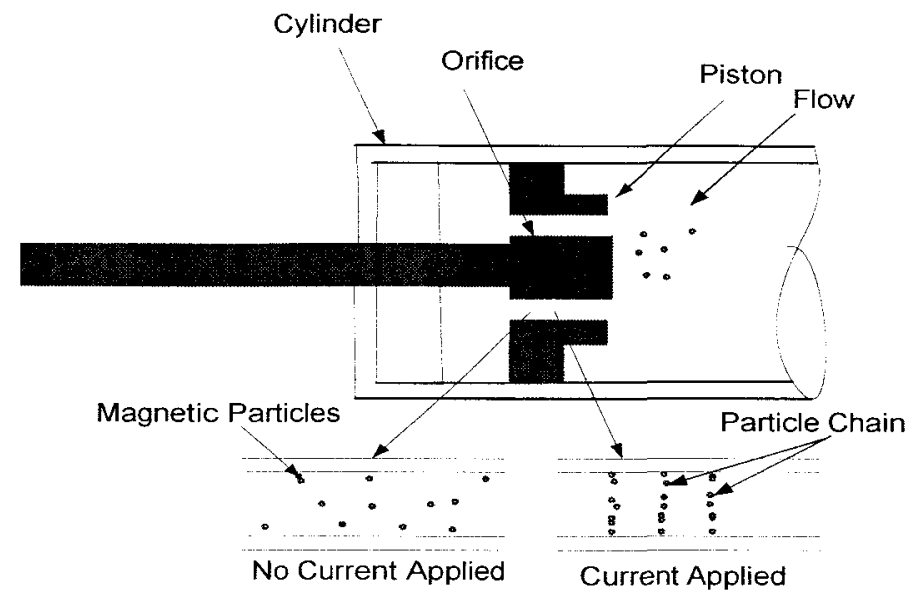

Fig 1.2 Behaviour of MR fluid without (left) and with electric signal (right) being applied. Note that the particles are aligned in same direction as the magnetic flux.

In the absence of a magnetic field ("inactivated"), the MR fluid behaves like the carrier oil. When subjected to a magnetic field, the particles that have been normally dispersed throughout the oil align themselves along the lines of the magnetic flux. Once aligned in this fashion, the chains of the magnetic particles resist against the trend of being removed out from their respective flux lines alignment and act as a barrier to the fluid flow as illustrated in Fig 1.2. This causes the variation in the viscous and shear properties of the fluid which consequently yields changes in the damping force.

MR fluid can be used in three different modes. The modes of operation are called "flow mode", "shear mode" and "squeeze-flow mode". In the case of flow mode, the fluid flows as a result of pressure gradient between two stationary plates. This mode is used for dampers and shock struts application. In shear mode, fluid flows between two plates moving relative to one another. This mode is used in clutches and brakes where rotational motion needs be controlled. In the case of squeeze-flow mode, fluid flows 
between two plates moving in the direction perpendicular to their planes. This mode can be used for applications controlling very small movements but involving large forces. The areas where the fluid is exposed to magnetic flux are usually referred to as "choking points". In the case of a typical MR damper, the MR fluid restricts the fluid flow from the one side of the piston to the other side, when the fluid is in the vicinity of the "choking points" as mentioned above.

When varying the strength of the magnetic field, the so called "apparent viscosity" of the fluid is changed. The term "apparent" is commonly used as there is no change of viscosity regarding the carrier fluid. The stronger the magnetic field applied, the higher is the apparent viscosity of the MR fluid (as a whole), thus also resulting in a higher damping force. MR fluids can change its state from liquid to near-solid in duration below $10 \mathrm{~ms}[14]$.

\subsubsection{MR dampers}

One of the variable damping concepts which was developed to overcome passive limitations was to make use of active dampers. However, using such technology leads to a significant increase in size, weight and power requirements of the system. A few studies have explored more attractive approach which is to implement semi-active energy dissipation using MR or ER fluids.

The need for a controllable damper has been realized by Carlson et al. [15]. His ER and MR fluid-based dampers offered changeable damping characteristics within a good bandwidth. Since then, the MR-fluid dampers are becoming more interesting for engineers as semi-active controllable dampers given that MR fluids offer better potentials

1 Apparent viscosity, $A V$, is the viscosity of a fluid measured at a specified shear rate. Therefore, In order to measure $A V$, the shear rate must be stated or defined. 
using low voltage source and can operate in a wider temperature range and with higher yield stress. A wide range of prototype MR dampers are currently being developed in civil engineering structures [16] and vehicle suspension [14] but some aeronautical applications have also been developed [11].

As illustrated in Fig 1.2, the MR fluid damper consists of upper and lower chambers which are separated by the piston. The piston consists of magnetic coils which are attached to the wall of the annular orifices of the piston. The MR fluid flows through the orifice and changes its viscosity when the magnetic flux is generated due to current excitation in the coil. This causes changes in the damping force generated by the MR damper. A quite beneficial feature of MR dampers is that, in the absence of an external field, they can still operate like passive shock struts. Therefore, they have fail-safe mode of operation.

Damping force developed by the MR damper is a function of command current generated by the controller. Force-velocity (F-v) characteristics of MR dampers under different constant values of command currents have been studied numerically and experimentally by many researchers $[9,14,16-18]$. It has been shown that the damping coefficient at low velocities in the pre-yield is far higher than the damping coefficient at higher velocities in the post-yield and that the response is nonlinear at low velocities. The F-v characteristics of a MR damper show hysteresis behaviour which depends on frequency and magnitude of the vibration and the values of the command current [14]. Hysteresis loop increases with increasing the frequency and the hysteresis width increases with increasing the excitation amplitude. Some studies have been done to characterize the hysteresis behaviour of the MR dampers using mechanical models. 
Bingham plastic model which is described by Wilkinson [19] is often used to show MR fluid behavior. Stanway et al. [20] proposed a model based on Bingham plastic model which consists of a viscous damping force and a yield stress related Coulomb friction force. This model might not be a proper model for control analysis since it does not give a nonlinear F-v response at low velocities [16]. However, such model provides some insights on the sensitivity of the performances. A viscoelastic-plastic model proposed by Gomota and Filisko [21] is an extension of the model proposed by Stanway et al. [20] and describes the behavior of the ER fluids. Bouc-Wen model is also used to show the hysteresis behavior of the MR and ER fluids [16]. However, in both Bouc-Wen model and the model proposed by Gomota and Filisko [21], the F-v responses do not roll off in the area where the velocities are small. A model proposed by Spencer et al. [16] is a modified version of the Bouc-Wen model and provides a good estimation of the nonlinear F-v response at low velocities. The model proposed by Spencer et al. [16] is capable of predicting the behavior of MR damper when the current is continuously varied however; all other mentioned models are valid when the applied voltage is held at a constant level. Models proposed by Wang et al. [14] and Dominguez et al. [17] can also predict the behavior of the MR dampers when the applied voltage and consequently the magnetic field is varied. Therefore, they can be used for control analysis. However, the experiments or nonlinear optimization needs to be done in order to calculate the characteristic parameters of the MR damper. In this work, Buckingham equation is written for Bingham plastic model to gain understanding on the relation between yield stress and the damping force. 


\subsubsection{Controller schemes for MR damper applications}

A number of semi-active control schemes based on variable damping concepts have been formulated to attenuate vibration and dynamic loads. Rakheja et al. [22] formulated an on-off control scheme using flow modulation devices in a conventional hydraulic damper. Relative position and velocity were measured to produce feedback signal. The on-off control scheme would also be used for MR damper by modulating the control current which would result in hi-low damping force variation. Lee et al. [23] proposed a sky-hook controller scheme for a full-car suspension featuring MR dampers. Choi et al. [24] designed a MR damper model for a full-vehicle suspension system and then utilized the PID control law to track the desired damping force and attenuate the vibration of the system. A quarter car model equipped with a MR damper was studied by Lam et al. [25] to formulate a sliding mode controller. A computer simulation has then been carried out to estimate the performances and effectiveness of the MR suspension system under varying excitation conditions. Wang et al. [14] proposed three different controller schemes for quarter car model featuring MR damper in order to generate desired damping force. On-off or hi-lo controller, inverse model based hi-lo and sliding mode controls were formulated which the later offers an enhanced robustness and maintains the stability of the system.

Batterbee et al. [3] designed and performed optimization of MR landing gear and illustrated the effectiveness of the proposed design methodology. Numerical simulations

were performed for the impact phase of an aircraft's landing and later the performance of the MR valve was experimentally validated in another work [26]. Lou et al. [27] presented a shear-mode ER based landing gear where a wide number of rotational 
shearing disks were used to provide control surface area. Translational motion of the piston was converted into rotational motion of the shearing disks utilizing a shear-mode ER device and then the simulation results illustrated that using an ER fluid can increase the energy absorption efficiency of the landing gear up to 100 percent. Berg and Wellstead [28] proposed a semi-active vibration control scheme applying a shear/squeeze mode ER device which was analyzed in series with a passive landing gear. Choi and Wereley [9] synthesized a sliding mode controller applying a flow-mode ER/MR landing gear shock strut. The results showed a significant attenuation in acceleration and the controlled current function vs. time was achieved. Ghiringhelli et al. [8, 29] formulated a semi-active control scheme for the landing gear of a small aircraft by adjusting the orifice area. A non-linear PID controller was utilized to attenuate the peak vertical load and increase the efficiency of the system. Both passive landing gear and the landing gear installed with a semi-active shock absorber were modeled and simulated and the results were compared.

These studies address a particular control goal for the landing gear system, including attenuating the acceleration and dynamic loads, optimizing the performance of the landing gear, or increasing the landing gear efficiency. In this study the aim of implementing a control scheme is to attenuate vibration and dynamic loads and consequently decrease the acceleration transmitted to the fuselage during the touch-down impact in landing. To achieve this aim, a PID controller is utilized for a landing gear system featuring a MR damper. The position of the piston in the MR damper is calculated every time and the difference between this measured value and the desired position value, 
which is considered as the error, is minimized using the controller by adjusting the control current input.

\subsection{Current Work}

This work presents the modeling and analysis of a MR damper for a landing gear system used in aircraft. Landing gear of a Navy A6-Intruder aircraft is used for modeling and simulation. This type of landing gear was used due to the fact that the available information about this aircraft enables coherent simulation and comparisons of the landing performances with the aircraft equipped with passive damper based landing gears. A physical model of the shock strut is introduced and lump mass based mathematical models of the landing gear with and without integrated MR damper are derived. A detailed description of the passive and open-loop simulation are given and the results are discussed and validated. A closed-loop PID controller is then formulated to reduce the acceleration encountered during landing. The simulations carried out for certain landing condition lead to the conclusion that implementation of MR damping systems in conjunction with an appropriate control scheme may suppress the vibration induced by landing.

\subsection{Thesis Organization}

Chapter 2 describes the modeling of the landing gear components. The landing gear of A6 Intruder is studied in order to obtain the motion equations of the system and consequently to analyze the dynamic of the system. The two-DOF model of the landing gear, which consists of upper mass, lower mass, damper and spring, is explained. 
Tire selection and passive shock strut model are discussed, the required changes are then made to generate MR shock strut model and finally the forces of the shock strut are formulated.

In Chapter 3, the landing gear system with the passive damper and MR damper with different constant current (passive on-mode) is simulated and the results of each are compared and discussed for different sink velocities. MR shock strut formulated in Chapter 2, is then integrated with the two-DOF landing gear system model, governing equations of motion are derived and natural frequency and mode shapes of the system are calculated. The inverse model of the MR shock strut relating MR yield stress to the MR shock strut force and strut velocity is formulated. Finally simulations are conducted for the landing gear system with integrated MR shock strut for different current excitation and the results are demonstrated and compared.

In Chapter 4, a PID controller is formulated using governing equations of the landing gear system and the inverse model of the MR damper in order to attenuate acceleration of the system. Simulations are conducted for the landing gear system associated with a PID controller in the term of acceleration, velocity, displacement, damping force and the damping energy of MR the shock strut and the results are compared with those of passive shock strut. Conclusion and some recommendations for future works are presented in Chapter 5. 


\section{CHAPTER 2}

\section{MODELING OF LANDING GEAR COMPONENTS}

\subsection{Introduction}

A high range of excitation conditions are applied on aircraft landing gear which entails variable damping. The magneto-rheological (MR) fluid based damper generates variable damping force with the low power consumption. These dampers offer rapid variation in damping force which can be effectually used to control vibration in broad range of frequency. MR damper has been mainly studied for application in vehicle suspension systems and limited study is available regarding their application in landing gear system.

In this chapter, modeling of both passive and MR landing gear of a Navy aircraft is investigated in order to simulate the dynamics of the system under varying impact conditions. At first, overall landing gear system is modeled and then a linear tire model is described and further explored. The passive shock strut is then modeled and the forces are formulated. Required changes are made to this passive model in order to create MR shock strut model. Finally, proposed MR shock strut model which fulfills the requirements of application in the landing gear system is analyzed and the forces are formulated.

\subsection{The Landing Gear Model}

This work discusses a development of a retractable main landing gear model for which equations of motion are obtained. For practical reason, the employed model has been selected as the main gear of a Navy A6-Intruder. Since the specific details of the 
A6 gear were available through work by Danials [30] and later by Horta et. al [31], this gear was chosen. Number of wheels per strut and their pattern are used to classify the landing gears. As shown in Fig 2.1(a,b) (the picture is taken from a A6 Intruder model), A6 has a single wheel main gear which makes the analysis less complicated. In the front view of the aircraft, it is shown that a linkage connects the shock absorber to the tire.

(a)

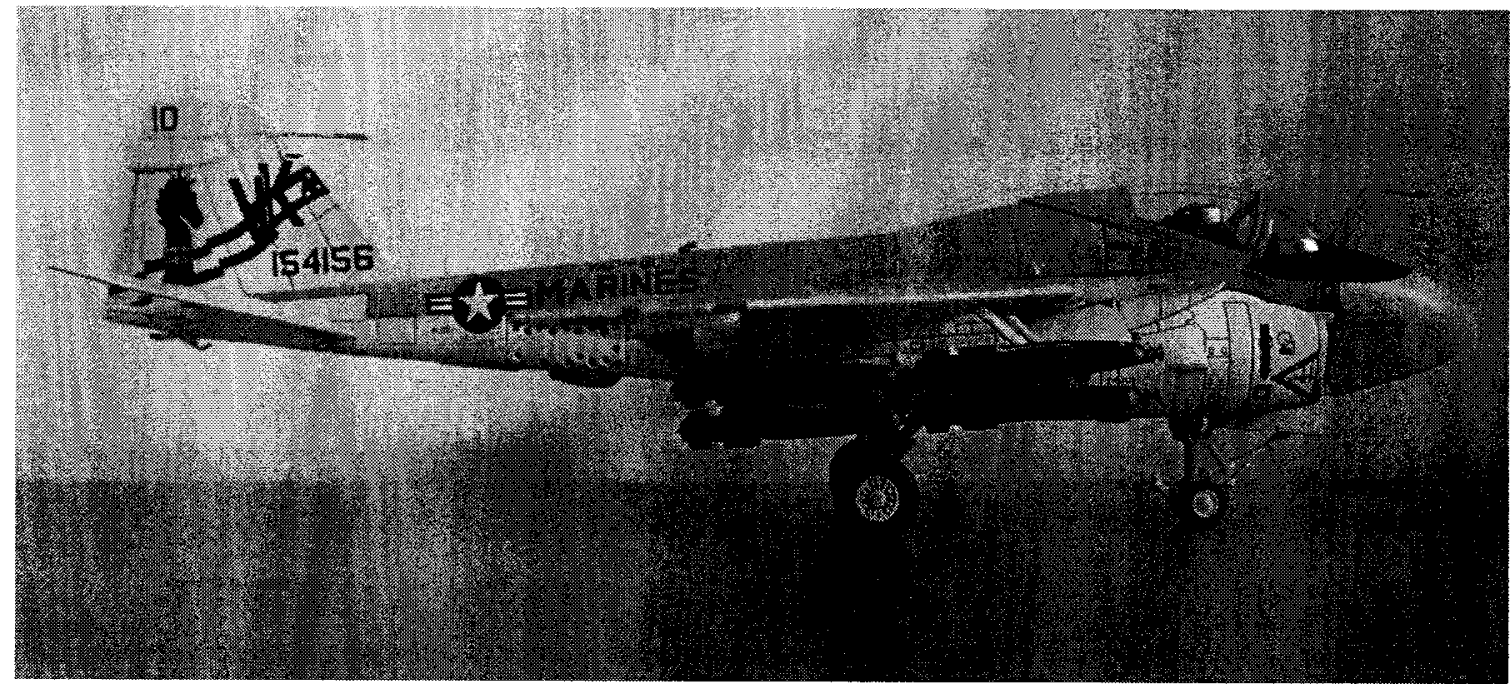

(b)

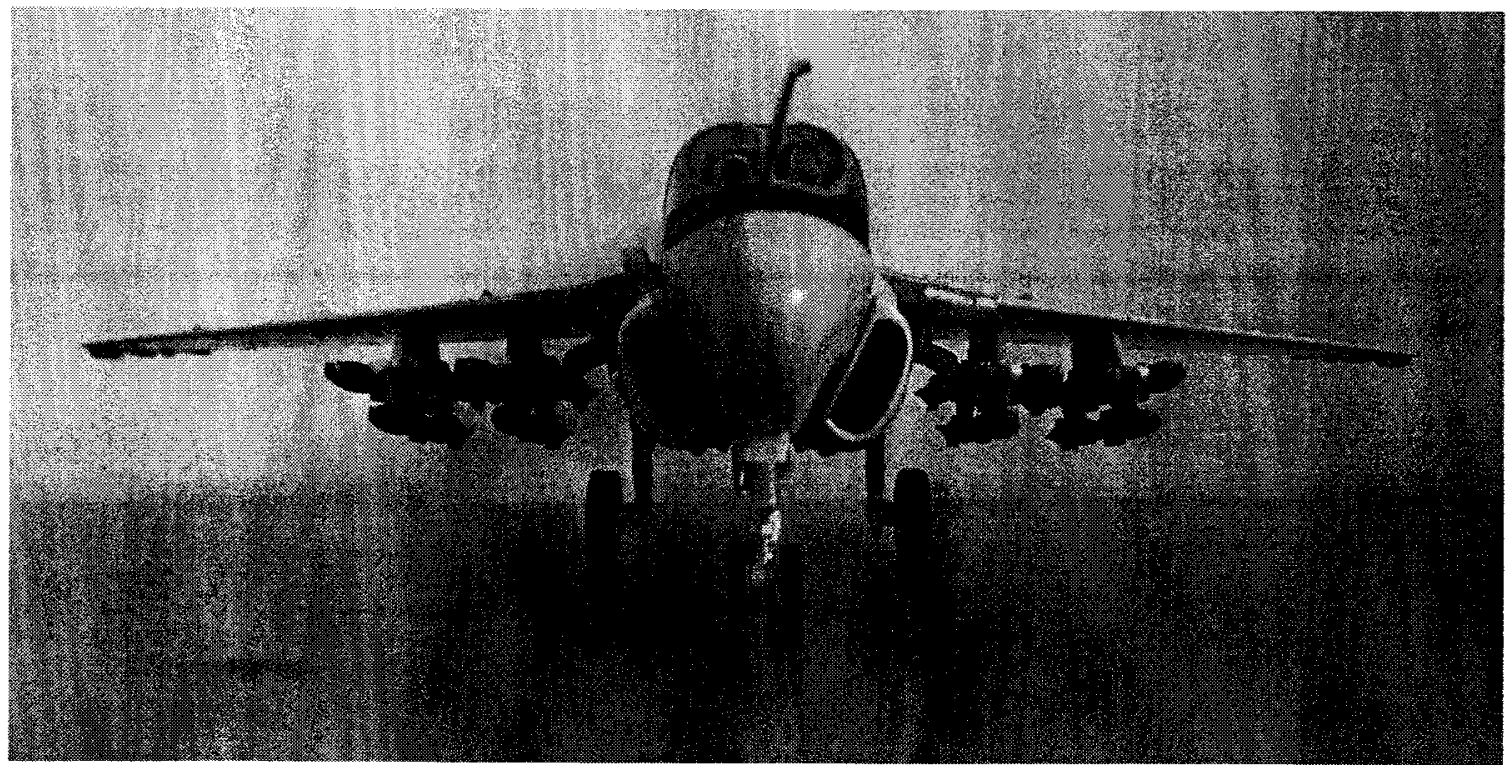

Fig 2.1 a) Side and b) front view of A6-Intruder aircraft. 
This linkage is not taken into consideration in the proposed mathematical model and consequently, the friction force due to the offset wheel is ignored.

As previously discussed, the part of the body resting on each gear can be considered as a rigid mass since the elastic deformation of the aircraft structure does not affect the landing gear performance particularly given the fact that the main gears of the aircraft are located near the nodal points of the wing bending modes [32]. Since the dynamics of the landing gear system is considered in this work, it is assumed that the landing gear is attached to a rigid mass which has single DOF in vertical translation. Simplified main gear components are presented in Fig 2.2. Here, $m_{u}$ is the rigid body mass which represents aircraft fuselage mass and is attached to the gear which is assumed rigid in bending.

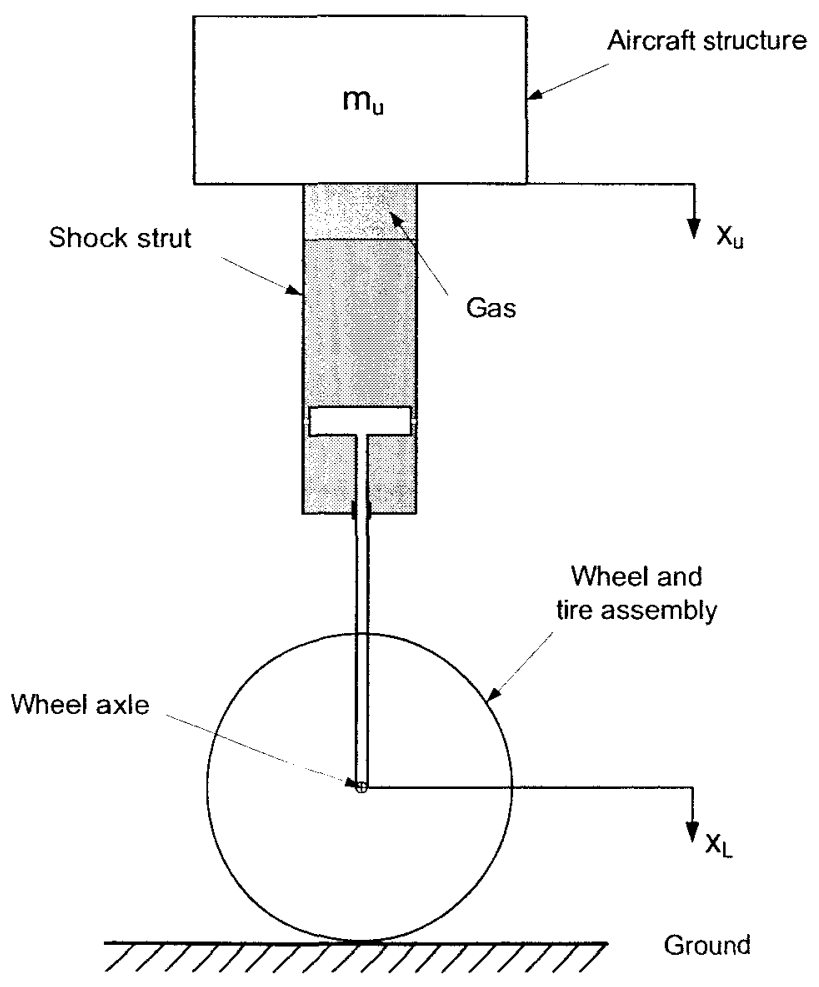

Fig 2.2 Simplified schematic of the landing gear system. 
The overall system can be expressed as a combination of the aircraft fuselage and the landing gear which has two DOF, defined by upper mass, $x_{u}$, and lower mass, $x_{L}$, vertical displacements. $x_{L}$ represents the tire deflection. The difference between the upper mass and the lower mass displacements determines the strut stroke, $x_{s}$.

In this chapter the modeling process of the main landing gear components for simulation of the landing impact structural dynamics is explained. To start with, the tire and passive shock strut are modeled using linear functions. This passive shock strut model is adjusted in order to generate the MR shock strut model. As a final point, all the forces of the proposed MR shock strut model are formulated.

\subsection{Tire Selection}

Characteristics of tires are mainly affected by the location of main landing gears due to changes in the static load on each tire. To place the position of the landing gears, most of the main aerospace companies normally provide general characteristics such as the maximum gross weight and the Mean Aerodynamic Chord (MAC). MAC is defined as that chord of an airfoil that is equal to the sum of all the airfoil's chord lengths divided by the number of chord lengths. In the beginning, MAC is superimposed on an aircraft side view. Forward and aft center of gravity (c.g.) limits are then placed on the MAC by a department concentrating in aircraft weight and balance [4]. The area between these two limits is called the c.g. range of the aircraft. The aircraft center of gravity must be placed in the c.g. range during the flight. The c.g. may change within this limit, since the weight of the aircraft changes due to fuel burn during flight. As a final point, the locations of the nose and main gears are determined and then the maximum static loads are calculated. In order to calculate maximum main and nose gear loads, minimum distances of the gears 
from c.g. are considered which are respectively presented by $M$ and $N$ in Fig 2.3. The loads are calculated as illustrated here:

Maximum main gear load (per strut) in after position of C.G.: $R_{1}=R(F-M) / 2 F$

Maximum nose gear load in forward position of C.G.: $R_{2}=R(F-N) / F$

where $\mathrm{R}$ is the maximum gross weight of the aircraft which is about $R=25099 \mathrm{lb}$. The geometric distances are presented in Fig 2.3.

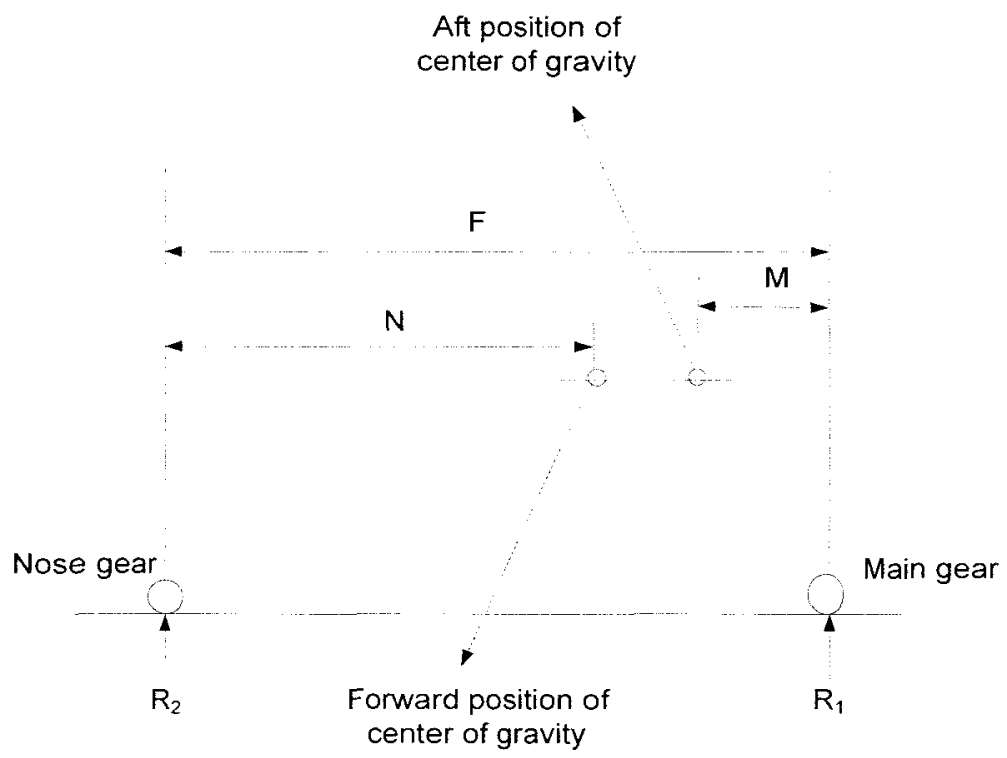

Fig 2.3 Diagram of forces for load calculation.

The preliminary tire selection is used to decide how many tires will be used on each strut and this step can be illustrated below. Aircrafts weighing below $60000 \mathrm{lb}$ have two main gear struts and either one or two tires per strut [4]. Since A6-Intruder weights below the above-mentioned value, it contains only one tire per strut and consequently static single wheel load is equal to $R_{1}$. The characteristics of the tire are presented in 
Table 2.1. The tire size is shown with two numbers multiplied together. The first number presents tire diameter and the second one presents tire section width.

Table 2.1 Tire usage: Data of the main gear tire [6]

\begin{tabular}{|l|l|l|l|l|l|}
\hline Manufacturer & Name & $\begin{array}{l}\text { Speed } \\
\text { Mph }\end{array}$ & $\begin{array}{l}\text { Tire size } \\
\text { in. }\end{array}$ & $\begin{array}{l}\text { Inflation } \\
\text { Pressure, } \\
\text { psi }\end{array}$ & $\begin{array}{l}\text { Weight } \\
\text { Lbs }\end{array}$ \\
\hline Grumman & A6-Intruder & 160 & $36 \times 11$ & 200 & 326.2 \\
\hline
\end{tabular}

The tire is an important element for the analysis of the behavior of the landing gear system during impact. A variety of high dynamic and thermal loads partially produced by the friction and partly produced by the breaks are applied on aircraft tires thus their safety factors have a significant importance for the designer.
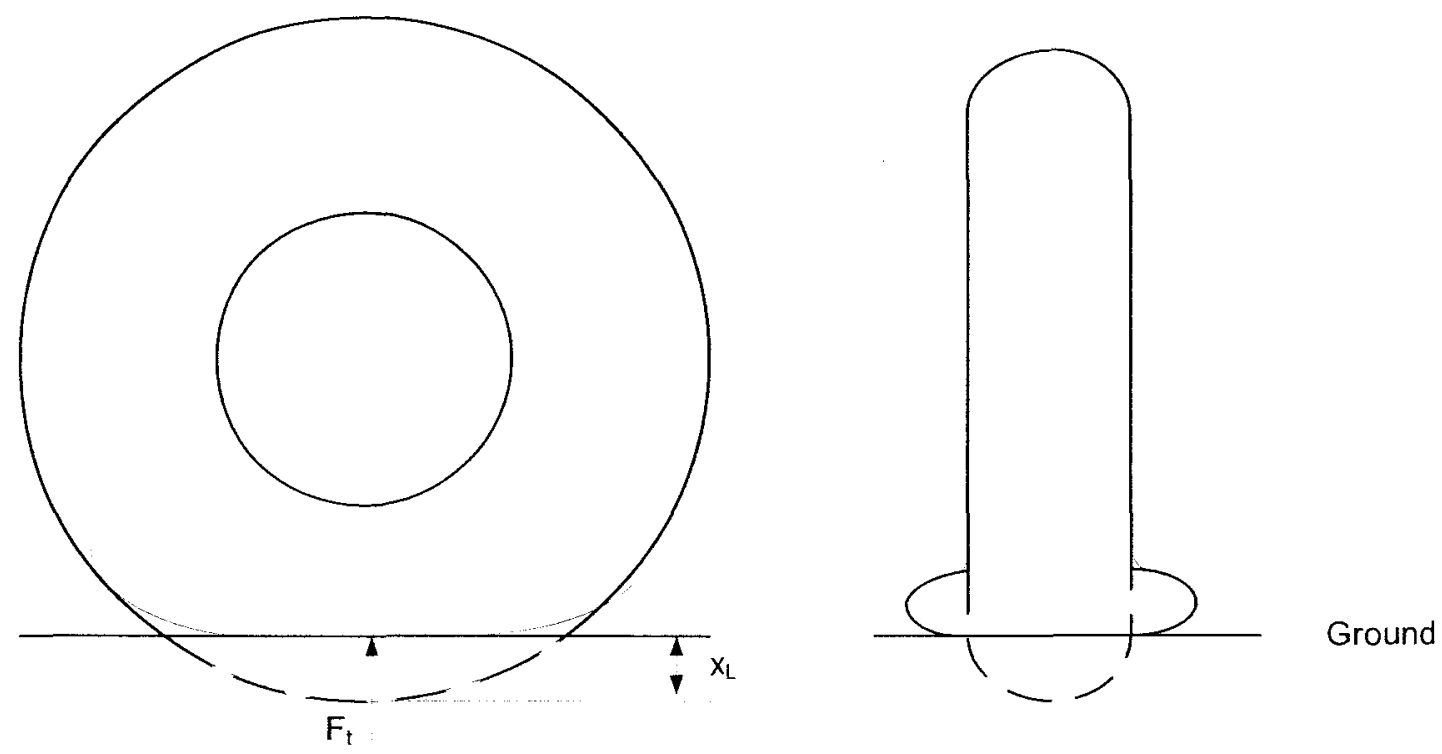

Fig 2.4 Schematic of tire under vertical loading. 
Variety of tire models applied in different kind of analysis is found in reported studies among which a simplified model is considered in this work. A6-Intruder main gear could be modeled as a simple two DOF gear therefore only vertical loading is considered in our calculation and no lateral, drag loading and twisting moment are required to be taken into account. The schematic of the tire under vertical loading is shown in Fig 2.4, where $x_{L}$ is the tire deflection and $F_{t}$ is the tire force.

The models considered in this thesis use data extracted from the open literature that describes the experiments performed on the specific components of the landing gears. A comprehensive set of tests on A6 landing gear have been performed by Daniels [30]. In this study, the experimental tests were designed to measure the total system mass, the frictional level of the bearings, the mass of the piston, the wheel, the tire, and the fluid inside the piston. The results of one of the quasi-static experiments provide data concerning the tire load-deflection relationship. The test set-up consists of a landing gear system connected to a shaker table through a jack lug allowing the movement of the strut by an input displacement. The strut was tested by vigorous shaking of the shaker table. The data of quasi-static tests provides the tire spring force, $F_{t k}$, as a function of deflection, $x_{L}$, which can be approximately represented by a third order polynomial as shown in Fig 2.5. As it can be seen, tire force versus deflection shows nonlinear behaviour at initial compression however as deflection increases, tire spring force shows linear behaviour around the operating point at $0.0406 \mathrm{~m}$.

Fig 2.6 shows simple approximation to the tire characteristics by fitting straight dashed lines (a) and (b) to the actual spring force-deflection curve. As can be seen, the line (a) is achieved by connecting the two points on the curve, $(0 \mathrm{~m}, 580 \mathrm{~N})$ and $(0.08 \mathrm{~m}$, 
$86980 \mathrm{~N})$, and line (b) is obtained by joining the other two points on the curve, $(0 \mathrm{~m}$, $580 \mathrm{~N})$ and $(0.04 \mathrm{~m}, 41450 \mathrm{~N})$. Since impact moment is considered in our analysis and in that time tire mostly operates with deflection greater than $0.04 \mathrm{~m}$, line (a) is selected as a better approximation. The slope of the selected line can determine the linear tire stiffness, $k_{t}$, which is calculated as $k_{t}=1,080,000 \mathrm{~N} / \mathrm{m}$.

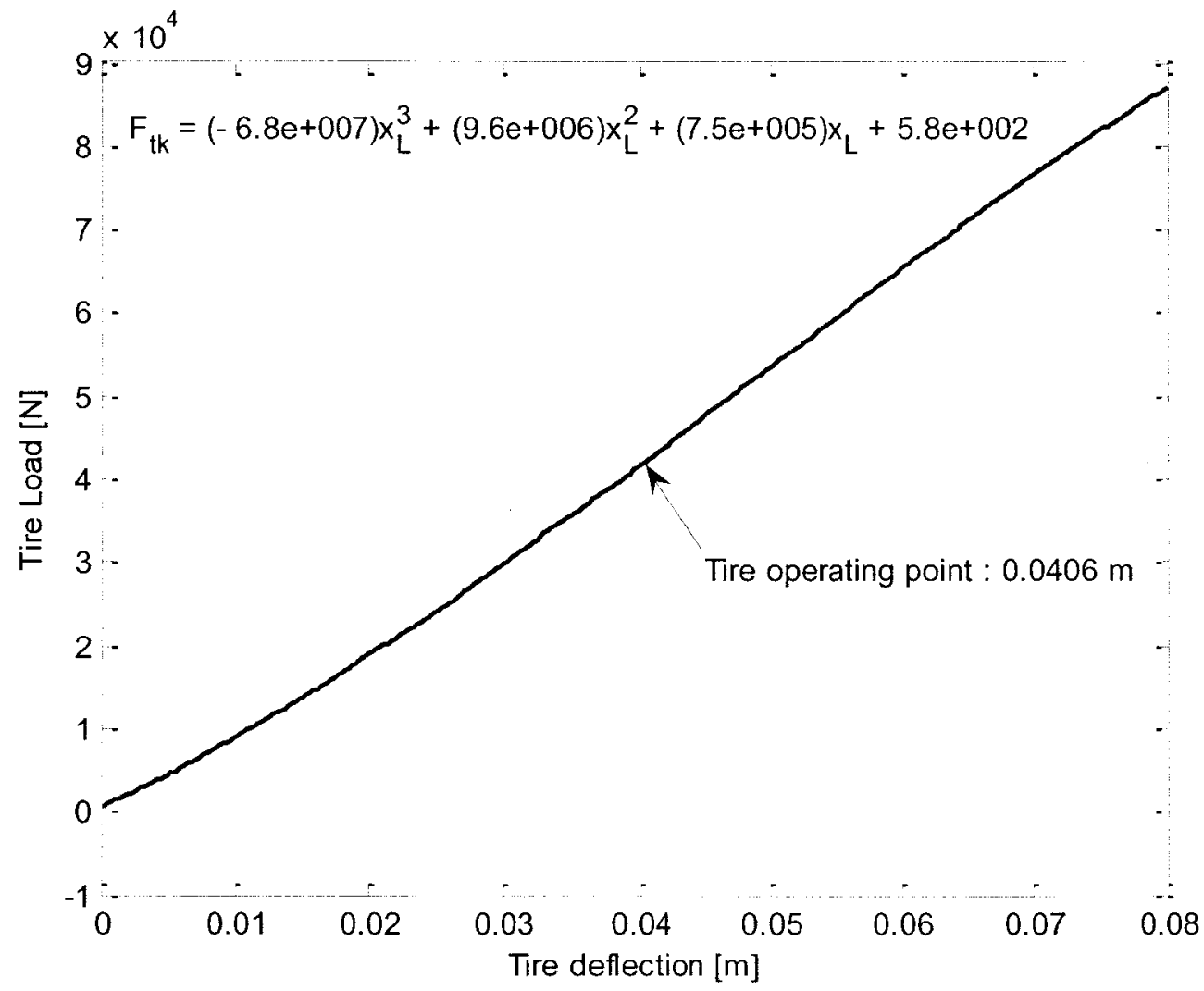

Fig 2.5 Tire spring force as a function of deflection. 


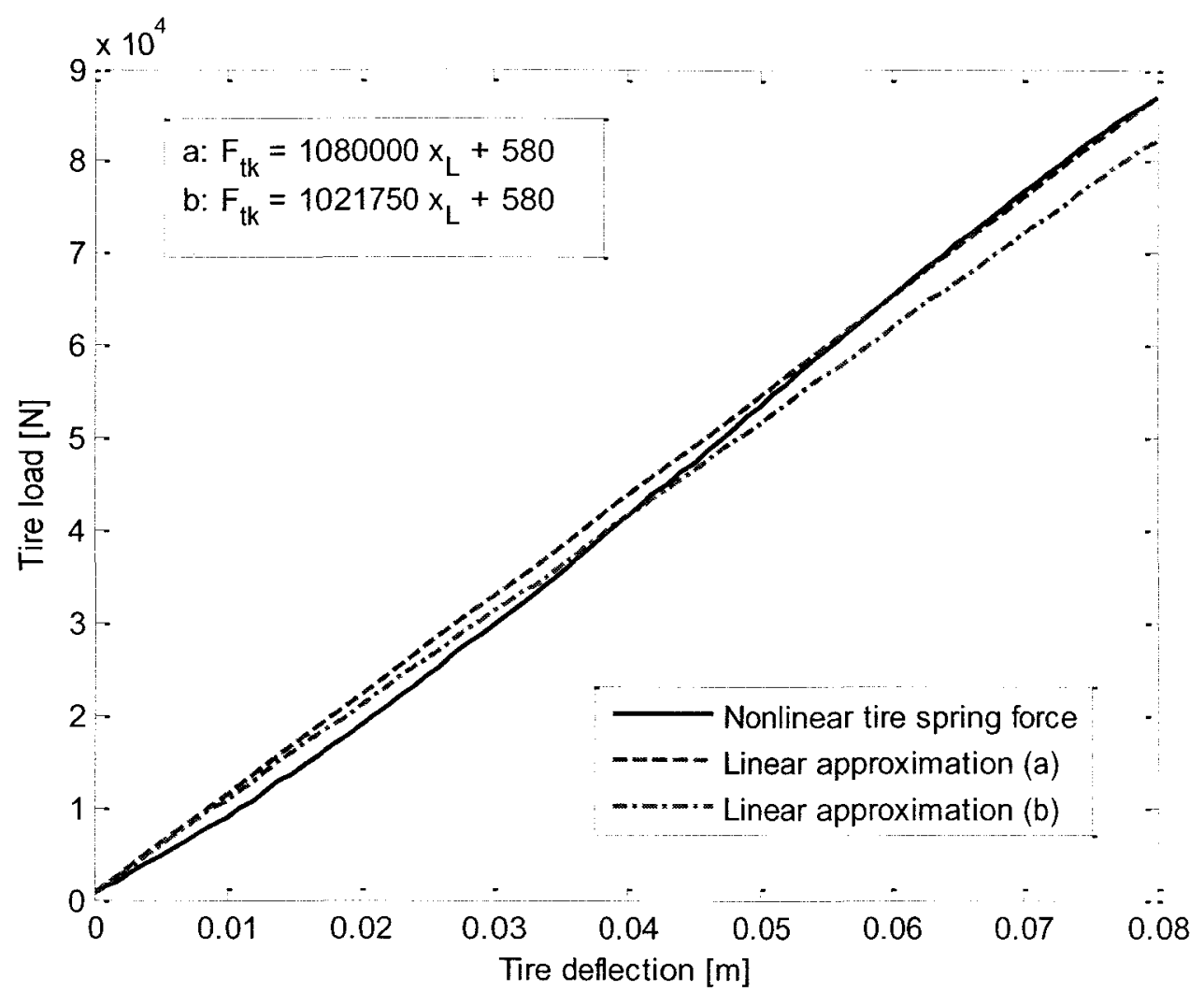

Fig 2.6 Approximation to the actual spring force-deflection curve.

Another test was performed by applying dynamic inputs to the system, such as step bumps, ramp inputs, varying sinusoidal inputs, etc in order to identify damping coefficient [30]. The landing gear system, which was updated by the static data, was simulated and the frequency response to a sinusoidal sweep from a runway input was obtained. The gear displacement and the pressure of the upper and lower chambers were then plotted and compared with the response of the test gear. The tire damping coefficient was adjusted such that the simulation results were in fairly good agreement with the results of test gear. The comparison provides us with damping coefficient of the tire, $c_{t}$, which is given $c_{t}=5000 \mathrm{Ns} / \mathrm{m}$. Further details of the experimental setup can be found in aforementioned reference [30]. 
As a final point, the tire vertical force, $F_{t}$, is defined as a linear function of the tire stiffness and damping which is given as:

$$
F_{t}=\left\{\begin{aligned}
c_{t} \dot{x}_{L}+k_{t} x_{L} & , x_{L}>0 \\
0, & x_{L}<0
\end{aligned}\right.
$$

The above tire model comprises the possible loss of contact with the ground due to extreme impact force. In this work, it is assumed that tire is always in contact with ground.

\subsection{MR Shock Strut Model}

In this section, the passive shock strut model is discussed. The required changes are then discussed in order to generate MR shock strut model. The forces of the shock strut are then formulated.

Today, most of the landing gears use oleo-pneumatic shock absorbers since they have the highest efficiencies among all liquid, coil spring and pneumatic shock absorbers and have also the best energy dissipations. In practice, the efficiency of the oleopneumatic shock absorbers is between 80 and $90 \%$ [4]. To design an oleo-pneumatic shock absorber, oil is held in the upper chamber whilst the strut is compressed. The amount of oil meets the full stroke for which the damper is designed for. The compensation for the variation in volume during stroke is carried by the volume of nitrogen, $N_{2}$, which is compressed above the level of the oil in the upper chamber. The schematic of a strut is shown in Fig 2.7. The pressurized $N_{2}$ works as a spring that carries the weight of the plane in ground operations. The upper chamber contains hydraulic fluid and the compressed gas which is represented by the light grey area in the figure. Upper and lower chambers are separated by the orifice plate. When the strut is stroking, the hydraulic fluid moves between the lower and upper chambers through the orifice. The 
orifice along with metering pin, which enables changes in size of the flow orifice, controls the damping characteristics of the gear as the pin moves through the orifice.

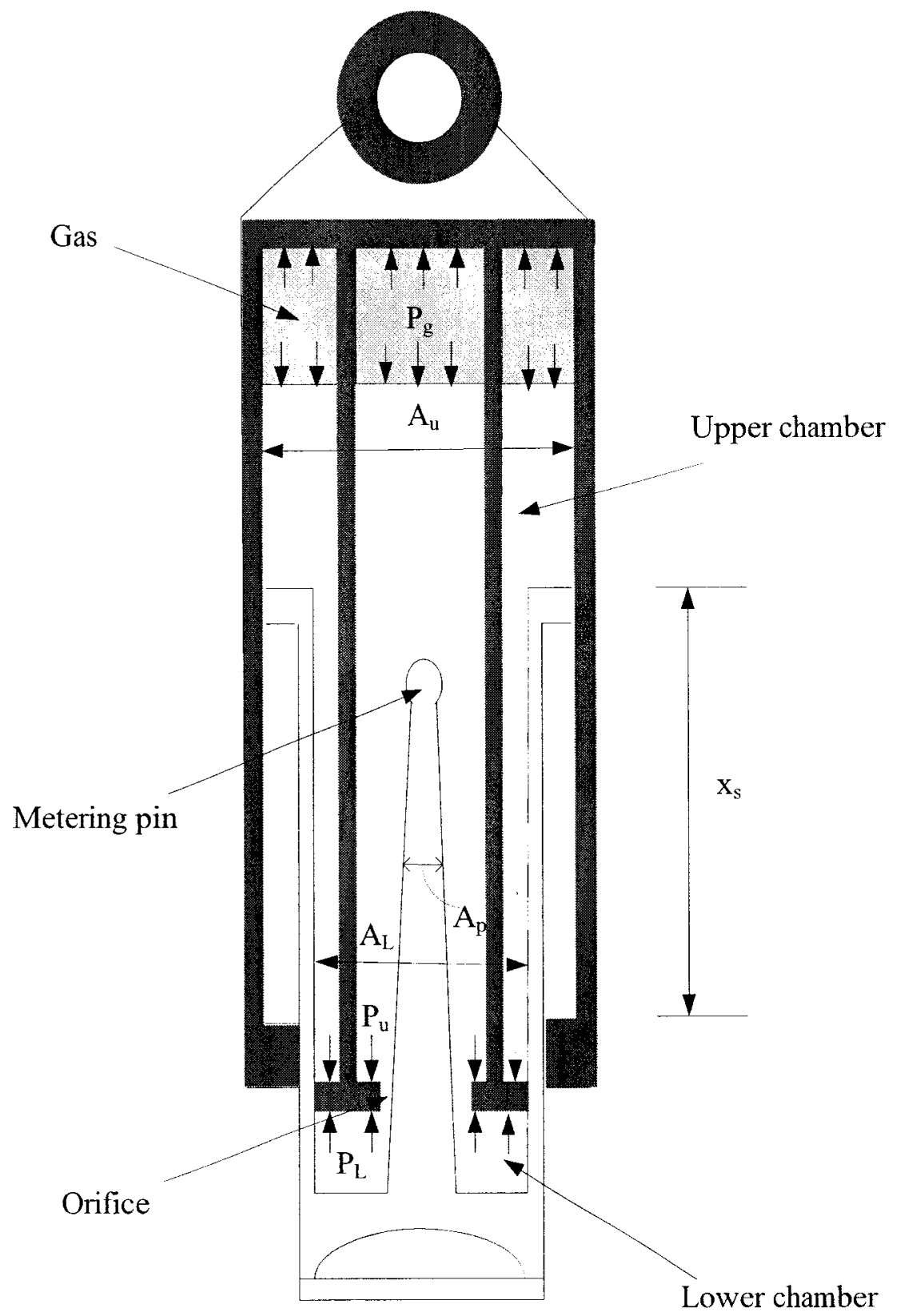

Fig 2.7 Sketch of a passive shock strut. 
The pressure drop across the orifice also generates a force which resists the closure of the shock strut. The gas spring force and the force due to pressure drop across the orifice represent stiffness and damping properties of the shock strut respectively. The former force is related to the energy stored into the accumulator and the latter is related to the energy dissipated by the fluid through the orifice. Therefore two independent terms can be formulated and then summed. The gas spring absorbs energy and represents the stiffness properties of the shock strut while the dashpot dissipates it at the same time and represents the damping properties.

Fig 2.8 shows the forces generated by the gas spring and the dashpot versus strut deflection. Isothermal gas curve represents gas spring gradual compression and polytropic gas curve is representative of fast compression [4].

As it can be seen from Fig 2.8, the area between the dynamic load and isothermal gas spring curve represents the dissipated energy through damping. Fig 2.8 also shows a typical landing gear cycle during touchdown. It consists of initial contact at time $t=0 \mathrm{~s}$, spin-up, maximum spin-up at time $t=0.05 \mathrm{~s}$, rebound reaction at time $t=0.10 \mathrm{~s}$, maximum vertical reaction at time $0.18 s \leq t \leq 0.20 s$, maximum travel at time $t \approx 0.30 \mathrm{~s}$ and static closure. These events are shown by letters $\mathrm{A}, \mathrm{B}, \mathrm{C}, \mathrm{D}, \mathrm{E}, \mathrm{F}$ and $\mathrm{G}$ respectively in Fig 2.8.

The design methodology proposed by Batterbee et al. [3] for MR shock struts is selected. This methodology is based upon replacing the orifice plate of the shock strut shown in Fig 2.7 with an MR valve. The goal is then to find a way of controlling the current in the valve that the landing impact transmitted to the aircraft can be attenuated. In the following sub-sections design methodology of a MR shock strut used in landing 
gear applications is discussed and the forces associated with the shock strut are formulated.

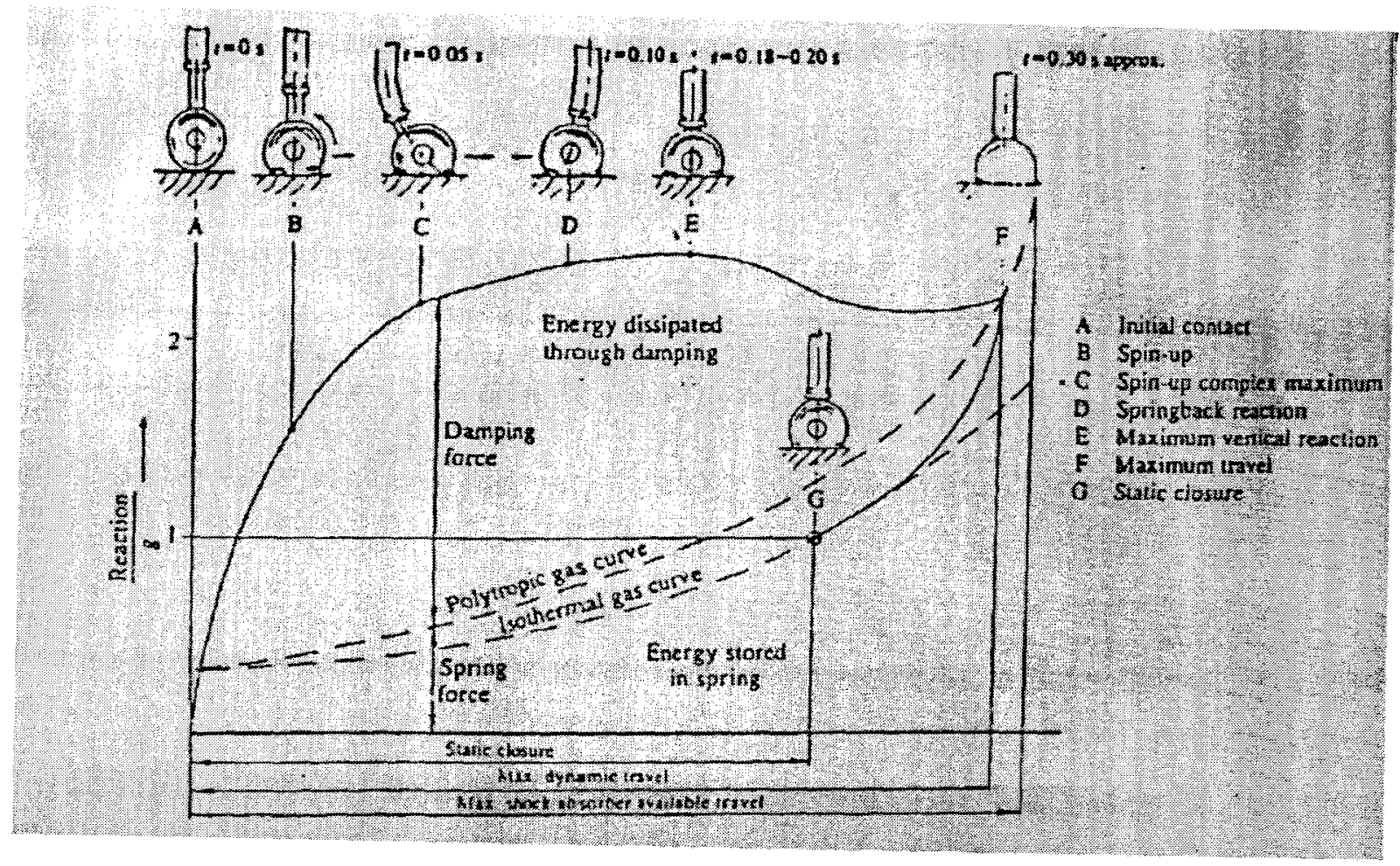

Fig 2.8 Load-deflection curve and the significant events during the landing cycle [4]

\subsubsection{Design consideration for a MR shock strut}

The metering pin of the shock strut shown in Fig 2.7 is removed and its orifice plate is replaced with an MR valve in order to redesign the MR shock strut. The MR fluid valve consists of annular orifices with a coil positioned around a bobbin as shown in Fig 2.9. The MR fluid flows through the orifice and changes its apparent viscosity, $A V$, when the magnetic flux is generated via the DC powering of the coil. This causes changes in the pressure drop along the active length of the valve, $l_{m r}$, where the magnetic flux crosses the orifice. 
Fig 2.9 shows the structure of the fluid inside the MR valve. In this figure the light blue region is representing the active fluid region which responds to the magnetic field by changing the electric current. On the other hand, the dark blue region is inactive fluid section which maintains a constant Newtonian viscosity and does not change viscosity due to the changes of magnetic field and thus remains inactive. The length of this inactive region of the MR valve is shown in the Fig 2.9 by $l_{i}$.

Efforts have been made by some researchers to optimize the geometry of the MR valve in order to optimize the damping force and the dynamic range of MR damper. By implementing the analytical methods from a magnetic perspective, they have stated that the magnetic behavior of the valve is insensitive to the orifice (valve gap) height, $D_{m}$. However, the nonlinear nature of the fluid interaction, shock strut compression and tire deflection are strongly dependent on this factor. According to this difference in sensitivity to the geometry, the optimization of damping effect would face some difficulties.

In a much more practical approach, the external geometry of the MR valve (length $L_{t}$ and diameter $\left.D_{t}\right)$ is first determined based on the design properties of an equivalent passive device. In the next step, the internal geometry of the MR valve which consists of the orifice height, $D_{m}$, and the active length, $l_{m r}$, has to be estimated. For the case studied in this research the approximate optimized value of the former parameter is determined in Chapter 3. The value of the later parameter is assumed to be nearly half of the total length of the valve, $L_{t}$, as this assumption is close to what has been assumed as the active length to total length ratio in previously mentioned works. The schematic of the MR shock strut is shown in Fig 2.10. 


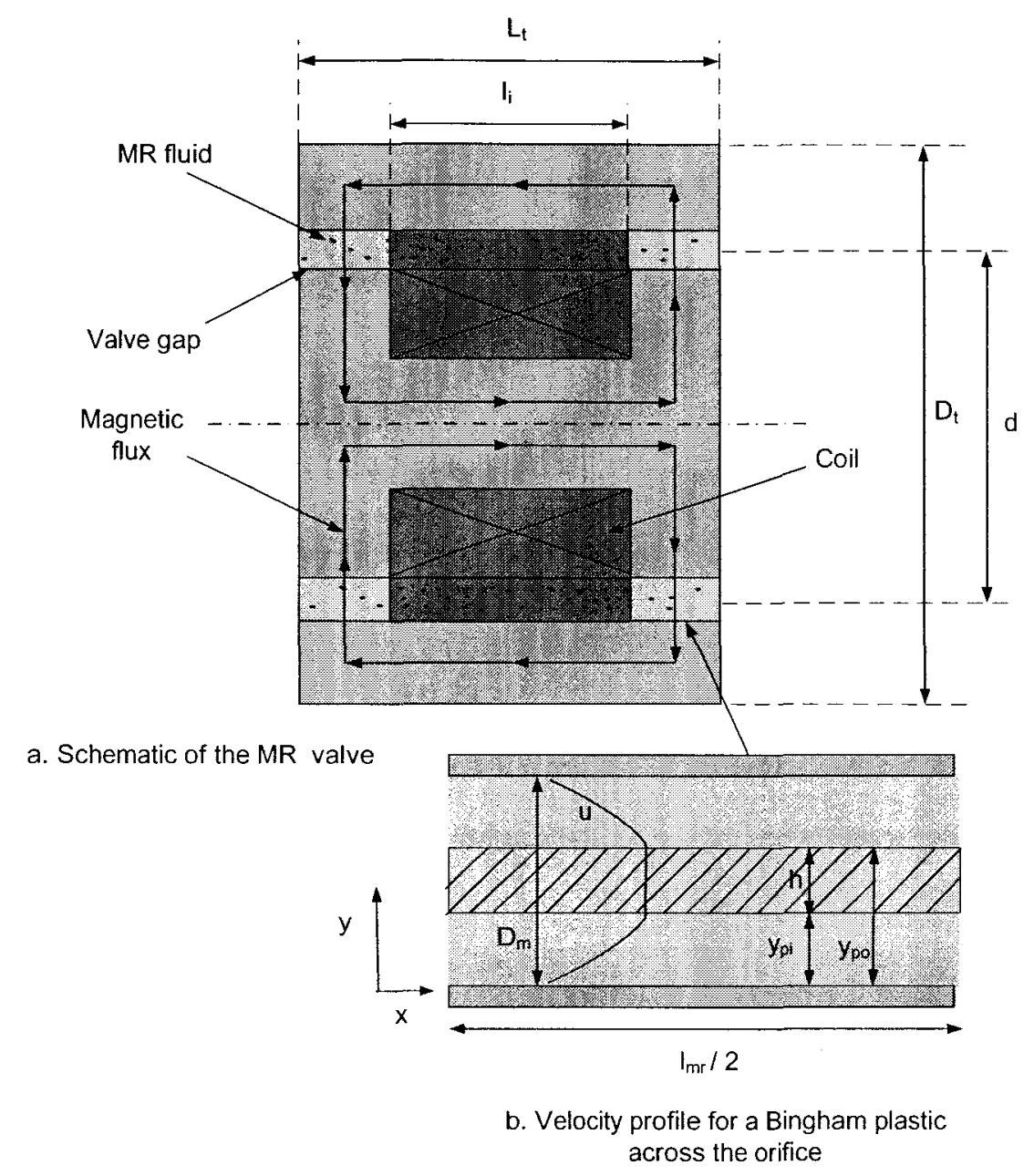

Fig 2.9 Schematic of the MR valve and the annular orifice featuring Bingham plastic model.

\subsubsection{Formulation of the forces}

The determination of the forces generated by MR shock strut are essential objectives of present research, since the design of a controller depends on the proper knowledge of the forces as function of the electrical current applied on the coils of the 
MR valve. It should be noted that without accurate knowledge of these forces it would be impossible to solve the equations of motion.

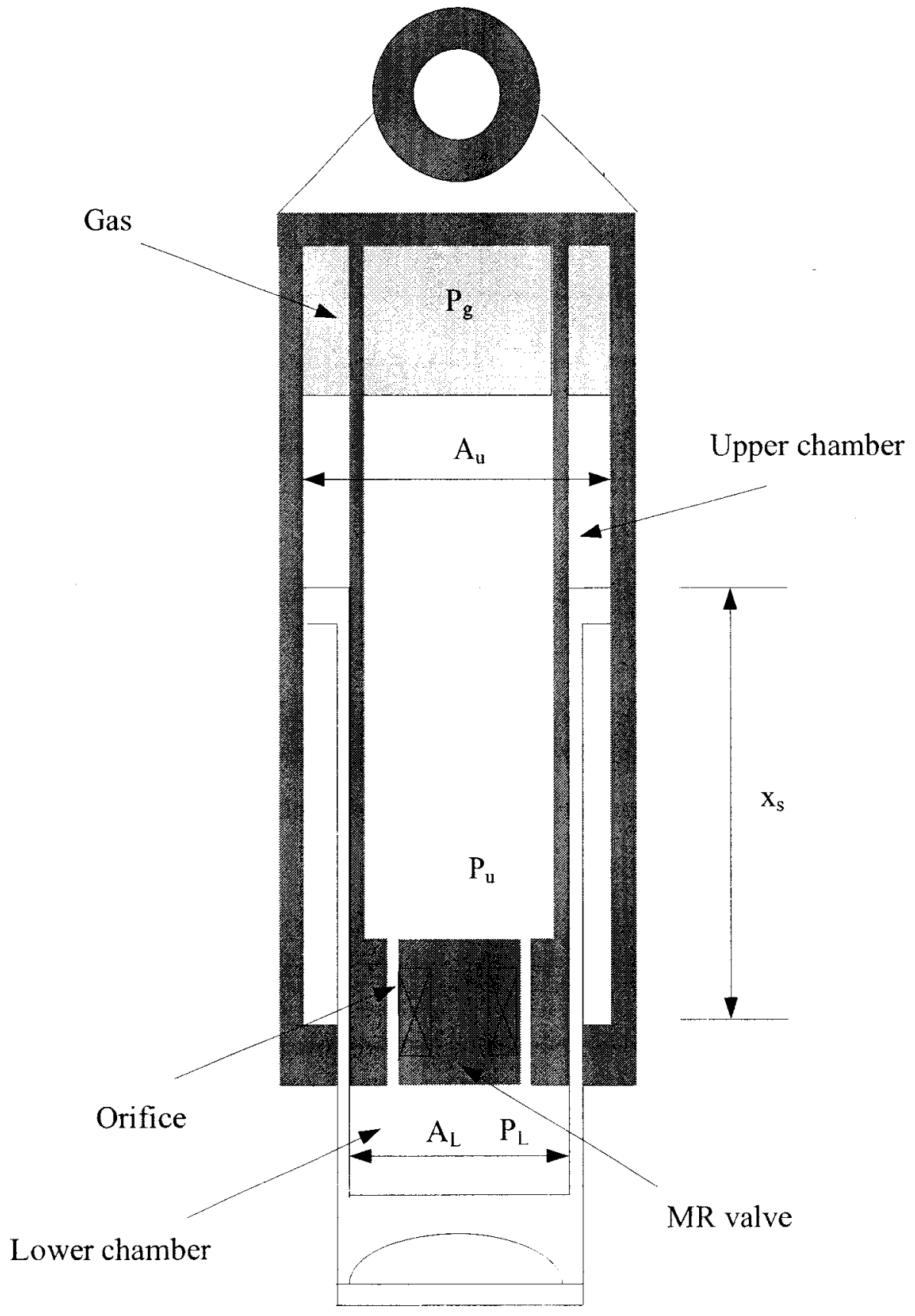

Fig 2.10 Schematic of MR shock strut. 
During touchdown, the fluid is pressurized from lower chamber to upper chamber through orifice which cause increase in gas pressure and consequently produces a force known as gas spring force. The pressure drop across the orifice also generates a force which resists the closure of the shock strut. The gas spring force and the force due to pressure drop across the orifice represent stiffness and damping properties of the shock strut respectively. The former force is related to the energy stored into the accumulator and the latter is related to the energy dissipated by the fluid through the orifice. Therefore two independent terms can be formulated and then summed.

In addition to gas spring force and the force due to fluid resistance, the friction force between wall and cylinder wall contribute to the balance of forces in the strut. Friction force is mainly composed of seal friction and friction due to the offset wheel in this type of landing gear. However, both frictions are neglected in this study given their reduce contribution to the damping phenomenon. The former is assumed to be negligible since no drag load is considered in the proposed landing gear model. The later is also neglected given that the tire is assumed to be directly connected to the shock strut without any linkage connection. The force of the shock strut due to pressure drop across the orifice and gas pressure can be expressed by Eq. (2.2).

$$
F_{s}=\left(P_{L}-P_{u}\right) A_{L}+P_{g} A_{u}=F_{p}+F_{g}
$$

where $P_{L}$ and $A_{L}$ are the pressure and the area of the lower chamber and $P_{u}$ and $A_{u}$ are the pressure and area of the upper chamber respectively for the strut shown in Fig $2.10 . P_{g}$ is the pressure of the accumulator which is $P_{g}=P_{u}$. In Eq. (2.2), the force of the shockstrut, $F_{S}$, is expressed as a combination of the force due to pressure drop across the 
orifice, $F_{p}$, which can be written as $F_{p}=\left(P_{L}-P_{u}\right) A_{L}$ and gas spring force, $F_{g}$, which is $F_{g}=P_{g} A_{u}$. The formulation of the forces is presented in the following sub-sections.

\section{Force due to Pressure Drop Across the Orifice}

To formulate the force due to pressure drop across the orifice, the two active and inactive regions of fluids (shown in light blue and dark blue respectively in Fig 2.9-a) have to be modeled and analyzed based on reasonable assumptions. The main assumption is that the inactive region is filled with Newtonian laminar flow while the active region contains a time-independent non-Newtonian fluid. The behavior of the non-Newtonian fluid of the active region can be described by the Bingham plastic model.

Therefore, the overall pressure drop across the orifice can be expressed as a combination of the pressure drop across the inactive length of orifice $\Delta P_{0}$ and the pressure drop across the active region of the orifice $\Delta P_{m r}$ :

$$
P_{L}-P_{u}=\Delta P_{0}+\Delta P_{m r}
$$

Multiplying each side of the Eq. (2.3) by $A_{L}$ gives:

$$
\left(P_{L}-P_{u}\right) A_{L}=\Delta P_{0} A_{L}+\Delta P_{m r} A_{L}
$$

where $F_{p}=\left(P_{L}-P_{u}\right) A_{L}$ is the overall force due to pressure drop across the orifice which can be written as the sum of the linear passive $F_{0}$ and nonlinear MR $F_{m r}$ forces due to pressure drops across the inactive and active regions of the orifice, respectively. Therefore Eq. (2.4) can be written in the form of:

$$
F_{p}=F_{m r}+F_{0}
$$

where $F_{0}=\Delta P_{0} A_{L}$ and $F_{m r}=\Delta P_{m r} A_{L}$. 
For very small annular gaps, the flow field may be modeled as flow between infinite parallel plates. Therefore, the flow inside the annular gap is modeled as flow between stationary infinite parallel plates which is shown in Fig 2.9-b. Pressure drop across the inactive region of the orifice, $\Delta P_{0}$, can be related to the volumetric flow rate using well-known Poiseuille equation for incompressible laminar flow between two stationary parallel plates as:

$$
\Delta P_{0}=\frac{12 \mu l_{i} Q}{a D_{m^{3}}{ }^{3}}
$$

where $Q$ is the volumetric flow rate, $\mu$ is the Newtonian viscosity, $l_{i}$ is the inactive length of the MR valve and $D_{m}$ is the orifice height. $a$ is the depth of the plate which is equal to mean annular perimeter of the valve. This value can be calculated as $a=\pi d$ where $d$ is the mean valve diameter. Considering the mass conservation for an incompressible fluid, the volumetric flow rate can be expressed in terms of flow velocity, $\dot{x}_{s}$, as:

$$
Q=A_{L} \dot{x}_{s}
$$

where $A_{L}$ is the lower chamber area. Substituting Eq. (2.7) into Eq. (2.6) yields:

$$
\Delta P_{0}=\frac{12 \mu l_{i} A_{L} \dot{x}_{S}}{a D_{m}^{3}}
$$

As previously discussed, force due to pressure drop across the inactive region of the orifice, $F_{0}$, is given as the product of the $\Delta P_{0}$ and $A_{L}$. Thus:

$$
F_{0}=\frac{12 \mu l_{i} A_{L}^{2} \dot{x}_{S}}{a D_{m}{ }^{3}}
$$

The force due to pressure drop across the inactive region of the orifice is a linear function in terms of flow velocity given the laminar flow assumption. Further, the force due to pressure drop across the active region of the MR valve can also be derived for laminar flow. The detailed formulation is given here. 
As previously discussed, the fluid in active region may be described by Bingham plastic model. Bingham plastic flow acts like a rigid material when the shear stress, $\tau$, is less than a critical value (yield stress, $\tau_{y}$ ) and once the shear stress exceeds the yield stress, it flows as a viscous fluid. This non-Newtonian fluid behaves as a solid plug (shown by hatched area with thickness of $h$ in Fig 2.9-b) if the shear stress becomes less than a certain value referred to as the yield stress.

Let us assume xy-coordinates on the bottom wall of the gap as shown in Fig 2.9-b where gap height is along the $\mathrm{y}$-axis and velocity of the flow is along the $\mathrm{x}$-axis. $y$ varies from 0 to $D_{m}$. As it can be seen in Fig 2.9-b, in a region near the axis, where $y_{p i}<y<$ $y_{p o}$ and the local shear stress is less than the yield value, $\tau_{y}$, the material does not shear. However, in the region further from the axis but closer to the walls where $y_{p i}>y>0$ or $D_{m}>y>y_{p o}$ (the shear stress is higher than the yield value), the shear rate is non-zero and can be described by the following equation:

$$
f(\tau)=\frac{d u}{d y}= \begin{cases}0 \quad, & |\tau|<\left|\tau_{y}\right| \\ \frac{\tau-\tau_{y} \operatorname{sgn}(u)}{\mu_{p}}, & \left|\tau_{y}\right|<|\tau|\end{cases}
$$

where, $f(\tau)$ is the shearing function which is the discontinuous counterpart of a linear continuous Newtonian shearing function. The main difference between a Newtonian and non-Newtonian flow can be described by this shearing function since it is always a continuous function of $\tau$ in Newtonian fluids and a discontinuous function for nonNewtonian fluids. $\tau_{w}$ is the shear stress at the wall, $u$ is the velocity of the flow, $\frac{d u}{d y}$ is the shear rate and $\mu_{p}$ is the Bingham plastic viscosity ${ }^{2}$. For Fraunhofer AD57 MR fluid

\footnotetext{
${ }^{2}$ A measure of the internal resistance to fluid flow of a Bingham plastic, expressed as the slope of the shear stress/shear rate line above the yield stress.
} 
which is assumed to be used in this work, Bingham plastic viscosity is $\mu_{p}=0.1 \mathrm{~Pa} . \mathrm{S}$ $[26]$.

Pressure drop across the active region of the orifice, $\Delta P_{m r}$, can be related to the volumetric flow rate using Buckingham equation for incompressible laminar flow as:

$$
4\left(\frac{l_{m r}}{D_{m} \Delta P_{m r}}\right)^{3} \tau_{y}-3\left(\frac{l_{m r}}{D_{m} \Delta P_{m r}}\right) \tau_{y}+\left(1-\frac{12 \mu_{p} l_{m r} Q}{a D_{m}{ }^{3} \Delta P_{m r}}\right)=0
$$

where $l_{m r}$ is the active length of the MR valve and is assumed to be $l_{m r}=0.024 \mathrm{~m}$ which is almost half of the total length of the MR valve. Detailed information can be found in Appendix A.

Eq. (2.11) also relates the pressure drop across the active region of the orifice and the yield stress. Substituting volumetric flow rate from Eq. (2.7) into Eq. (2.11) one can obtain:

$$
4\left(\frac{l_{m r}}{D_{m} \Delta P_{m r}}\right)^{3} \tau_{y}-3\left(\frac{l_{m r}}{D_{m} \Delta P_{m r}}\right) \tau_{y}+\left(1-\frac{12 \mu_{p} l_{m r} A_{L} \dot{x}_{s}}{a D_{m}{ }^{3} \Delta P_{m r}}\right)=0
$$

As previously discussed, force due to pressure drop across the active region of the orifice, $F_{m r}$, is given as the product of the $\Delta P_{m r}$ and $A_{L}$. Thus substituting $\Delta P_{m r}=$ $F_{m r} / A_{L}$ into Eq. (2.12), gives:

$$
4\left(\frac{l_{m r} A_{L}}{D_{m} F_{m r}}\right)^{3} \tau_{y}{ }^{3}-3\left(\frac{l_{m r} A_{L}}{D_{m} F_{m r}}\right) \tau_{y}+\left(1-\frac{12 \mu_{p} l_{m r} A_{L}^{2} \dot{x}_{s}}{a D_{m}^{3} F_{m r}}\right)=0
$$

Eq. (2.13) can be solved for $F_{m r}$ which would depend on $\tau_{y}$ and $\dot{x}_{s}$. In general:

$$
F_{m r}=f\left(\dot{x}_{s}, \tau_{y}\right)
$$

As it can be seen, the force due to pressure drop across the active region of the orifice is a nonlinear function which depends on the value of the flow velocity and the yield stress. 
It has been theoretically and experimentally shown that the yield stress is a powerlow function of the magnetic flux density and consequently input current $I$ [18]. The relation between yield stress and the input current is assumed as a nonlinear curve shown in Fig 2.11 which is provided by the experiments done by Batterbee et al. [26].

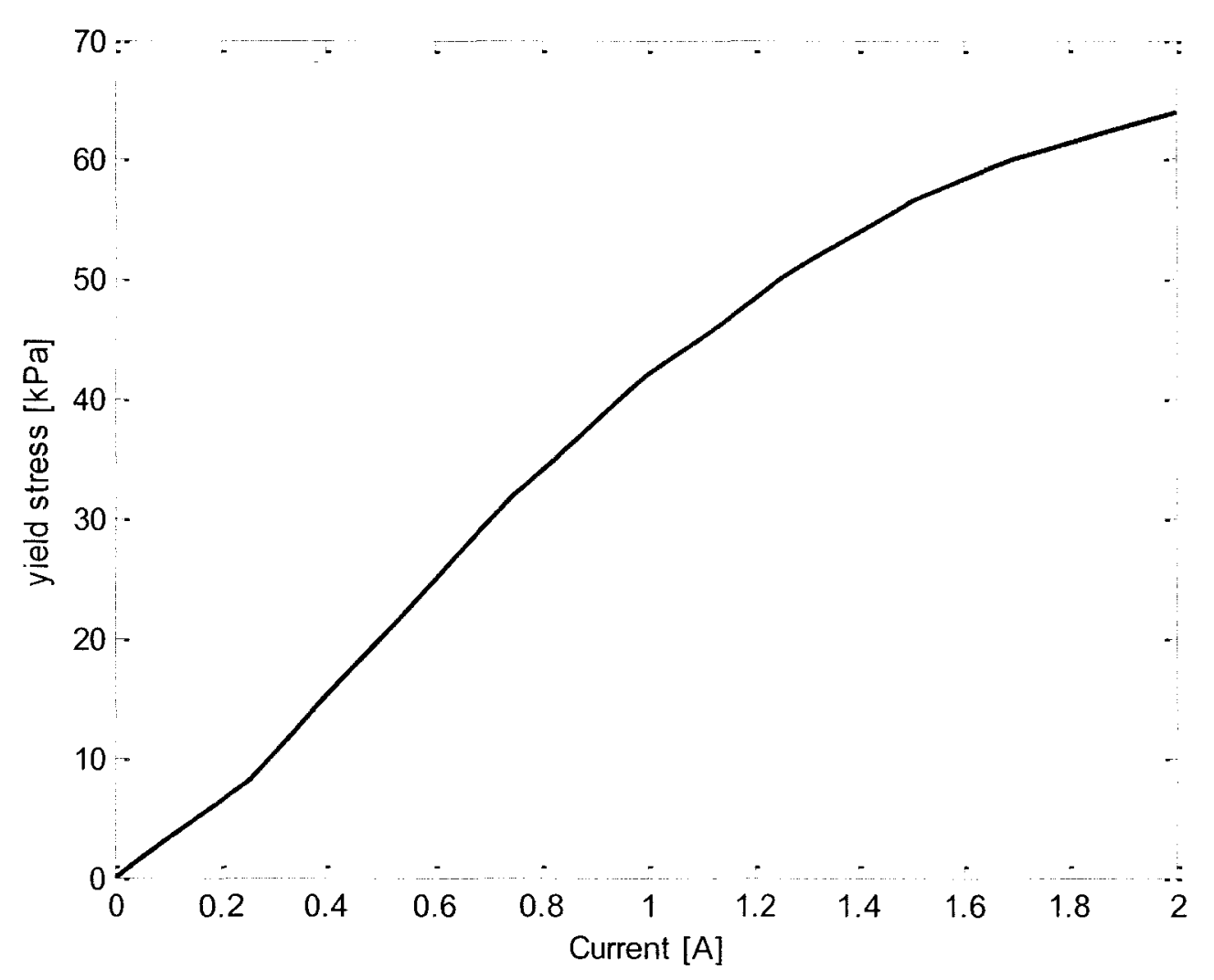

Fig 2.11 Yield stress as a function of the input current.

As it can be seen from Fig 2.11, the data is provided for the current range of $I=0 \mathrm{~A}$ to $I=2 \mathrm{~A}$. The experiments shows that function behaves linearly for the currents below $0.22 \mathrm{~A}$ and as the current increases, the yield stress shows nonlinear behavior.

In the case of zero field, when the yield stress is zero, Eq. (2.13) reduces to Poiseuille equation as described before in Eq. (2.9). In Chapter 4, when the desired MR 
damping force is estimated, one can substitute it into Eq. (2.13) to obtain the desired yield stress. Subsequently, the yield stress/current relationship can be used to estimate the corresponding desired input current.

\section{Gas Spring Force}

As previously discussed, the force of the shock strut consists of the gas spring force and the force due to the pressure drop across the orifice. Here, to derive gas pressure-strut stroke relation and consequently formulate the gas spring force, polytropic gas law for a closed system can be used:

$$
P_{g} V_{g}{ }^{n}=P_{g e} V_{g e}{ }^{n}=C
$$

where $P_{g}$ and $V_{g}$ are gas pressure and volume at any stroke. $P_{g e}$ and $V_{g e}$ are gas pressure and volume at full extension. $C$ is a constant and $n$ is an exponent which depends on the rate of compression. For normal ground handling activity, when the rate of compression is low, the process is isothermal meaning that $n=1$. In the case of dynamic and fast compression such as impact phase, polytropic process is applied in which $n>1$. Since this work focuses on the analysis of the landing gear behavior during impact phase, ploytropic process is assumed. For the polytropic process, $n$ is either $n=1.1$ or $n=$ 1.35 [4]. The former is used when the gas and hydraulic fluid are mixed and the latter is used when they are separated and the gas is located in an accumulator. As previously shown in Fig 2.7, the gas and the hydraulic fluid are separated in the shock strut used in this work. Therefore, polytropic exponent of $n=1.35$ is chosen for our calculation.

The gas volume at any stroke, $V_{g}$, can be written as a function of stroke, $x_{s}$, as:

$$
V_{g}=V_{g e}-A_{u} x_{S}
$$

where $A_{u}$ is the area of the upper chamber as shown in Fig 2.7. 
Substituting Eq. (2.16) for $V_{g}$ in the Eq. (2.15), one can solve for the gas pressure at any stroke, $P_{g}$, as:

$$
P_{g}=\frac{P_{g e} V_{g e}{ }^{n}}{V_{g}{ }^{n}}=P_{g e}\left(\frac{V_{g e}}{V_{g e}-A_{u} x_{s}}\right)^{n}
$$

As previously disused, gas spring force, $F_{g}$, can be expressed as:

$$
F_{g}=A_{u} P_{g}
$$

Substituting $P_{g}$ from Eq. (2.17) into Eq. (2.18), one can obtain gas spring force-stroke relation as:

$$
F_{g}=A_{u} P_{g e}\left(\frac{V_{g e}}{V_{g e}-A_{u} x_{s}}\right)^{n}
$$

$P_{g e}$ and $V_{g e}$ are calculated in Appendix B as $P_{g e}=662324.17 \mathrm{~Pa}$ and $V_{g e}=0.0074 \mathrm{~m}^{3}$, respectively. $A_{u}$ is assumed to be $A_{u}=0.0182 \mathrm{~m}^{2}$ and the fully extended stroke of the selected shock strut $S$ is assumed to be $S=0.38 \mathrm{~m}$ based on the data found from the work done by Daniels et al. [30].

Fig 2.11 illustrates the effect of the exponent $n$ on the gas spring force. The isothermal compression curve for $n=1$ and two polytropic compression curves for $n=1.1$ and $n=1.35$ are shown. As it can be seen from the Fig 2.12, for small strokes, gas spring force does not change significantly by increasing the exponent. However, for larger strokes, gas spring force increases by increasing the exponent. 


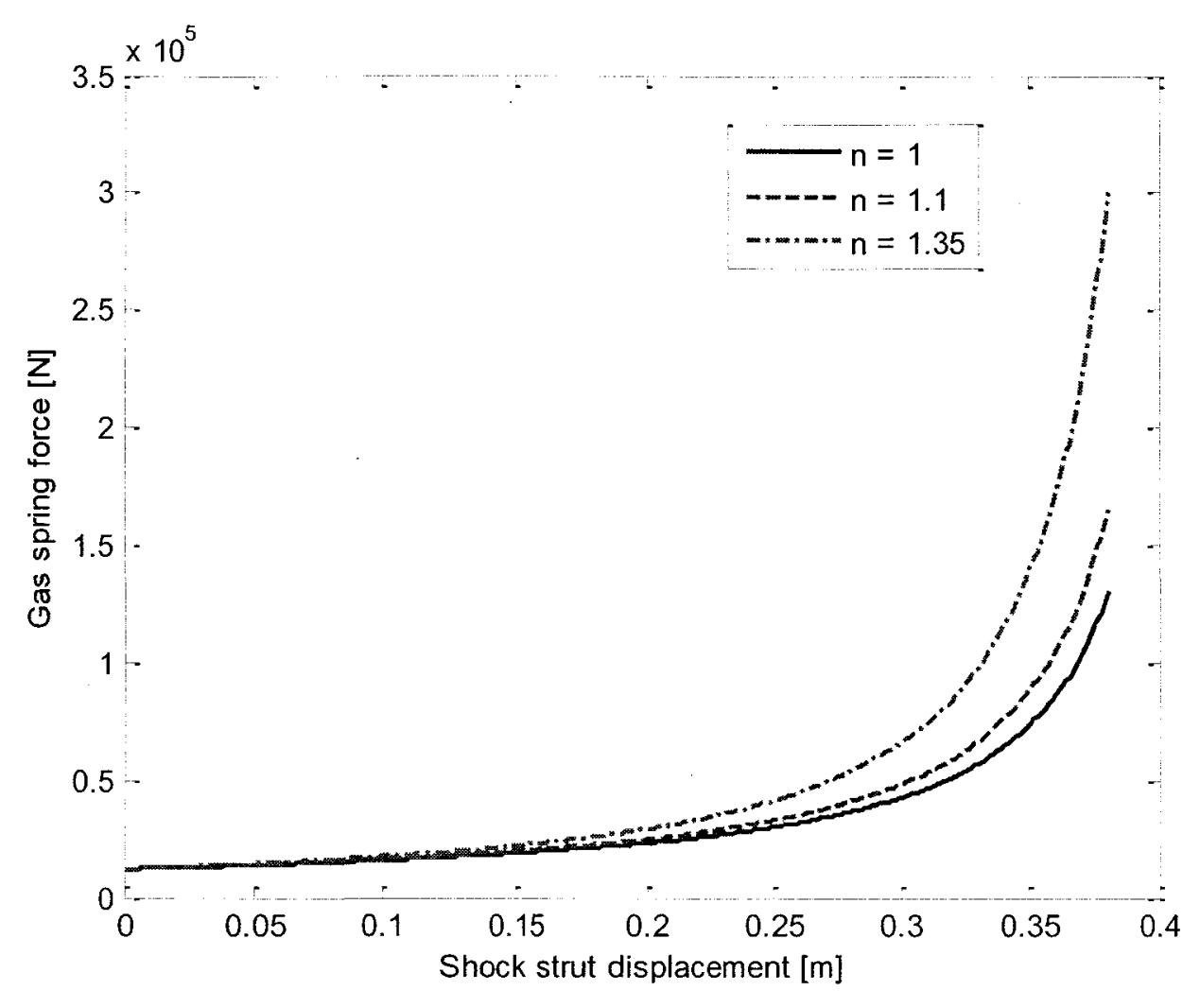

Fig 2.12 Isothermal and polytropic compression curves.

\subsection{Summery}

Overall landing gear model of a Navy aircraft was generated based on series of assumptions in order to investigate dynamic analysis under various impact conditions in the next chapter. The full model comprising of landing gear components were developed and the associated forces were formulated.

MR shock strut model was created based upon changing the orifice plate of the passive shock strut with MR valve. MR damping force was attained as a function of the electrical current applied on the MR damper's coils and the gas spring force was formulated. 


\section{CHAPTER 3}

\section{MODELING OF THE LANDING GEAR INTAGRATED WITH MR DAMPER}

\subsection{Introduction}

In this chapter, MR shock strut, formulated in Chapter 2, is integrated with the two-DOF landing gear system model and governing equations of motion are derived. Natural frequency and mode shapes of the system are then calculated. The inverse model of the MR shock strut relating MR yield stress to the MR shock strut force and strut velocity is also formulated. Finally simulations are conducted for the landing gear system with integrated MR shock strut for different current excitation and the results are demonstrated and compared. Using developed governing equations and inverse model, a PID controller will be formulated to reduce the acceleration of the system in the next Chapter.

\subsection{Development of Equations of Motion}

In this section, the MR landing gear system is first modeled and the governing equations are derived. The equations will subsequently be used to identify the natural frequencies and mode shapes of the system.

As previously discussed in Chapter 2, the MR landing gear system can be studied using a simplified two-DOF landing gear model. Therefore, the pitch and roll motions of the upper and lower masses are not considered in the model. The whole aircraft body is assumed as a rigid body mass (the upper mass) and tire is modeled by a rigid body mass (the lower mass), spring and damper. The two-DOF model of the main landing gear 
system including MR shock strut model and the free body diagram of the lower and upper masses are presented in Fig 3.1. As previously discussed in chapter 2, the total force in the MR shock strut, $F_{a}$, is the combination of the linear damping, nonlinear MR damping, and nonlinear gas spring forces which can be expressed as:

$$
F_{a}=F_{0}+F_{m r}+F_{g}
$$

where $F_{0}$ is the linear damping force due to pressure drop across the inactive length of the orifice, $F_{m r}$ is the nonlinear MR damping force due to pressure drop across the activation length of the orifice and $F_{g}$ is the accumulator gas spring force.

As discussed in Chapter 2, Eq. (2.9), $F_{0}$ can be expressed as:

$$
F_{0}=c_{0} \dot{x}_{s}=c_{0}\left(\dot{x}_{u}-\dot{x}_{L}\right)
$$

where $x_{u}$ and $x_{L}$ are the displacement of the upper and lower mass respectively, $x_{s}$ is the relative displacement of the shock strut and $c_{0}$ is the constant viscous damping coefficient defined as:

$$
c_{0}=\frac{12 \mu_{p} l_{i} A_{L}^{2}}{a D_{m}^{3}}
$$

Also according to Eqs. (2.14) and (2.19) in Chapter 2, $F_{m r}$ and $F_{g}$ can be expressed as:

$$
\begin{aligned}
& F_{m r}=f\left(\dot{x}_{s}, \tau_{y}\right) \\
& F_{g}=A_{u} P_{g e}\left(\frac{V_{g e}}{V_{g e}-A_{u} x_{s}}\right)^{n}
\end{aligned}
$$

where relative parameters in Eqs. (3.4) and (3.5) were defined in Chapter 2. 


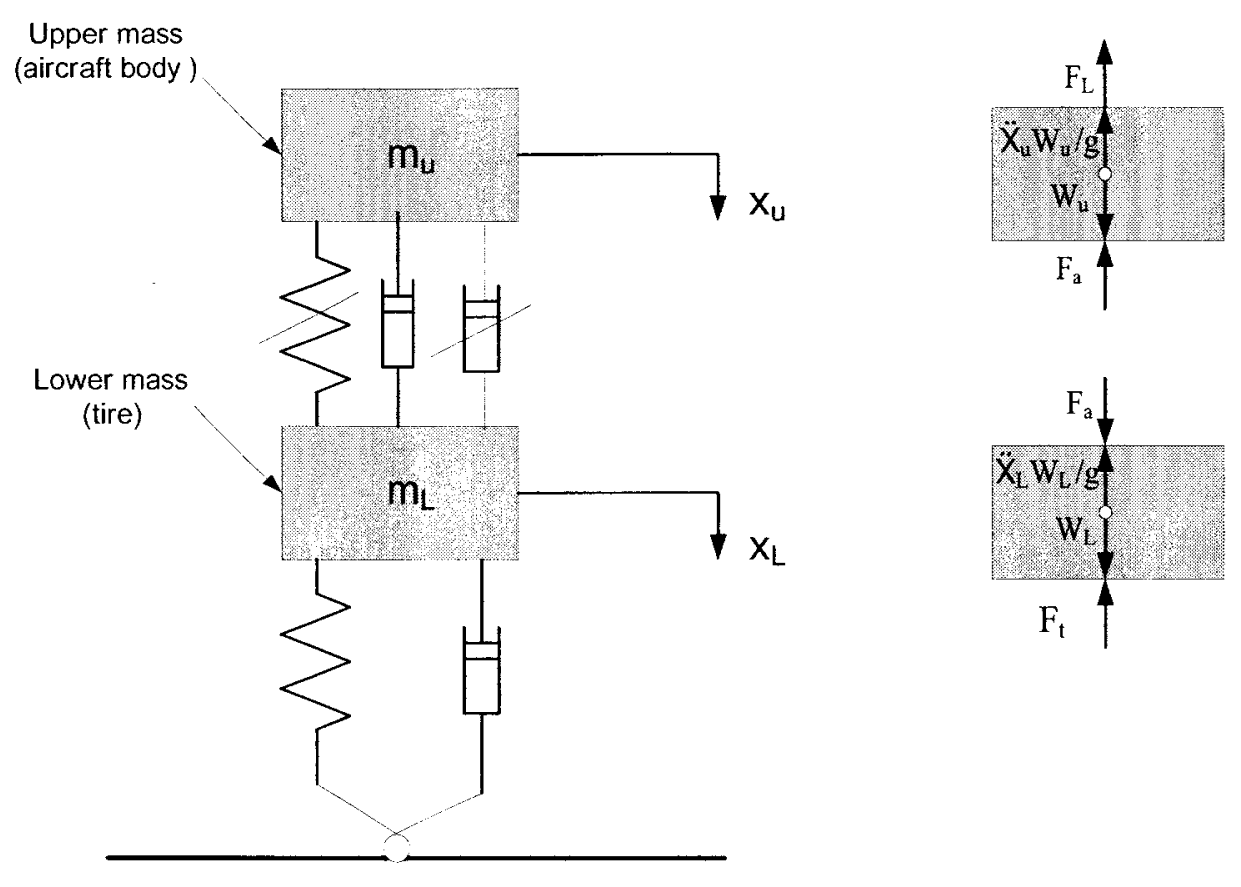

Fig 3.1 Two-DOF model of the landing gear system and the free body diagram of the upper and lower mass.

Considering free-body diagram in Fig 3.1, the governing equations of motion for the main landing gear model can be expressed as:

$$
\begin{aligned}
& \frac{W_{u}}{g} \ddot{x}_{u}+F_{a}-W_{u}+F_{L}=0 \\
& \frac{W_{L}}{g} \ddot{x}_{L}-F_{a}+F_{t}-W_{L}=0
\end{aligned}
$$

where $W_{u}$ is the airframe weight and $W_{L}$ is the wheel tire weight. It is noted that $x_{u}$ and $x_{L}$ are measured from the positions of $W_{u}$ and $W_{L}$ at the instant $t=0$ when the tire first contacts the ground. $\ddot{x}_{u}$ and $\ddot{x}_{L}$ are the upper and lower mass accelerations respectively and $g$ is the gravitational acceleration. 
$F_{t}$ is the tire force studied in chapter 2 Eq. (2.1), and is represented here as:

$$
F_{t}=\left\{\begin{aligned}
k_{t} x_{L}+c_{t} \dot{x}_{L}, & x_{L} \geq 0 \\
0, & x_{L}<0
\end{aligned}\right.
$$

where $k_{t}$ is the tire stiffness and $c_{t}$ is damping coefficient of the tire which were determined as $k_{t}=1080000 \mathrm{~N} / \mathrm{m}$ and $c_{t}=5000 \mathrm{Ns} / \mathrm{m}$.

$F_{L}$ is the lift force exerted from the air on the aircraft body and has upward direction. During the landing, the lift force varies and can be expressed as a function of time by an equation given by Choi and Wereley [9]:

$$
F_{L}=[1.2-0.9 \tanh (3 t)]\left(W_{u}+W_{L}\right)
$$

where $t \geq 0$ is the time in seconds.

The lift force described in Eq. (3.9) is plotted in Fig 3.2 for the time range of 0 to $0.2 \mathrm{sec}$. It should be noted that touchdown occurs in less than 0.3 seconds (see Fig 2.8) and since the landing impact analysis is investigated in this work, simulation is run for the time range of 0 to $0.2 \mathrm{sec}$.

As shown in Fig 3.2, the nonlinear lift force in the range of 0 to $0.2 \mathrm{sec}$ can be approximated by a linear function with good accuracy. The linear function is achieved by joining two selected points of $(0.042 \mathrm{sec}, 53.5 \mathrm{KN})$ and $(0.161 \mathrm{sec}, 39.6 \mathrm{KN})$ on the actual curve.

Here, the interpolated linear lift force function shown in Fig 3.2 is used in our analysis. The function can be expressed as

$$
F_{L}=k_{L_{1}} t+F_{L_{1}}
$$

where $k_{L_{1}}$ and $F_{L_{1}}$ are constant values and found to be $k_{L_{1}}=-120000 \mathrm{~N} / \mathrm{s}$ and $F_{L_{1}}=59000 \mathrm{~N}$ in order to minimize the error between the approximate linear function and the actual lift force. 


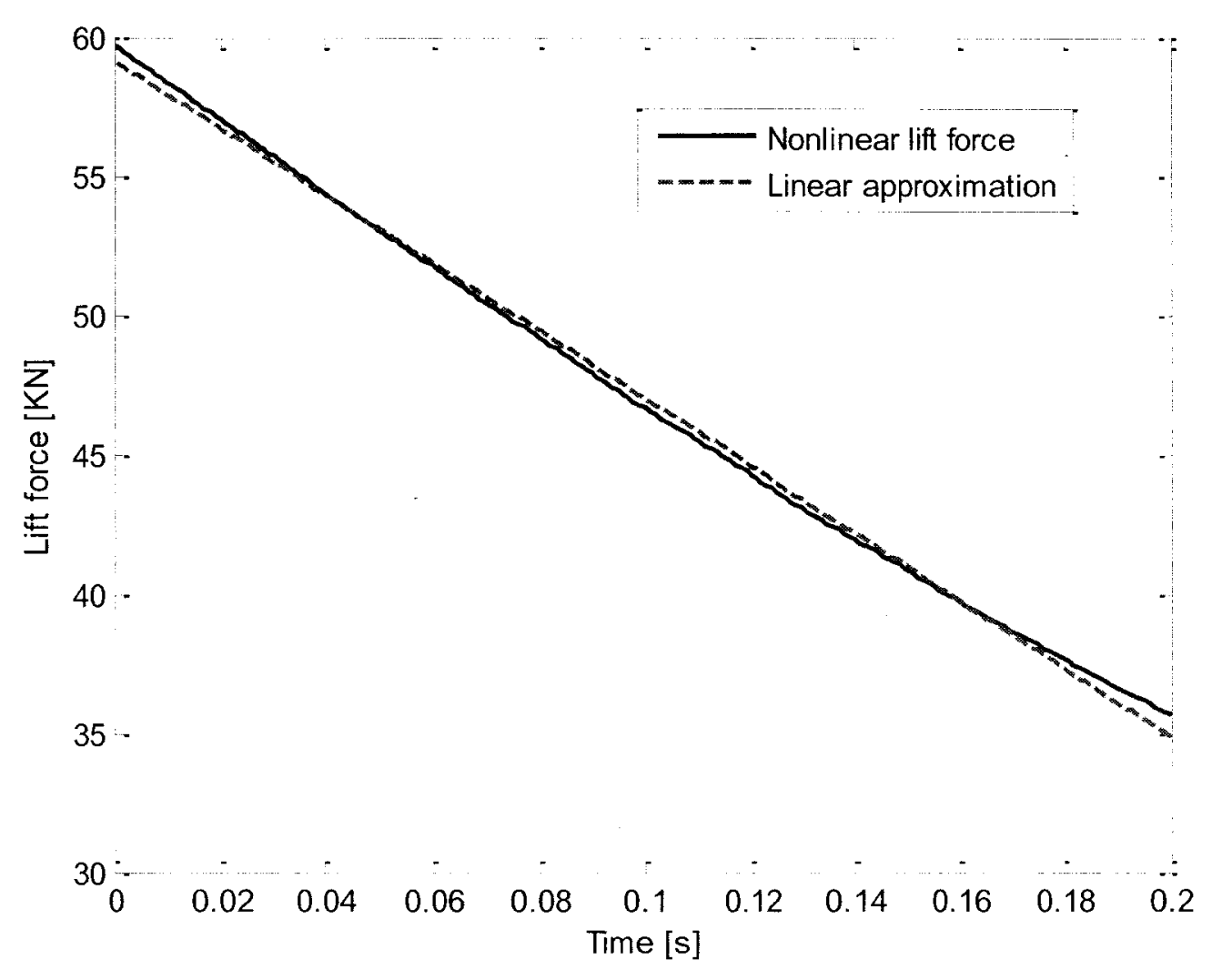

Fig 3.2 Nonlinear and linear lift forces versus time.

\subsubsection{Calculation of the natural frequencies and the normal modes of the system}

To calculate the natural frequencies and the normal modes of the system, let us first assume the MR shock strut is in passive mode (no induced current or magnetic field). In this case one can substitute for $\tau_{y}=0$ in Eq. (2.13) and derive the following relation:

$$
F_{m r}=\frac{12 \mu_{p} l_{m r} A_{L}^{2}}{a D_{m}^{3}} \dot{x}_{s}=c_{m} \dot{x}_{S}
$$

where $c_{m}$ is an equivalent MR viscous damping coefficient defined as $c_{m}=\frac{12 \mu_{p} l_{m r} A_{L}{ }^{2}}{a D_{m}{ }^{3}}$. 
In order to simplify the frequencies and mode calculations, the gas spring force is interpolated as a linear function. Therefore, the polytropic compression curve for the polytropic exponent of $n=1.35$, shown in Fig 2.1 , is simply approximated by the linear functions as shown in Fig 3.3.

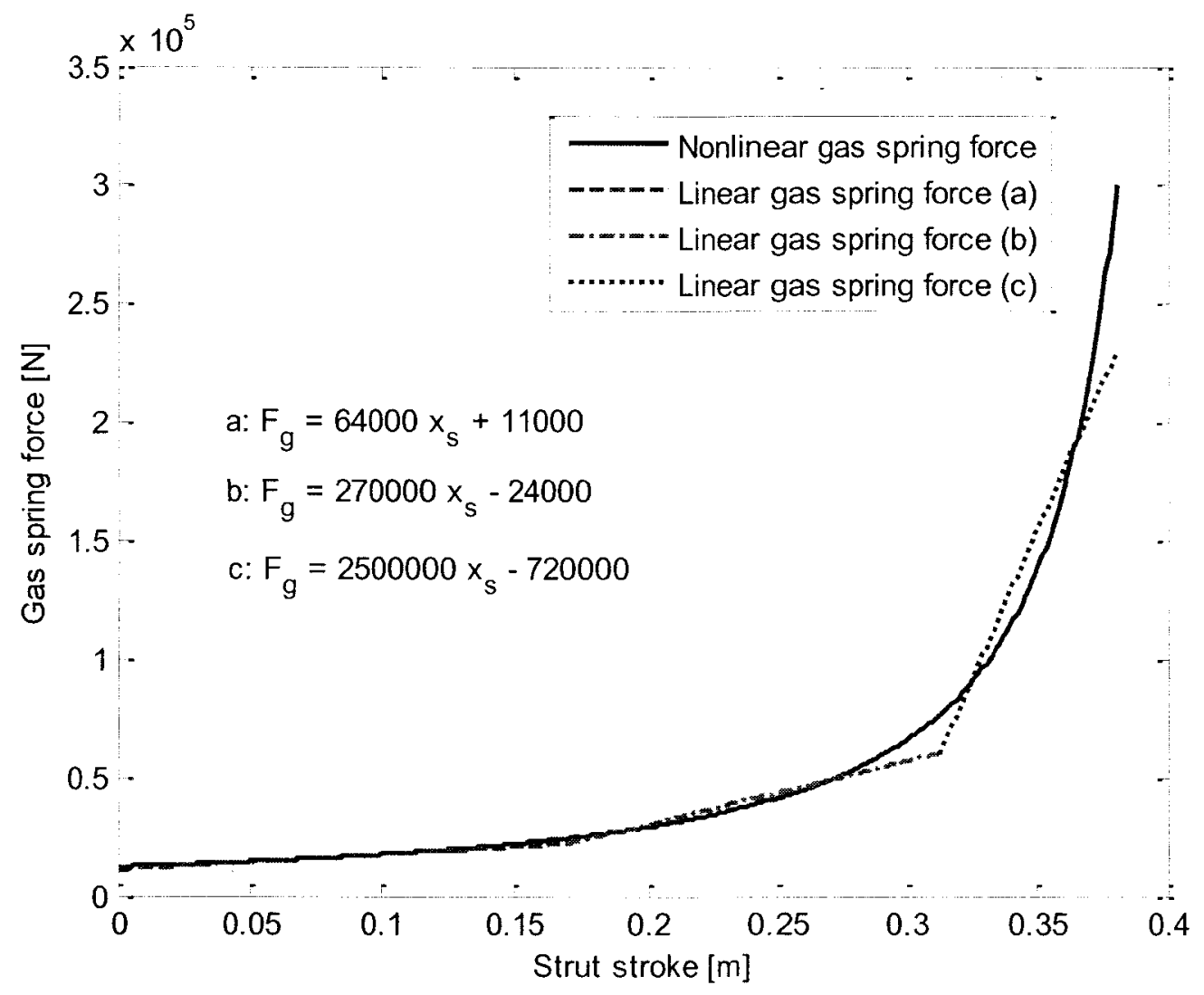

Fig 3.3 Linear and non-linear gas spring force.

This approximation is obtained by fitting three straight-line segments to the actual force-stroke curve in such a way that there will be minimum error between the actual and approximated value. The segments are chosen as: one straight-line segment from $x_{s}=0$ to $x_{s}=0.17 \mathrm{~m}$, one segment from $x_{s}=0.17 \mathrm{~m}$ to $x_{s}=0.312 \mathrm{~m}$ and finally one from 
$x_{s}=0.312 m$ to $x_{s}=0.38 \mathrm{~m}$. The error for the first two segments is almost zero. The error for the third segment is about $\% 23$.

Thus the gas spring force, $F_{g}$, can be described as:

$$
F_{g}=k_{g_{i}} x_{s}+F_{g_{i}}
$$

or here

$$
F_{g}=\left\{\begin{array}{lll}
k_{g_{1}} x_{s}+F_{g_{1}}, \text { for } i=1 \quad \& \quad & 0 \leq x_{s} \leq 0.17 m \\
k_{g_{2}} x_{s}+F_{g_{2}}, \text { for } i=2 \quad \& \quad & 0.17 m<x_{s} \leq 0.312 m \\
k_{g_{3}} x_{s}+F_{g_{3}}, \text { for } i=3 \quad \& \quad & 0.312<x_{s} \leq 0.38 m
\end{array}\right.
$$

in which $k_{g_{i}}$ and $F_{g i}$ are constant values and found to be:

$$
\begin{aligned}
& k_{g_{1}}=64000 \frac{\mathrm{N}}{\mathrm{m}}, k_{g_{2}}=270000 \frac{\mathrm{N}}{\mathrm{m}}, k_{g_{3}} 2500000 \mathrm{~N} / \mathrm{m} \\
& F_{g_{1}}=11000 \mathrm{~N}, F_{g_{2}}=-24000 \mathrm{~N}, F_{g_{3}}=-720000 \mathrm{~N}
\end{aligned}
$$

Now substituting Eqs. (3.2), (3.10), (3.11) and (3.12) into equations of motion given in Eqs. (3.6) and (3.7), one can obtain:

$$
\begin{aligned}
& \frac{w_{u}}{g} \ddot{x}_{u}+\left(c_{m}+c_{0}\right)\left(\dot{x}_{u}-\dot{x}_{L}\right)+k_{g_{i}}\left(x_{u}-x_{L}\right)=W_{u}-\left(k_{L_{1}} t+F_{L_{1}}\right)-F_{g_{i}}=f_{1}(t) \\
& \frac{w_{L}}{g} \ddot{x}_{L}+\left(c_{m}+c_{0}\right)\left(\dot{x}_{L}-\dot{x}_{u}\right)+k_{g_{i}}\left(x_{L}-x_{u}\right)+c_{t} \dot{x}_{L}+k_{t} x_{L}=W_{L}+F_{g_{i}}=f_{2}(t)
\end{aligned}
$$

where $f_{1}(t)$ and $f_{2}(t)$ are time dependent functions which represent the external forces. Casting Eq. (3.14) and Eq. (3.15) in the matrix form, we may write:

$$
[M]\{\ddot{x}\}+[C]\{\dot{x}\}+[K]\{x\}=[F]
$$

where $\{x\}$ is the displacement vector, $[M]$ is the mass matrix, $[C]$ is the damping matrix, $[K]$ is the stiffness matrix and $\{F\}$ is the force vector given as:

$$
\begin{aligned}
& \{x\}=\left[\begin{array}{l}
x_{u} \\
x_{L}
\end{array}\right] \\
& \{F\}=\left[\begin{array}{l}
f_{1}(t) \\
f_{2}(t)
\end{array}\right]
\end{aligned}
$$




$$
\begin{aligned}
& {[M]=\left[\begin{array}{cc}
\frac{W_{u}}{g} & 0 \\
0 & \frac{W_{L}}{g}
\end{array}\right]} \\
& {[C]=\left[\begin{array}{cc}
\left(c_{m}+c_{0}\right) & -\left(c_{m}+c_{0}\right) \\
-\left(c_{m}+c_{0}\right) & \left(c_{m}+c_{0}\right)+c_{t}
\end{array}\right]} \\
& {[K]=\left[\begin{array}{cc}
k_{g_{i}} & -k_{g_{i}} \\
-k_{g_{i}} & k_{g_{i}}+k_{t}
\end{array}\right]}
\end{aligned}
$$

To obtain the undamped natural frequencies of the system, the free vibration analysis has been conducted where $f_{1}(t)$ and $f_{2}(t)$ are set to be zero in the equations.

For an undamped system the equations of motion for free vibration can be expressed as:

$$
\left[\begin{array}{cc}
\frac{W_{u}}{g} & 0 \\
0 & \frac{W_{L}}{g}
\end{array}\right]\left[\begin{array}{l}
\ddot{x}_{u} \\
\ddot{x}_{L}
\end{array}\right]+\left[\begin{array}{cc}
k_{g_{i}} & -k_{g_{i}} \\
-k_{g_{i}} & k_{g_{i}}+k_{t}
\end{array}\right]\left[\begin{array}{l}
x_{u} \\
x_{L}
\end{array}\right]=\left[\begin{array}{l}
0 \\
0
\end{array}\right]
$$

The solutions to the above differential equation can be assumed in the following harmonic forms:

$$
\begin{aligned}
& x_{u}=X_{u} \cos \omega t \\
& x_{L}=X_{L} \cos \omega t
\end{aligned}
$$

where $X_{u}$ and $X_{L}$ are the amplitude of the upper and lower mass, respectively and $\omega$ is the undamped natural frequency. Substituting assumed $x_{u}$ and $x_{L}$ into Eq. (3.22), we obtain

$$
\left[\begin{array}{cc}
\left(-\frac{w_{u}}{g} \omega^{2}+k_{g_{i}}\right) & -k_{g_{i}} \\
-k_{g_{i}} & \left(-\frac{W_{L}}{g} \omega^{2}+k_{g_{i}}+k_{t}\right)
\end{array}\right]\left[\begin{array}{l}
X_{u} \\
X_{L}
\end{array}\right]=\left[\begin{array}{l}
0 \\
0
\end{array}\right]
$$

In order for this equation to have nontrivial solutions, the determinant of the matrix needs to be zero. Thus,

$$
\left|\begin{array}{cc}
\left.-\frac{W_{u}}{g} \omega^{2}+k_{g_{i}}\right) & -k_{g_{i}} \\
-k_{g_{i}} & \left(-\frac{W_{L}}{g} \omega^{2}+k_{g_{i}}+k_{t}\right)
\end{array}\right|=0
$$


Expanding the determinant leads to the following characteristic equation:

$$
\omega^{4}\left(m_{u} m_{L}\right)+\omega\left(-m_{u} k_{g_{i}}-m_{u} k_{t}-m_{L} k_{g_{i}}\right)+k_{g_{i}} k_{t}=0
$$

where $m_{u}=\frac{w_{u}}{g}$ and $m_{L}=\frac{W_{L}}{g}$ are the upper and lower mass and assumed to be $m_{u}=$ $10864.3 \mathrm{lb}$ and $m_{u}=326.2 \mathrm{lb}$, respectively. The solution of the characteristic equation for $k_{g_{1}}=64000 \frac{N}{m}$, when $x_{s} \leq 0.17 \mathrm{~m}$, provides two undamped natural frequencies of the system, $\omega_{1}=0.5627 \mathrm{~Hz}$ and $\omega_{2}=14.1374 \mathrm{~Hz}$.

and substituting $\omega_{1}$ into the Eq. (3.25), one can obtain

$$
X_{u}=8.6877 X_{L}
$$

Substituting $\omega_{2}$ into the Eq. (3.25) and solve for $\left[\begin{array}{l}X_{u} \\ X_{L}\end{array}\right]$, yields:

$$
X_{u}=-0.0035 X_{L}
$$

Now setting $X_{L}=1$, one can obtain the normal modes of the system, $\emptyset_{1}$ and $\emptyset_{2}$, as follows:

$$
\begin{aligned}
& \emptyset_{1}=\left[\begin{array}{l}
X_{u} \\
X_{L}
\end{array}\right]=\left[\begin{array}{c}
8.6877 \\
1
\end{array}\right] \\
& \emptyset_{2}=\left[\begin{array}{l}
X_{u} \\
X_{L}
\end{array}\right]=\left[\begin{array}{c}
-0.0035 \\
1
\end{array}\right]
\end{aligned}
$$

\subsection{Inverse Model of the MR Damper}

The hysteretic inverse model of the MR damper is derived in this section on the basis of the MR damper model developed in Chapter 2. This inverse model is applied to track the desired damping force. Force tracking control of the MR damper is implemented using PID control scheme which will be discussed in the next Chapter. The magnitude of the error between damping force and desired force is calculated to generate the derive current. 


\subsubsection{Formulation of an inverse model of the MR damper}

Buckingham equation explained in Chapter 2, can be used to derive the inverse model and consequently design the controller. Eq. (2.13) can be written as:

$$
4\left(\frac{l_{m r} A_{L}}{D_{m} F_{m r}}\right)^{3} \tau_{y}^{3}-3\left(\frac{l_{m r} A_{L}}{D_{m} F_{m r}}\right) \tau_{y}+\left(1-\frac{12 \mu_{p} l_{m r} A_{L}^{2} v_{s}}{a D_{m}{ }^{3} F_{m r}}\right)=0
$$

where $v_{s}=\dot{x}_{s}$ is the strut velocity. As it can be seen, yield stress, $\tau_{y}$, is a function of MR damping force, $F_{m r}$, and shock strut velocity, $v_{s}$, which can be expressed as:

$$
\tau_{y}=f\left(F_{m r}, v_{s}\right)
$$

In order to obtain function $f$ and subsequently $\tau_{y}$ in terms of $F_{m r}$ and $v_{s}$, one should solve Eq. (3.32) for $\tau_{y}$. Eq. (3.32) is a third degree equation with respect to $\tau_{y}$. To solve the equation, one may write Eq. (3.32) into following form:

$4\left(\frac{l_{m r} A_{L}}{D_{m} F_{m r}}\right)^{3} \tau_{y}{ }^{3}-3\left(\frac{l_{m r} A_{L}}{D_{m} F_{m r}}\right) \tau_{y}+\left(1-\frac{12 \mu_{p} l_{m r} A_{L}^{2} v_{s}}{a D_{m}^{3} F_{m r}}\right)=k \tau_{y}{ }^{3}+m \tau_{y}+n=0$

where $k, m$ and $n$ are the coefficients of the Eq. (3.32) defined as:

$$
\begin{aligned}
& k=4\left(\frac{l_{m r} A_{L}}{D_{m} F_{m r}}\right)^{3} \\
& m=-3\left(\frac{l_{m r} A_{L}}{D_{m} F_{m r}}\right) \\
& n=\left(1-\frac{12 \mu_{p} l_{m r} A_{L}^{2} v_{s}}{a D_{m}^{3} F_{m r}}\right)
\end{aligned}
$$

It should be noted that, $k>0, m<0$ and $n \geq 0 . F_{m r}$ reaches its minimum value at $n=0$ in which MR damper behaves like a passive damper. Desired damping force can be calculated using PID controller scheme. This force can be substituted in the Eq. (3.33) to obtain the required yield stress to be generated by the MR damper. 
As previously discussed in Chapter 2, yield stress is also a function of the command current $i_{c}$ as:

$$
\tau_{y}=g\left(i_{c}\right)
$$

The function $g\left(i_{c}\right)$ was shown in Fig 2.11 in Chapter 2. Subsequently knowing desired yield stress, one can obtain inverse command current, $i_{c}$, as:

$$
i_{c}=g^{-1}\left(\tau_{y}\right)
$$

in order to generate the required yield stress and subsequently desired damping force.

\subsection{Performance Analysis}

In this section, the initial conditions of the landing gear system are first determined. The landing gear system with the passive damper and MR damper including different constant current is then simulated using MATLAB SIMULINK. The results of each are compared and discussed for different sink velocities.

\subsubsection{Initial conditions}

As previously discussed in Chapter 2, in the fully extension position, the shock strut is subjected to a preload force due to the initial air pressure of the accumulator. Therefore, the shock strut does not begin to deflect at the time of touchdown until this force is overcome. Due to this, the shock strut is assumed to be rigid in compression and bending and consequently has only one degree of freedom during this time. In order to attain the initial conditions required for analysis of the two-DOF system discussed earlier, the equations of motion for single DOF system prior to the shock strut deflection are derived. 
During the first phase of the motion prior to shock strut deflection, lower and upper mass displacement can be considered as:

$$
x_{u}=x_{L}=x
$$

where $x$ is the displacement of the mass in single DOF system. Therefore the equation of motion for the single DOF can be written as:

$$
\frac{W}{g} \ddot{x}=W-k_{L_{1}} t-F_{L_{1}}-k_{t} x-c_{t} \dot{x}
$$

where $\mathrm{W}$ is aircraft and tire mass. Eq. (3.44) can be solved for $\mathrm{x}$ and $\ddot{\mathrm{x}}$ with the following initial conditions:

$$
x(0)=0, \dot{x}(0)=v
$$

where $v$ is the sink velocity of the aircraft.

Eq. (3.6) for 2 DOF model derived before can also be written as follows considering $\mathrm{x}_{\mathrm{u}}=\mathrm{x}:$

$$
\frac{W_{u}}{g} \ddot{x}=W_{u}-F_{L}-F_{m r}-F_{0}-F_{g}
$$

Assuming damping force to be zero, $F_{m r}=F_{0}=0$, the air spring force to be as its initial value in fully extended position, $F_{g}=A_{\mathcal{u}} P_{g e}$. Eq. (3.43) can then be expressed as:

$$
\ddot{x}=\frac{W_{u}-K_{L_{1}} t-F_{L_{1}}-A_{u} P_{g e}}{W_{u} / g}
$$

Eq. (3.44) can be solved and the acceleration curve can be achieved as a function of time. The point of intersection between this curve and acceleration curve obtained from Eq. (3.41) gives the instant when the shock strut begins to deflect, $t_{d}$. The initial conditions for the two-DOF system can subsequently be determined from the response of the single DOF system at time $t_{d}$. Therefore, the initial conditions of the two-DOF system can be expressed as: 


$$
\begin{aligned}
& x_{u}\left(t_{d}\right)=x_{L}\left(t_{d}\right)=x\left(t_{d}\right)=x_{0} \\
& \dot{x}_{u}\left(t_{d}\right)=\dot{x}_{L}\left(t_{d}\right)=\dot{x}\left(t_{d}\right)=v_{0}
\end{aligned}
$$

where $x_{0}$ and $v_{0}$ are the upper mass and lower mass initial displacement and velocity respectively at $t=t_{d}$.

\subsubsection{Simulation results}

In this section, the equations of motion given in Section 3.2 with the initial conditions taken from section 3.4.1 are solved using MATLAB SIMULINK in order to analyze the passive landing gear. The MR damping force-strut velocity relation is then obtained by solving Buckingham equation for a constant yield stress. Substituting this function into the equations of motion, one can solve equations of motion for a constant yield stress in order to analyze MR landing gear with constant current. The results of the two cases are compared and shown for different sink velocities.

Navy aircrafts are designed to higher sink speeds than other aircrafts. A navy aircraft can withstand $8 \mathrm{ft} / \mathrm{s}$ at maximum gross weight. In practice, this sink speed is rarely achieved. Here the simulation results are obtained for sink speeds of $2.7 \mathrm{~m} / \mathrm{s}(8.86$ $\mathrm{ft} / \mathrm{s})$ and $3.2 \mathrm{~m} / \mathrm{s}(10.5 \mathrm{ft} / \mathrm{s})$ which result in normal impacts. The instant $t_{d}$, in which the simulation starts, for the former sink speed is $t_{d}=0.0013 \mathrm{sec}$ and for the latter is $t_{d}=0.0021 \mathrm{sec}$. 


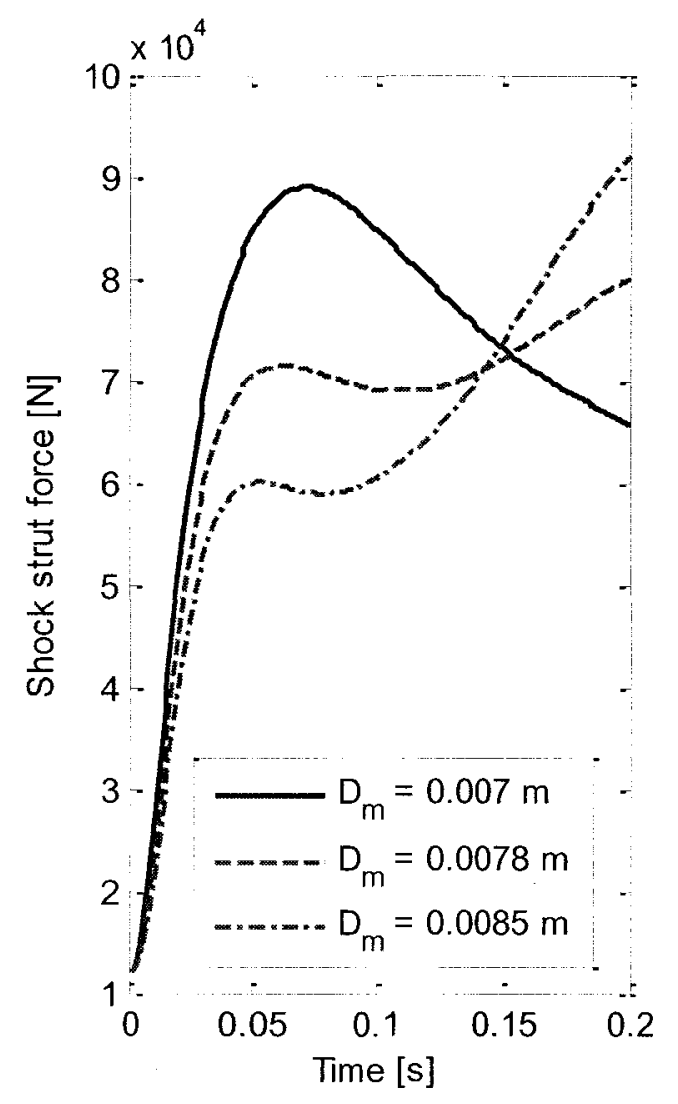

(a)

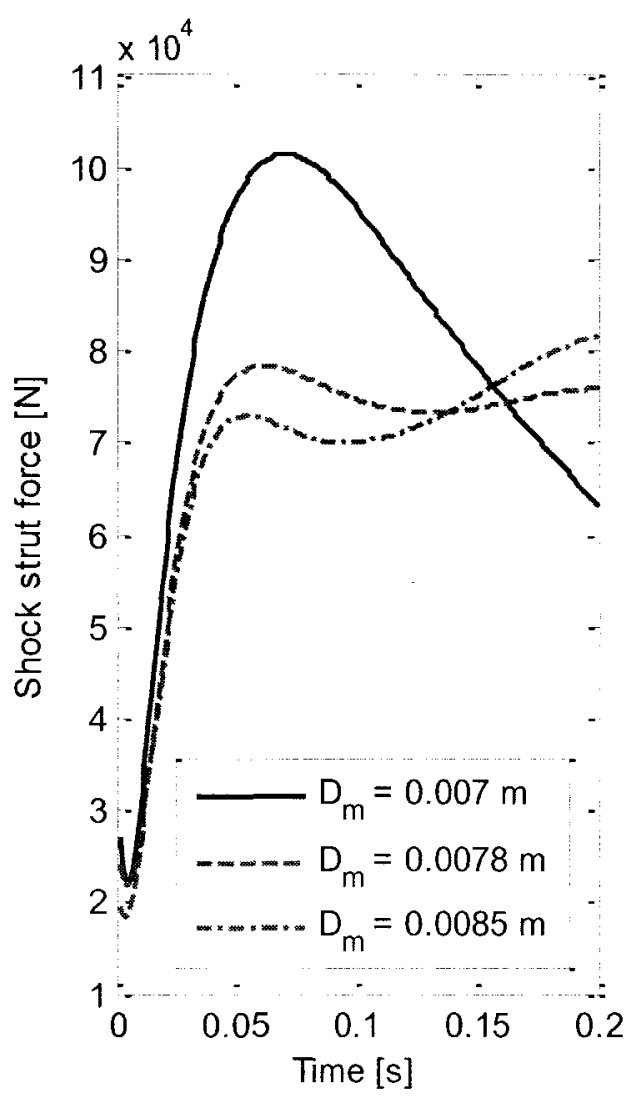

(b)

Fig 3.4 Time history of shock strut force, $v=3.2 \mathrm{~m} / \mathrm{s}$ : a) $\mathrm{I}=0 \mathrm{~b}$ ) $\mathrm{I}=2 \mathrm{~A}$.

The simulation results for shock strut force, $F_{a}$, versus time with sink velocity of $v=$ $3.2 \mathrm{~m} / \mathrm{s}$ and current excitations of 0 and $2 \mathrm{~A}$ is shown in Fig 3.4.The results are obtained for different orifice height to show the effect of this parameter on the shock strut force.

As it can be seen, changing orifice height has a significant effect on shock strut force. For orifice heights lower than $D_{m} \leq 0.007 \mathrm{~m}$, the shock strut experiences significantly larger impact force compared with that for valve with orifice height larger than $D_{m}>0.0085 m$. 

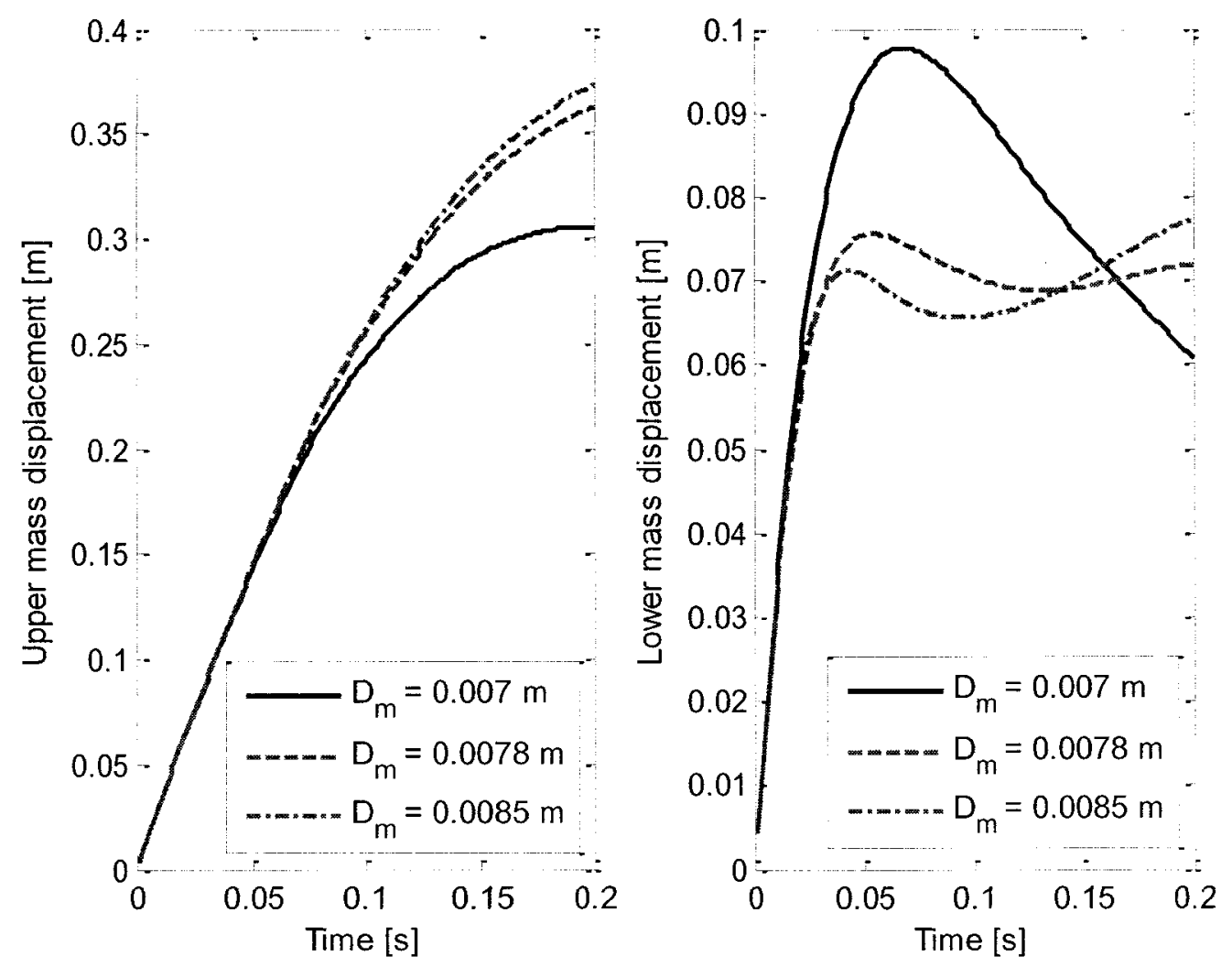

Fig 3.5 Time history of landing gear displacement in case of $\mathrm{I}=2 \mathrm{~A}$ and $\mathrm{v}=3.2 \mathrm{~m} / \mathrm{s}$.

As it can be seen, for $D_{m}=0.0078 \mathrm{~m}$, there is no significant variation in the shock strut force after reaching its first peak value and also strut does not experience large impact force at its first peak. Therefore, orifice height of $D_{m}=0.0078 \mathrm{~m}$ is selected as designed orifice height. Comparing Fig 3.4-a with Fig 3.4-b, one can conclude that by increasing the current input from 0 to $2 \mathrm{~A}$, shock strut force increases.

Fig 3.5 to Fig 3.7 present the upper mass and lower mass displacements, velocities and accelerations respectively at the sink speed of $v=3.2 \mathrm{~m} / \mathrm{s}$ and applied current excitation of $I=2 \mathrm{~A}$. Fig 3.5 shows that as the orifice height increases, the upper mass displacement increases and the lower mass displacement decreases. 

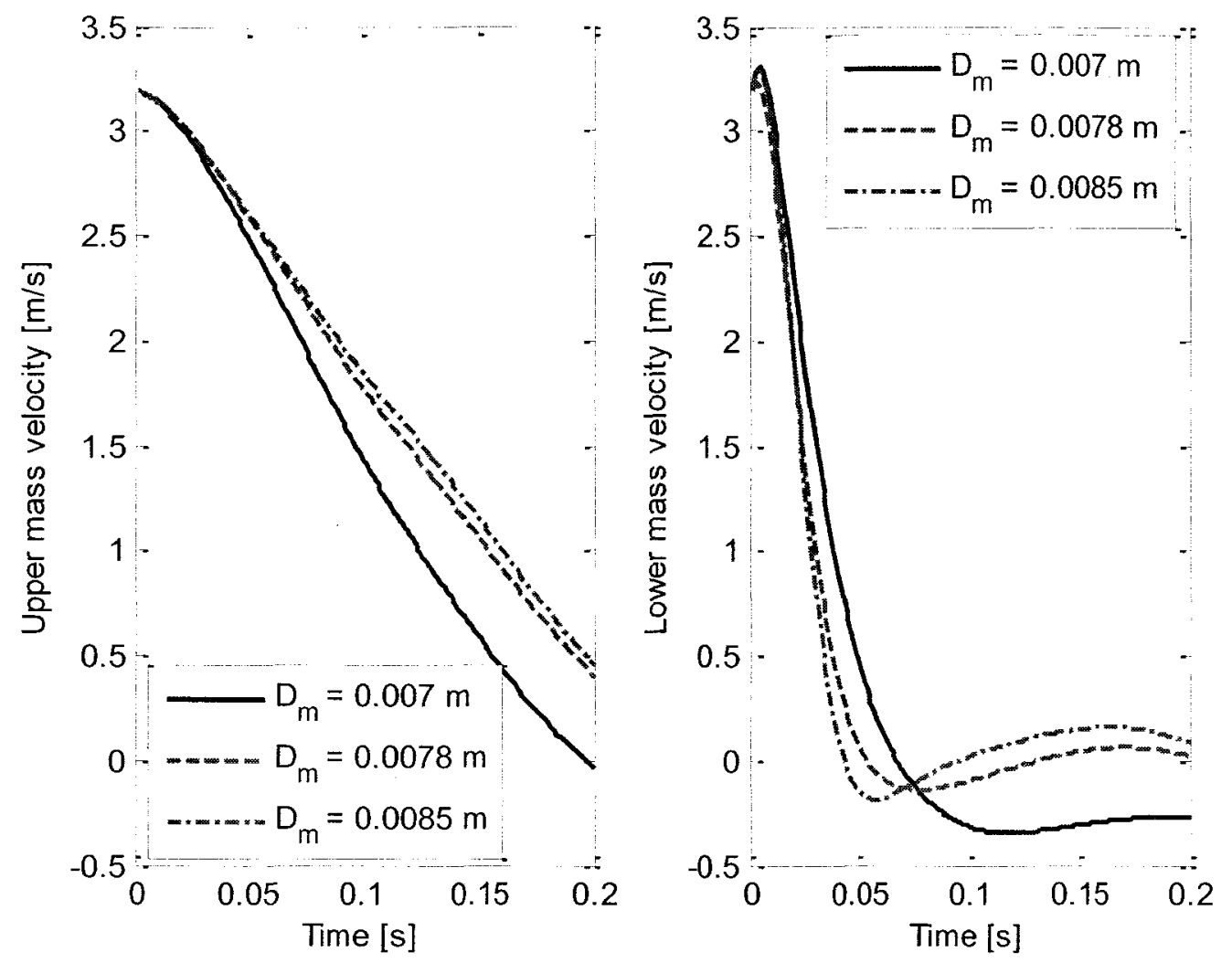

Fig 3.6 Time history of landing gear velocity in case of $\mathrm{I}=2 \mathrm{~A}$ and $\mathrm{v}=3.2 \mathrm{~m} / \mathrm{s}$.

Fig 3.6 also shows upper and lower mass velocities with current excitation of $I=2 A$ and sink speed of $v=3.2 \mathrm{~m} / \mathrm{s}$. As it can be realized the upper mass velocity increases as the orifice height increases. However, the lower mass velocity decreases as the orifice height increases up to certain time which after that the lower mass velocity also start increasing by increasing the orifice height. Fig 3.7 presents acceleration factor which is defined as the acceleration relative to gravitational acceleration. It can be seen that as the orifice height increases, the upper mass acceleration decreases and the lower mass acceleration increases in the first stage of the impact (at time less then approximately $0.04 \mathrm{~s}$ ). Therefore, orifice heights greater than $D_{m}>0.0078 m$ result in lower mass accelerations with maximum magnitude higher than $110 \mathrm{~m} / \mathrm{s}^{2}$. 

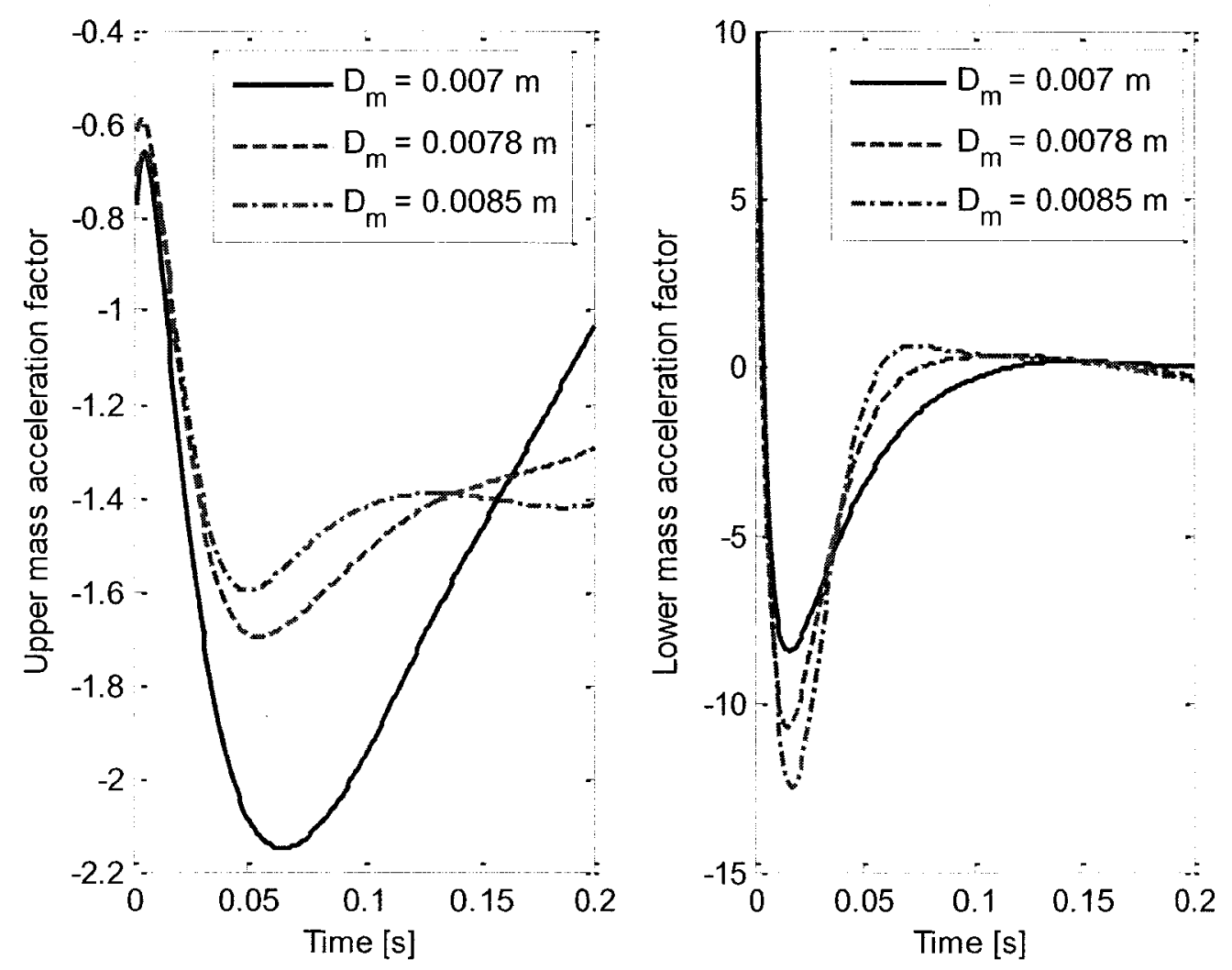

Fig 3.7 Time history of landing gear acceleration in case of $\mathrm{I}=2 \mathrm{~A}$ and $\mathrm{v}=3.2 \mathrm{~m} / \mathrm{s}$.

Figs 3.8 to 3.11 demonstrate the variation of shock strut force, upper mass and lower mass displacement, velocity and acceleration for different current $(=0$ and $I=2 A$ ) with sink velocity of $v=2.7 \mathrm{~m} / \mathrm{s}$.

Fig 3.8 shows the variation of total shock strut force, $F_{a}$, which is the combination of the total damping force, $F_{p}$, and the gas spring force, $F_{g}$, versus strut stroke for different currents. It can be seen that total shock strut force increases as the current increases. Since the gas spring force is the same for all current conditions, it can be concluded that the overall force due to pressure drop across the orifice or total damping force increases by increasing the current. It can also be realized that gas spring force contributes only small portion of the total shock strut force initially. However at the last 
stage of the impact, where the strut displacement is larger, the gas spring force becomes the large portion of the total shock strut force.

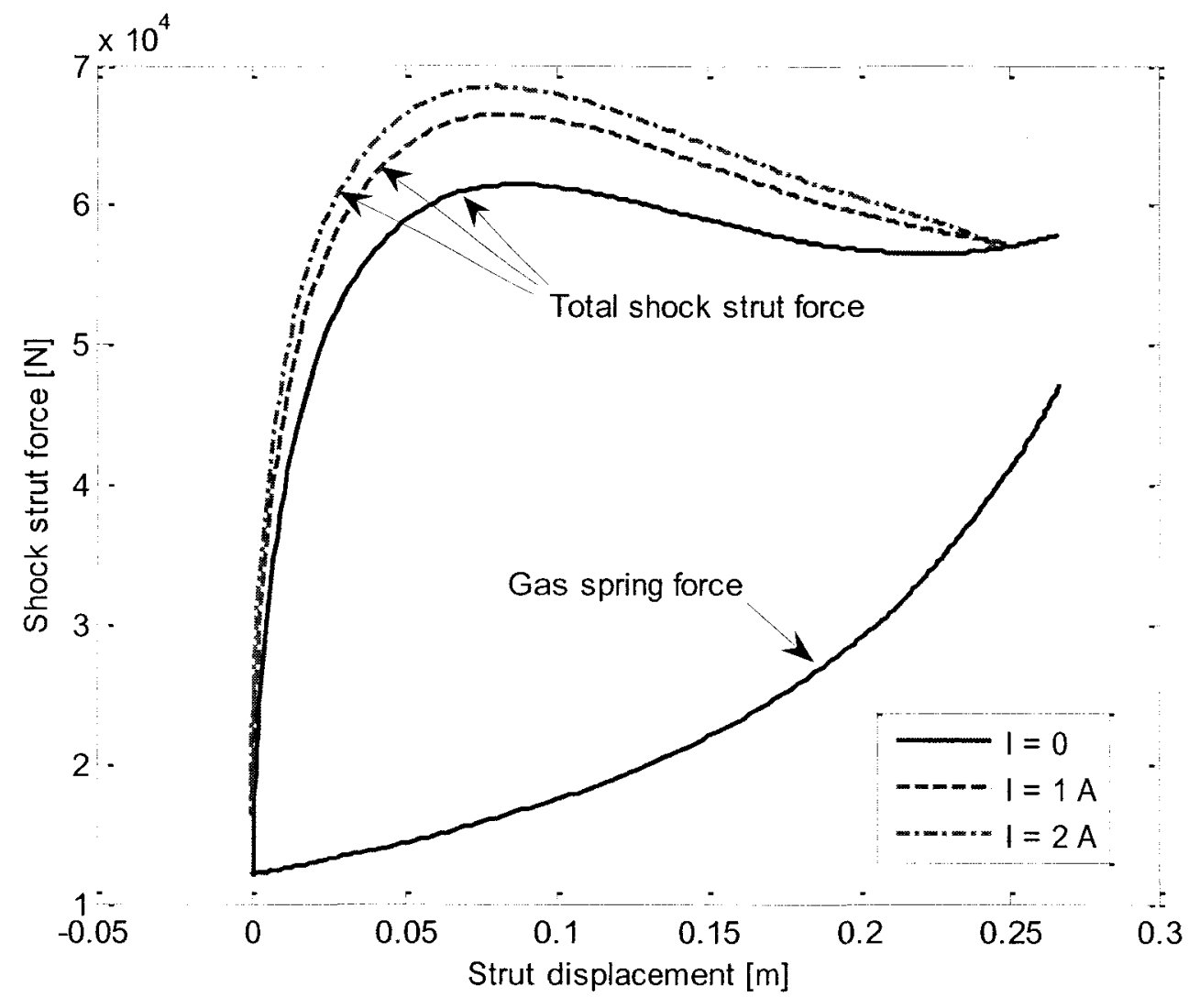

Fig 3.8 Shock strut force versus strut displacement, v=2.7 m/s .

It should be noted that the area between the gas spring force and the total force represents the dissipated energy during impact thus by increasing the current, more energy can be dissipated and the efficiency can be increased. 


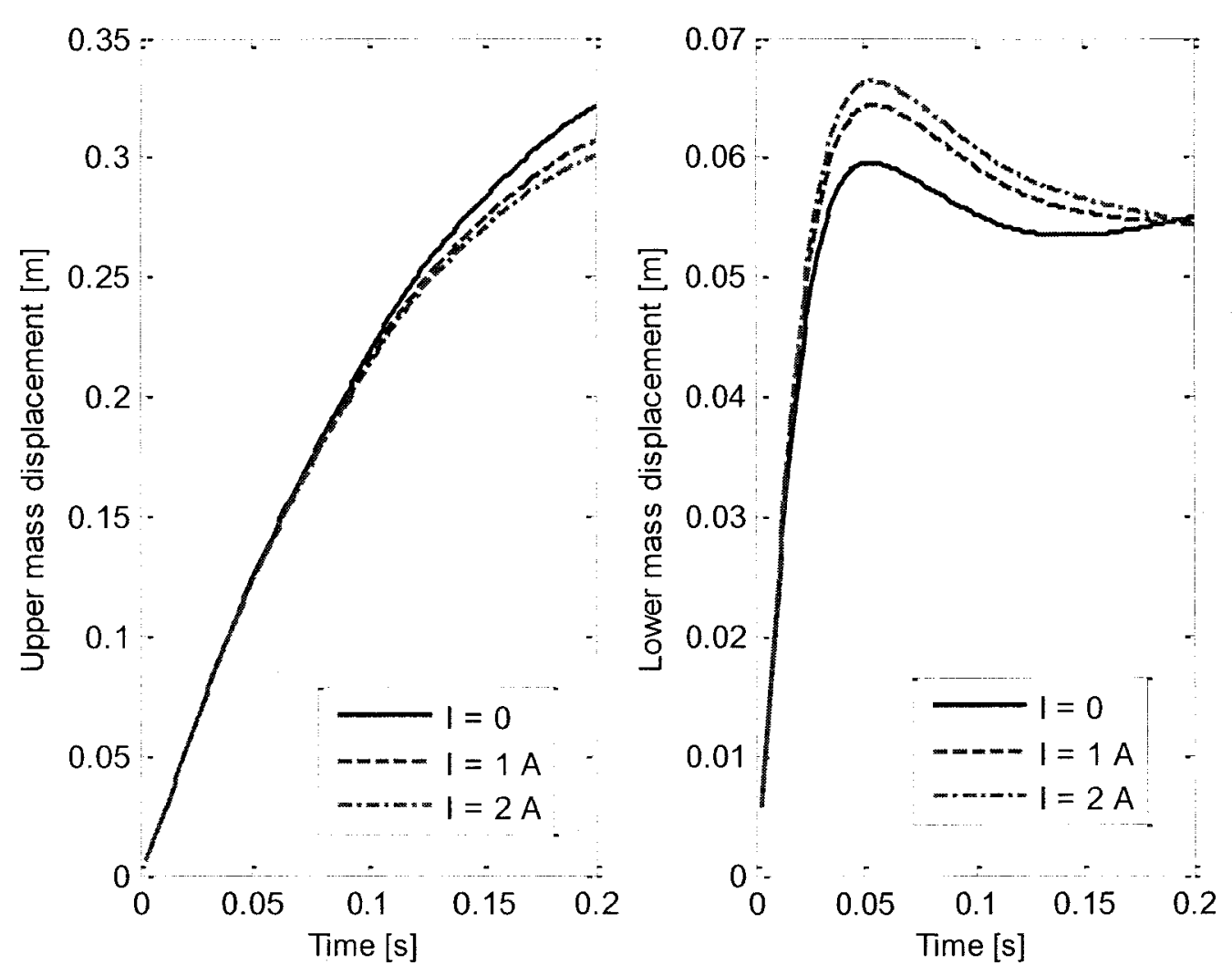

Fig 3.9 Time history of landing gear displacement, $v=2.7 \mathrm{~m} / \mathrm{s}$.

Fig 3.9 shows the displacement of the upper mass and lower mass versus time at the sink velocity of $v=2.7 \mathrm{~m} / \mathrm{s}$ for different current excitations. As it can be seen, displacement of the upper mass slightly reduces after $t=0.1 \mathrm{~s}$ by increasing the current. However, displacement of the lower mass increases after $t=0.02 \mathrm{~s}$, by increasing the current. It should be noted that lower mass displacements are within the acceptable range of tire deflection as tire force was previously calculated in Chapter 2 for only a range of deflection not exceeding $x_{L}=0.09 \mathrm{~m}$. Upper mass displacements are also within the acceptable range as shock strut stroke was shown to be $x_{s}=0.38 \mathrm{~m}$ in Chapter 2 .

Fig 3.10 presents the upper mass and lower mass velocities under different current excitations. As it can be realized upper mass velocity decreases slightly as the current 
increases. The lower mass velocity does not seem to be considerably changed at time before $t<0.1$. However, at time after about $t>0.1$, it decreases as the current increases.

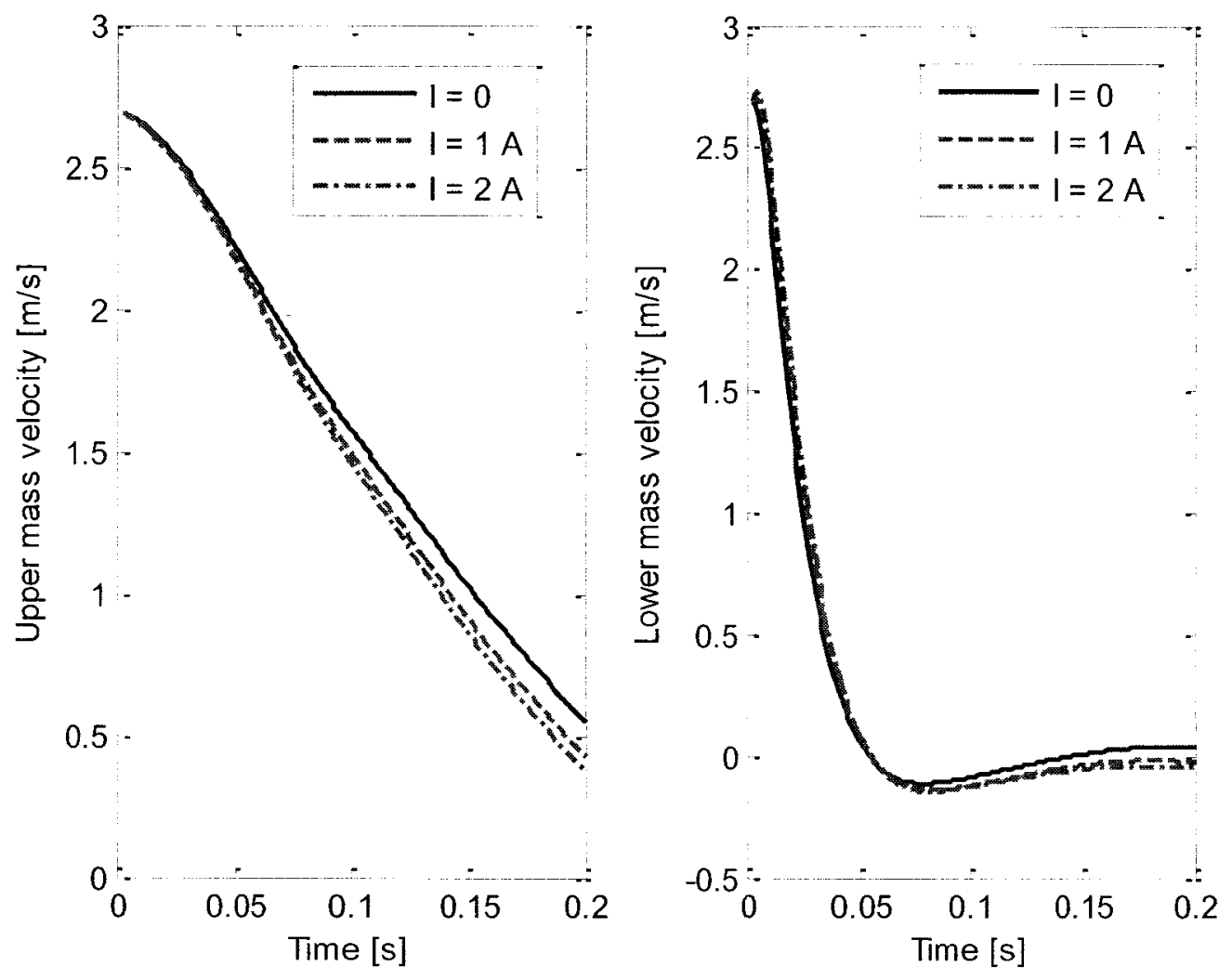

Fig 3.10 Time history of landing gear velocity, $v=2.7 \mathrm{~m} / \mathrm{s}$.

Upper mass and lower mass acceleration for sink velocity of $v=2.7 \mathrm{~m} / \mathrm{s}$ under different current excitations are also shown in Fig 3.11. As it can be seen from the figure, the magnitude of upper mass acceleration increases noticeably by increasing the current. Lower mass acceleration slightly decreases before the peak and then increases after the peak by increasing the current. However, in general, it has not been affected noticeably by changing the current excitation. 

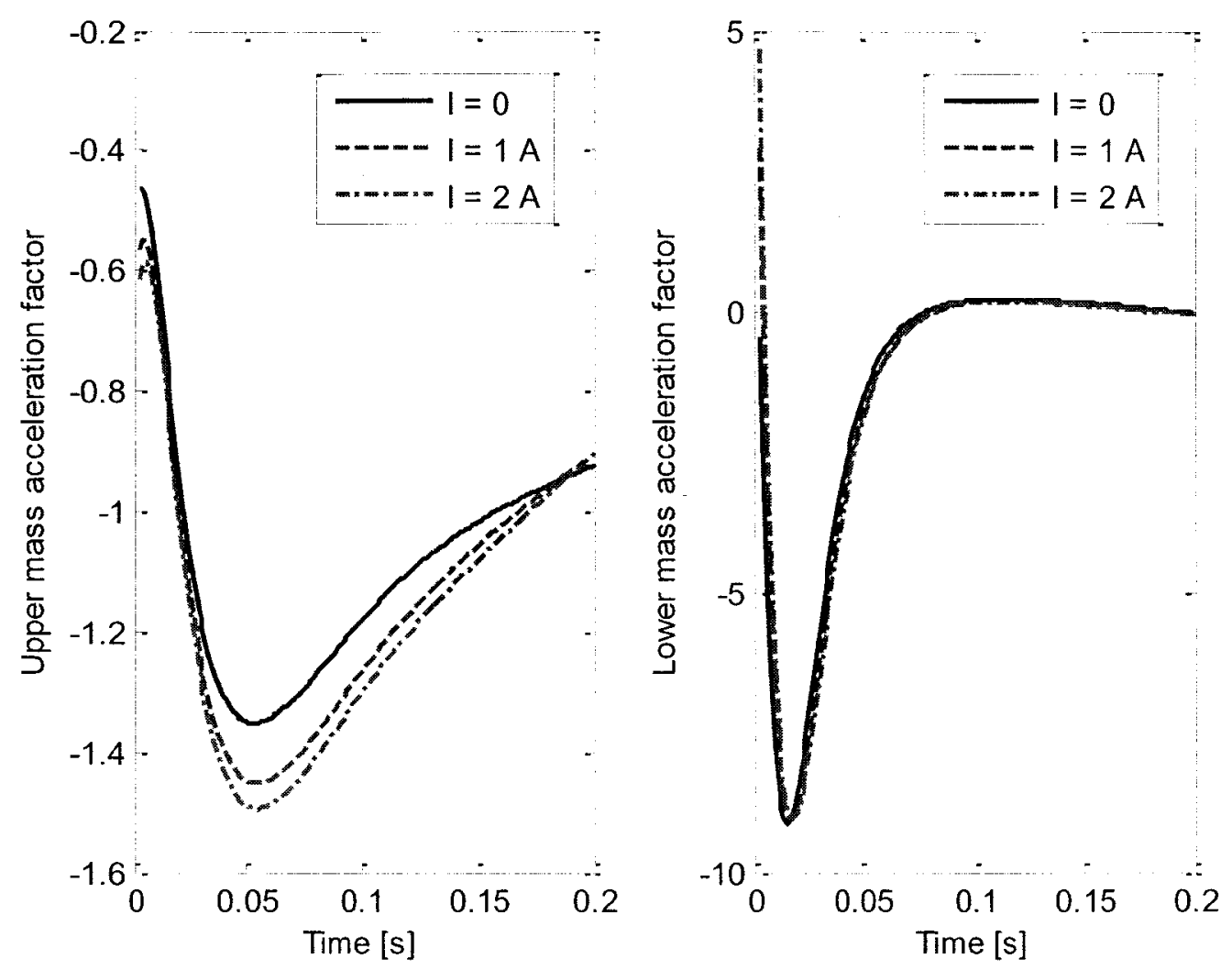

Fig 3.11 Time history of landing gear acceleration, $v=2.7 \mathrm{~m} / \mathrm{s}$.

Fig 3.12 to Fig 3.15 present the time history of the shock strut force, upper mass and lower mass displacement, velocity and acceleration factor, respectively for more severe impact condition with sink velocity of $v=3.2 \mathrm{~m} / \mathrm{s}$. Similar observation can be realized for this sink speed as well. 


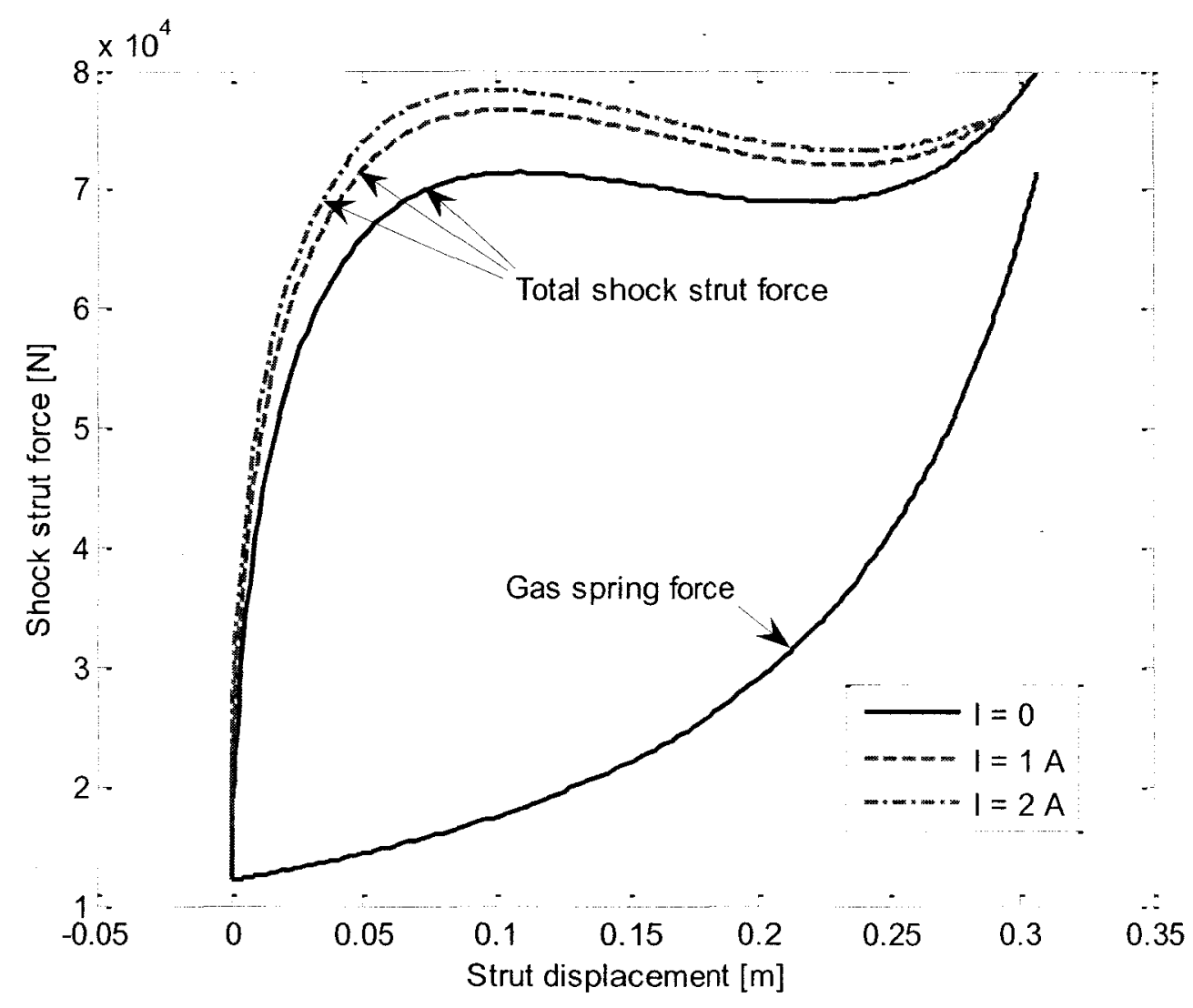

Fig 3.12 Shock strut force versus strut displacement, $v=3.2 \mathrm{~m} / \mathrm{s}$.

Comparing Fig 3.8 and Fig 3.12, one can state that the total shock strut force increases as the sink velocity increases. It should be noted that for the sink velocity of $v=3.2 \mathrm{~m} / \mathrm{s}$, the upper and lower mass displacement are still within acceptable ranges discussed before. 

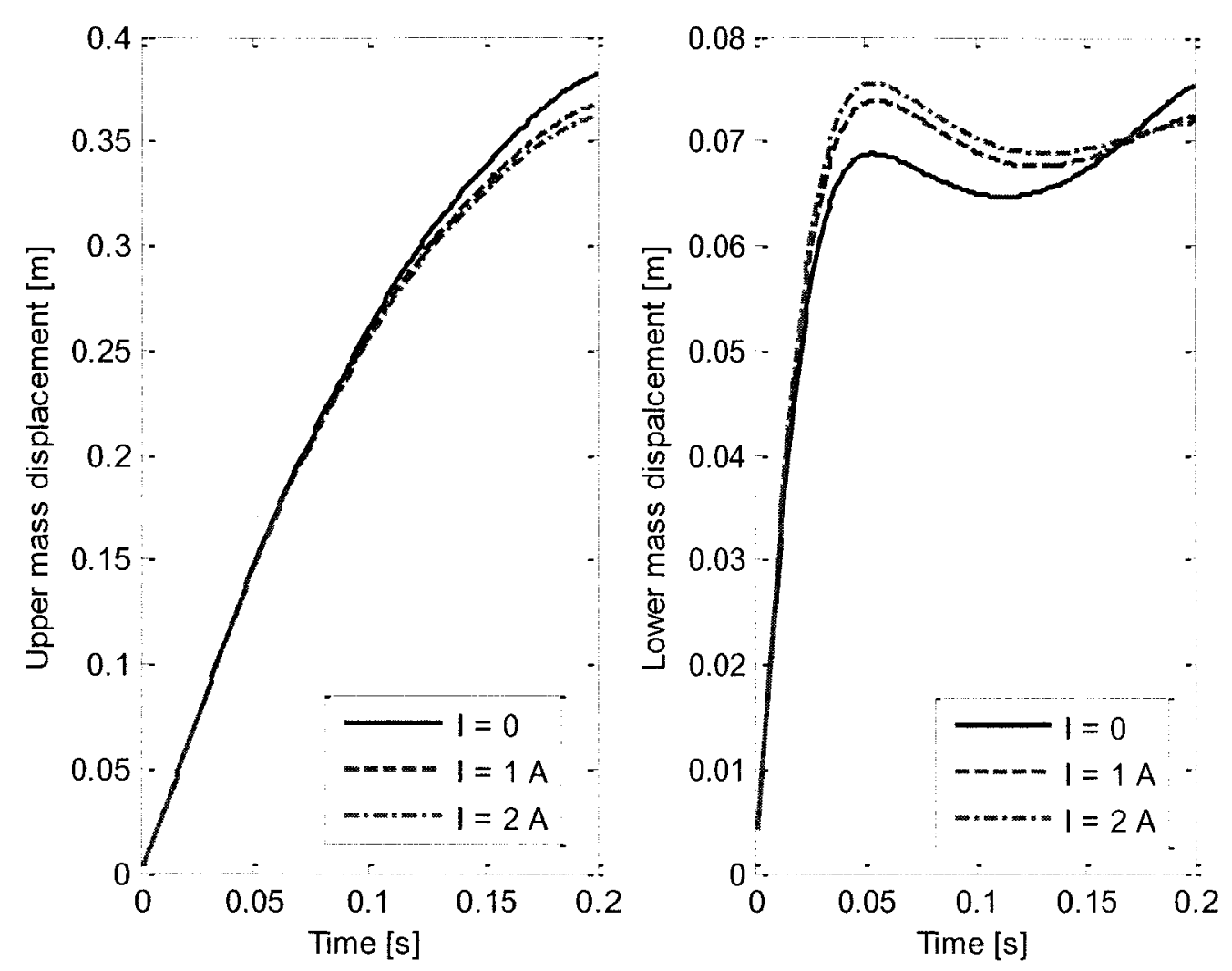

Fig 3.13 Time history of landing gear displacement, $v=3.2 \mathrm{~m} / \mathrm{s}$.

Fig 3.15 shows that the peak of the lower mass acceleration factor which occurs at about $t=0.02 \mathrm{~s}$, has been increased from around $\ddot{x}_{L}=9 \mathrm{~g}$ at sink velocity of $v=$ $2.7 \mathrm{~m} / \mathrm{s}$ to about $\ddot{x}_{L}=11 \mathrm{~g}$ at sink velocity of $v=3.2 \mathrm{~m} / \mathrm{s}$. 

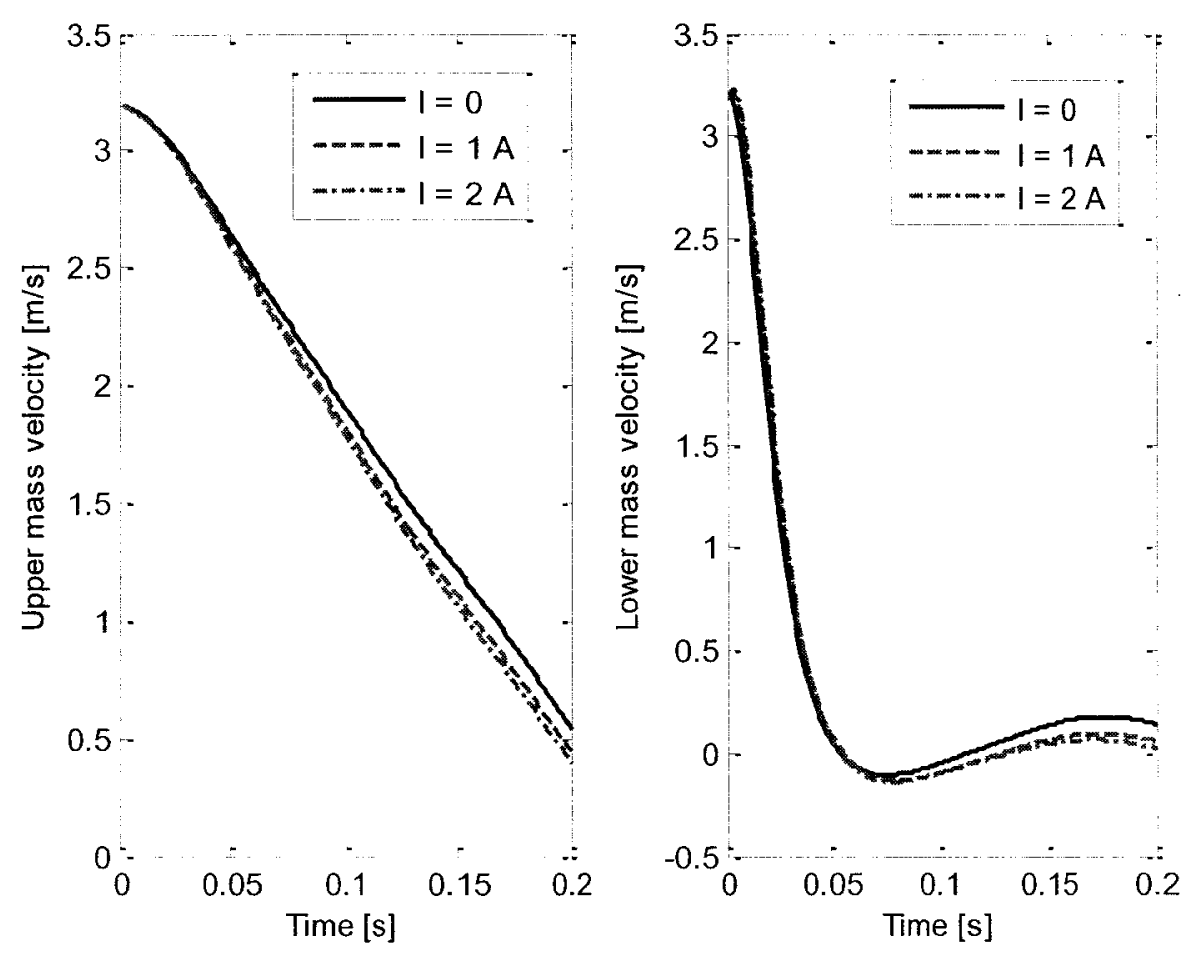

Fig 3.14 Time histories of landing gear velocity, $v=3.2 \mathrm{~m} / \mathrm{s}$.
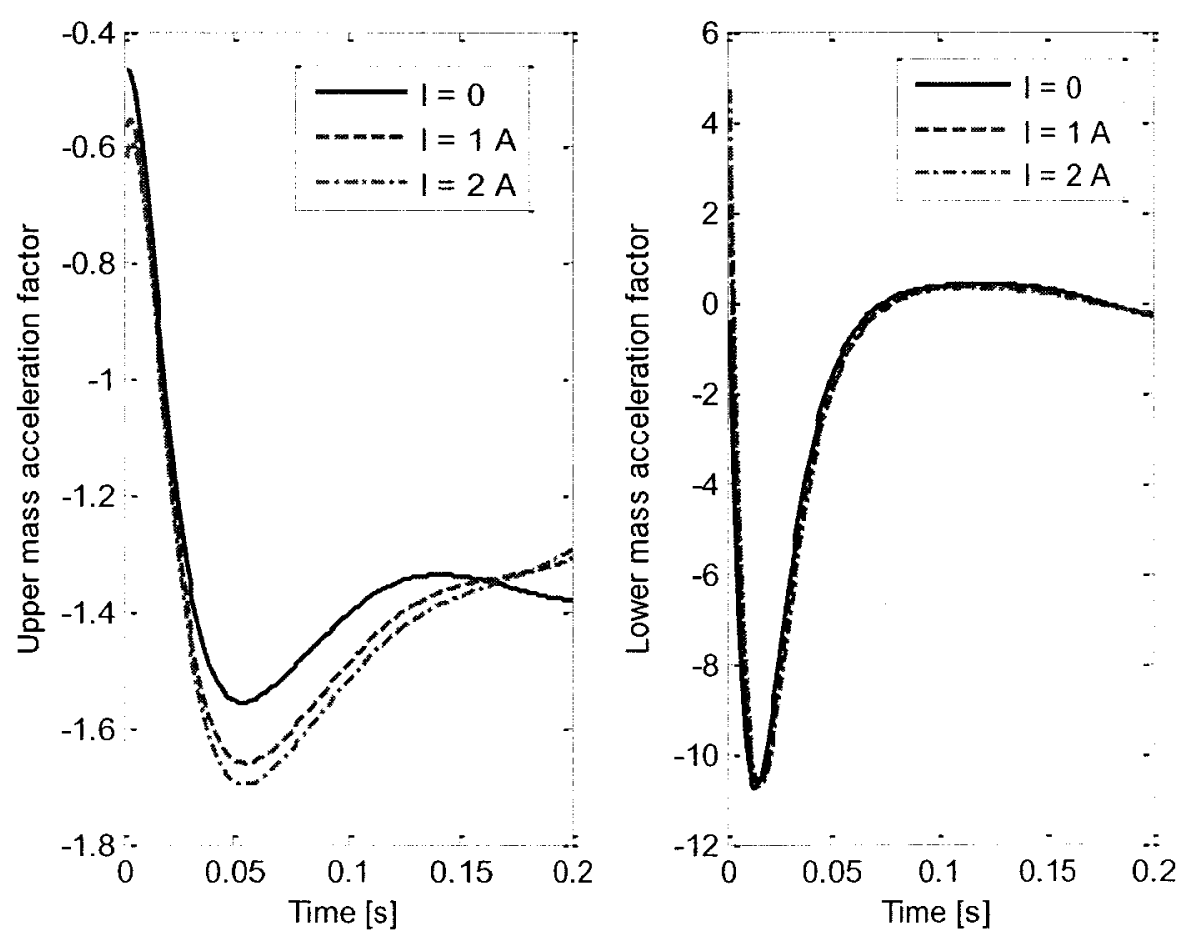

Fig 3.15 Time history of landing gear acceleration, $v=3.2 \mathrm{~m} / \mathrm{s}$. 


\subsection{Summery}

Two-DOF MR landing gear model was constructed using MR shock strut model generated in Chapter 2. Governing equations of motion were derived in order to perform dynamic analysis of the system.

The inverse model of the MR shock strut was formulated to attain MR damping force as a function of MR yield stress and strut velocity. The MR landing gear system was simulated for different current excitation and impact condition and the results were compared. 


\section{CHAPTER 4}

\section{CONTROLLER DESIGN}

\subsection{Introduction}

Depending on the different sink speeds, angles of attack and masses; aircraft landing gears could face a wide range of impact conditions which may possibly cause structural damage or failure. Thus, in hard landing scenarios, the landing gear must absorb sufficient energy in order to minimize dynamic stress on the aircraft airframe. However, compromising for this requirement can reduce the performance for less severe impact conditions and consequently decrease fatigue life of the aircraft structure. Furthermore, damping requirements of landing impact phase conflicts with those of taxing phase which result in performance compromise [3]. Fully active and semi-active control systems are the possible solutions to overcome these limitations. The fully active approach has been widely developed and tested for military applications [5], [30] and [31]. However, this approach has not been implemented in the commercial applications as they can cause complex systems and a significant increase in size, weight, and power requirement. The semi-active approach is a compromise between fully active and passive systems. It contains the fail-safe feature of the passive systems and adaptability of the active systems with low power consumption. The semi-active control systems have been extensively developed in automotive application [14], but few studies of the application in landing gear system have been reported [2]. Among semi-active control strategies, those based on smart fluids such as magneto-rheological (MR) and electro-rheological (ER) fluids have received recent interest as the rheological properties can be continuously 
controlled using magnetic or electric field. Compared with ER fluids, MR fluids are not sensitive to the impurities of the temperature variation and also require lower power.

As previously discussed in Chapter 2, MR damper was modeled and simulated to work in A6 Intruder landing gear system. Governing equations of the landing gear system and the inverse model of the MR damper were then obtained in Chapter 3. In this Chapter, a proportional-integral-derivative (PID) controller is formulated using governing equations of the landing gear system and the inverse model of the MR damper in order to attenuate acceleration of the system. Comparing PID and Skyhook control, one can conclude that PID control is capable of tracking the target force more precisely. Furthermore, PID control is less sensitive to variations in damper temperature and wear

[33]. One of the limitations of the Skyhook control is that it involves time delay which needs to be compensated using a force-tracking control [34]. PID control is consequently selected in this work.

Finally simulations are conducted for the landing gear system for different current excitation and the results are compared. A discussion about the most desirable output is presented.

\subsection{PID Controller Scheme}

In this section, the proposed block diagram of the landing gear system is given. The Laplace transform of the governing equations are then obtained using the block diagram and the transfer function equations of the system are consequently formulated. The proposed block diagram of the landing gear system is shown in Fig 4.1. 


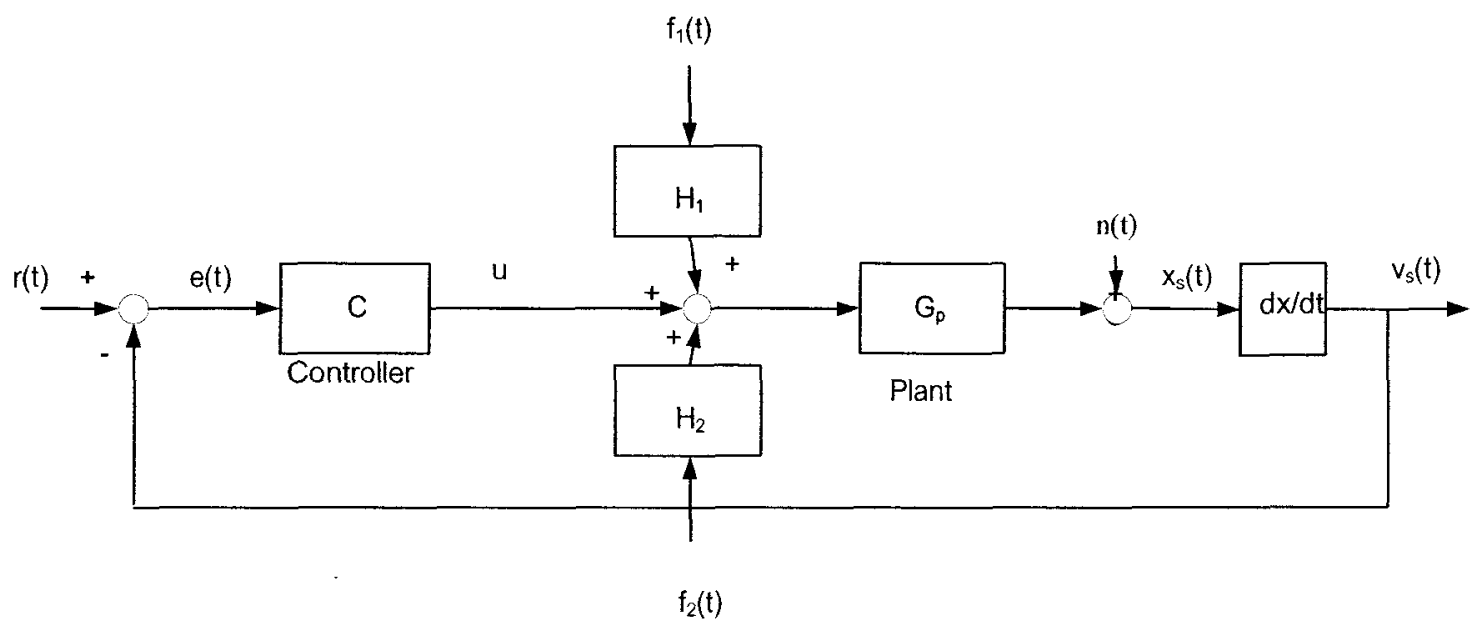

Fig 4.1 Proposed block diagram of the landing gear system.

As it can be seen from Fig 4.1, the target damping force, $F_{d}$, is considered as the control force and is defined by $u(t)$, which is the first input of the system and output of the controller. This force can be measured by utilization of a shock strut measurement device called strut's pressure sensor. The sensor can be installed on the shock strut in order to measure the pressure spike at the point of impact [35]. The combination of the measured pressure spike and the static pressure gives the total pressure at a certain area. The product of the total pressure and the area provides the shock strut force.

The external forces $f_{1}(t)$ and $f_{2}(t)$ are assumed as the second and third inputs of the system which are shown in Fig 4.1. The response of the proposed control system is partly excited by the initial conditions or initial state. This excitation signal is shown by $n(t)$ in Fig 4.1. Strut displacement, $x_{s}(t)$, is taken as the output of the system. However, strut acceleration and velocity are also verified to meet the controller design requirements which will be discussed later in this Chapter. As previously discussed in Chapter 2, the settling time is assumed to be less than $0.2 \mathrm{Sec}$, the lower mass displacement should not 
exceed $0.09 \mathrm{~m}$ (maximum allowable deflection of the tire selected for A6 Intruder) and the strut displacement should not exceed $0.38 \mathrm{~m}$ (fully extended stroke of the selected shock strut). In practice, the output of the system is measured by a sensor and fed back to the reference value. As shown in Fig 4.1, the strut velocity, $v_{s}(t)$, is obtained using the derivative gain and is fed back to the reference signal or desired velocity, $r(t)$. In order to achieve $r(t)$, the reference acceleration, $\frac{d r(t)}{d t}$, for a system with sink velocity of $v=3.2 \mathrm{~m} / \mathrm{s}$ is assumed to be a curve shown in Fig 4.2. This curve is equivalent to $90 \%$ of the strut acceleration of the passive landing gear with the sink velocity of $v=3.2 \mathrm{~m} /$ $s$. The reference velocity and displacement can then be shown as the first and second integral of the reference acceleration, respectively.
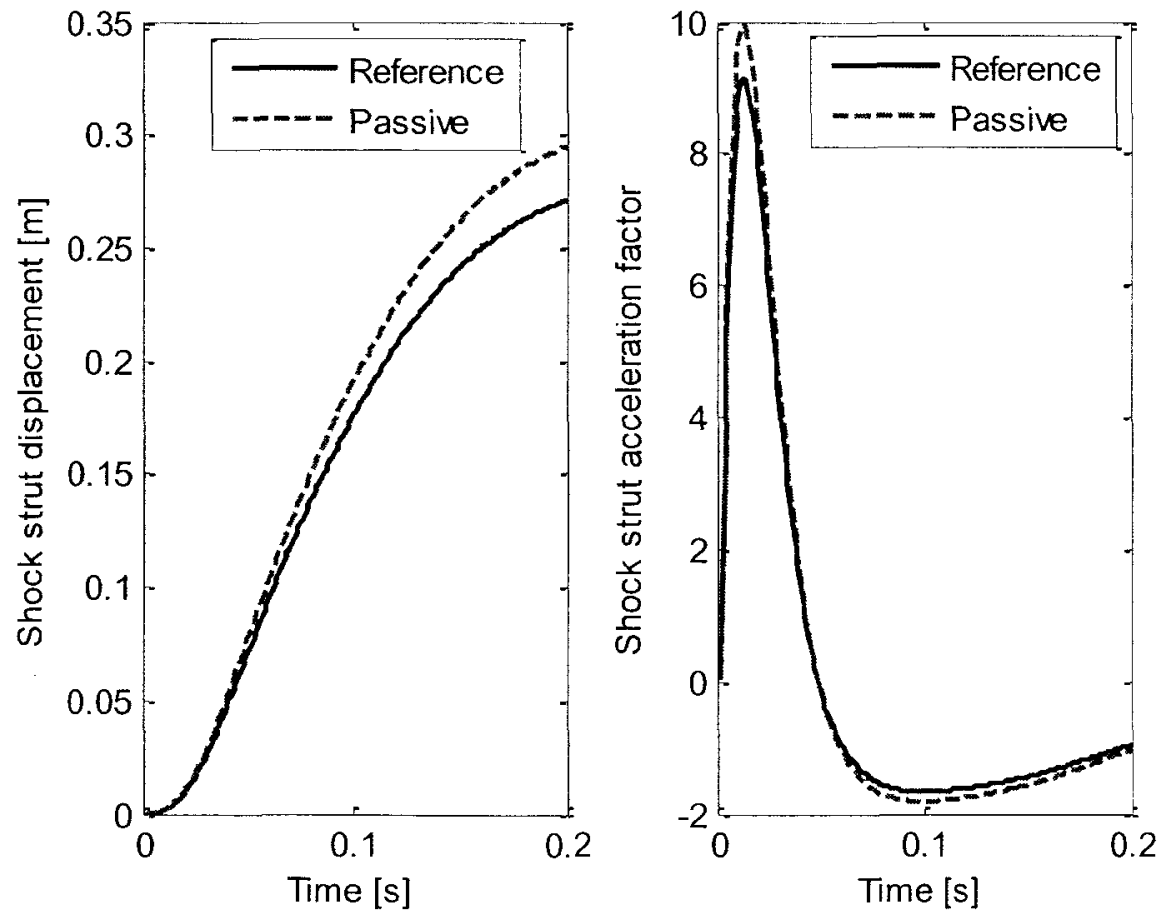

Fig 4.2 Time history of reference and passive displacement and acceleration, $v=3.2 \mathrm{~m} / \mathrm{s}$. 
As it can be seen from Fig 4.1, the tracking error of the system $e(t)$ can be expressed as:

$$
e(t)=r(t)-v_{s}(t)
$$

where $r(t)$ is the reference signal and $v_{s}(t)$ is the strut velocity.

$G_{p}$ is the plant transfer function. $H_{1}$ and $H_{2}$ are the open-loop transfer functions of the input $f_{1}(t)$ and $f_{2}(t)$ respectively. $C$ is the transfer function of the PID controller that is going to be designed. The $G_{p}, H_{1}, H_{2}$ and $n(t)$ are determined in the next sub-section in order to obtain $C$.

On the other hand, it is required to superpose a semi-active constraint on the desired damping force since the MR shock strut is a semi-active device. The semi-active device will only be able to generate high damping force if shock strut velocity, $v_{s}$, and upper mass velocity, $v_{u}$, are of similar sign. When $v_{s}$ and $v_{u}$ are of opposite sign, the damping force is suppressed. This constraint can be summarized in the following form [9]:

$$
u= \begin{cases}u & \text { if } v_{s} v_{u} \geq 0 \\ 0 & \text { if } v_{s} v_{u}<0\end{cases}
$$

As shown in Fig 4.3, the controller output, $u(t)$, is the combination of proportional $P$, integral $I$ and derivative $D$, terms which can be expressed as:

$$
u(t)=P+I+D
$$

where

$$
\begin{aligned}
& P=K_{p} e(t) \\
& I=K_{i} \int_{0}^{t} e(\tau) d \tau \\
& D=K_{d} \frac{d}{d t} e(t)
\end{aligned}
$$


and $K_{p}, K_{i}$ and $K_{d}$ are proportional, integral and derivative gain of the PID controller respectively. As discussed earlier, the tracking error $e(t)$ represents the difference between the desired input value or reference signal $r(t)$ and the actual output value $v_{s}(t)$. This error will be sent to the PID controller and the controller calculates the sum of recent errors (integral of the error) and the rate at which the error has been changing (derivative of the error). The output of the controller $u(t)$ is now equal to weighted sum of the error, integral of the error and the derivative of the error as shown in Fig 4.3. Control action can be provided for the landing gear system by tuning the three constants $K_{p}, K_{i}$ and $K_{d}$ in the PID controller.

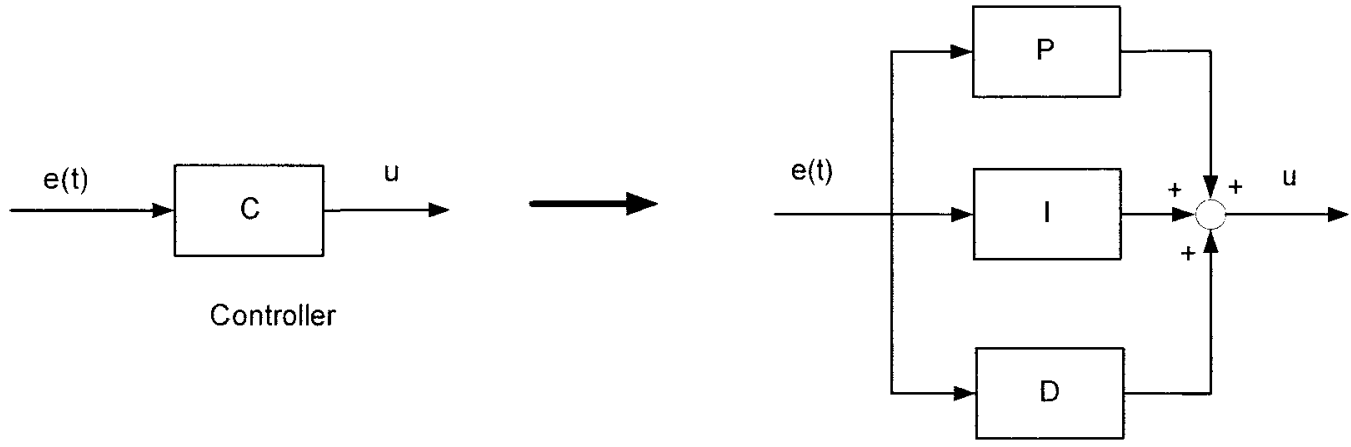

Fig 4.3 Block diagram of the PID controller.

These constants will be computed in the following section. First, transfer functions are derived using Laplace Transform of the governing equations. A MATLAB program is then written using the transfer function equations in order to design the controller.

\subsubsection{Transfer function equations}

As previously discussed in Chapter 3, the shock strut is subjected to a preload force due to the initial air pressure of the accumulator. Therefore, the shock strut does not 
begin to deflect at the time of touchdown until this force is overcome at instant $t=t_{d}$. The system is assumed to have only one degree of freedom during this time. Therefore, one can conclude that the shock strut displacement is $\mathrm{x}_{\mathrm{s}}=0$ for time $t \leq t_{d}$ and it is $x_{s} \neq 0$ for $t>t_{d}$. According to this fact, the controller needs to be designed for only $t>t_{d}$ when the sock strut begins to deflect.

For a system with sink velocity of $v=3.2 \mathrm{~m} / \mathrm{s}, t_{d}$ was previously calculated as $t_{d}=0.0013 \mathrm{~s}$ in sub-section (3.4.1). Thus as previously discussed in Chapter 3, initial conditions are assumed to be as:

$$
\begin{aligned}
& x_{u}\left(t_{d}\right)=x_{L}\left(t_{d}\right)=x_{0} \\
& \dot{x}_{u}\left(t_{d}\right)=\dot{x}_{L}\left(t_{d}\right)=v_{0}
\end{aligned}
$$

where $x_{0}$ and $v_{0}$ are constant values and found to be $x_{0}=0.0042 \mathrm{~m}$ and $v_{0}=3.19 \mathrm{~m} /$ $s$.

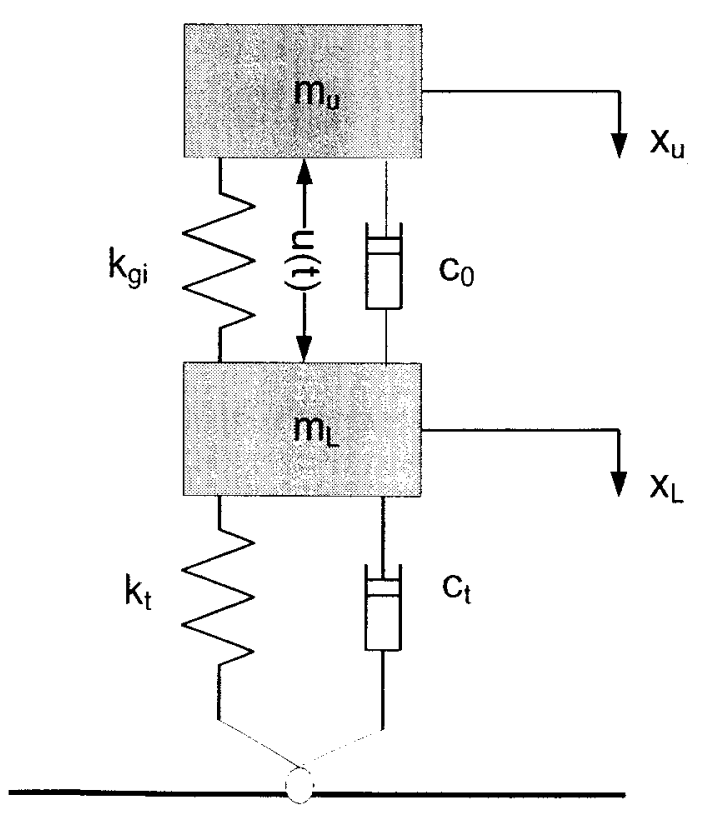

Fig 4.4 Two-DOF model of the system. 
The two-DOF landing model is shown in Fig 4.4. As can be seen, the MR damping force, $F_{m r}$, is substituted with the input $u(t)$. Therefore $u(t)$ is the force from the controller that is going to be designed. Substituting $u(t)=F_{m r}$ in the equations of motions one can get :

$\frac{W_{u}}{g} \ddot{x}_{u}+c_{0}\left(\dot{x}_{u}-\dot{x}_{L}\right)+k_{g_{i}}\left(x_{u}-x_{L}\right)+u(t)=W_{u}-\left(k_{L_{1}} t+F_{L_{1}}\right)-F_{g_{i}}=f_{1}(t)$
$\frac{W_{L}}{g} \ddot{x}_{L}+c_{0}\left(\dot{x}_{L}-\dot{x}_{u}\right)+k_{g i}\left(x_{L}-x_{u}\right)+c_{t} \dot{x}_{L}+k_{t} x_{L}-u(t)=W_{L}+F_{g_{i}}=f_{2}(t)$

By taking Laplace transform of the above equations, one can attain transfer function equations. Laplace transform of Eqs. (4.9) and (4.10) can be expressed as:

$m_{u}\left(s^{2} X_{u}-s x_{0}-v_{0}\right)+k_{g i}\left(X_{u}-X_{L}\right)+c_{0} s\left(X_{u}-X_{L}\right)=-U+F_{1}$

$m_{L}\left(s^{2} X_{L}-s x_{0}-v_{0}\right)-k_{g i}\left(X_{u}-X_{L}\right)-c_{0} s\left(X_{u}-X_{L}\right)+k_{t} X_{L}+c_{t}\left(s X_{L}-x_{0}\right)=U+F_{2}$

where $X_{u}, X_{L}, U, F_{1}$ and $F_{2}$ are the Laplace transforms of the $x_{u}, x_{L}, u, f_{1}$ and $f_{2}$ respectively and $s$ is the complex angular frequency. $m_{u}$ and $m_{L}$ are the mass of the upper mass and lower mass respectively. Eqs. (4.11) and (4.12) can be written in the matrix form as:

$\underbrace{\left[\begin{array}{cc}m_{u} s^{2}+c_{0} s+k_{g i} & -c_{0} s-k_{g i} \\ -c_{0} s-k_{g i} & m_{L} s^{2}+s\left(c_{0}+c_{t}\right)+k_{g i}+k_{t}\end{array}\right]}_{A}\left[\begin{array}{l}X_{u} \\ X_{L}\end{array}\right]=\left[\begin{array}{c}-U+F_{1}+m_{u}\left(s x_{0}+v_{0}\right) \\ U+F_{2}+m_{L}\left(s x_{0}+v_{0}\right)+c_{t} x_{0}\end{array}\right]$

where $A$ is a newly defined matrix. Using Eq. (4.13), one can solve for $X_{u}$ and $X_{L}$. The inverse matrix of $A$ needs to be determined in order to solve for $X_{u}$ and $X_{L}$. Multiplying each side of Eq. (4.13) by the inverse matrix of $A, A^{-1}$, one can get:

$\left[\begin{array}{l}X_{u} \\ X_{L}\end{array}\right]=\underbrace{\frac{1}{\Delta}\left[\begin{array}{cc}m_{L} s^{2}+s\left(c_{0}+c_{t}\right)+k_{g i}+k_{t} & c_{0} s+k_{g i} \\ c_{0} s+k_{g i} & m_{u} s^{2}+c_{0} s+k_{g i}\end{array}\right]}_{A^{-1}}\left[\begin{array}{c}-U+F_{1}+m_{u}\left(s x_{0}+v_{0}\right) \\ U+F_{2}+m_{L}\left(s x_{0}+v_{0}\right)+c_{t} x_{0}\end{array}\right]$

where $\Delta$ is the determinant of $A$ and can be expressed as: 


$$
\Delta=\left(m_{u} s^{2}+c_{0} s+k_{g i}\right)\left(m_{L} s^{2}+s\left(c_{0}+c_{t}\right)+k_{g i}+k_{t}\right)-\left(c_{0} s+k_{g i}\right)\left(c_{0} s+k_{g i}\right)
$$

$\Delta$ is assumed to be $\Delta \neq 0$ in order for Eq. (4.14) to have unique solution.

Now the transfer function of the plant, $G_{p}(s)$, can be written as:

$$
G_{p}(s)=\frac{X_{s}(s)}{U(s)}=\frac{X_{\mathcal{u}}(s)-X_{L}(s)}{U(s)}
$$

Since the system is linear, to compute the transfer function of the plant, we may assume $F_{1}=F_{2}=0$ and also all the initial conditions equal to zero in Eq. (4.14) or, equivalently, disregard $F_{1}, F_{2}$ and all the initial conditions.

Thus, Eq. (4.14) can be written as:

$$
\left[\begin{array}{l}
X_{u} \\
X_{L}
\end{array}\right]=\frac{1}{\Delta}\left[\begin{array}{cc}
m_{L} s^{2}+s\left(c_{0}+c_{t}\right)+k_{g i}+k_{t} & c_{0} s+k_{g i} \\
c_{0} s+k_{g i} & m_{u} s^{2}+c_{0} s+k_{g i}
\end{array}\right]\left[\begin{array}{c}
-U \\
U
\end{array}\right]
$$

Considering Eq. (4.17), $\mathrm{X}_{\mathrm{u}}$ and $X_{L}$ can be expressed as:

$$
\begin{aligned}
& X_{u}=-\left(m_{L} s^{2}+s\left(c_{0}+c_{t}\right)+k_{g i}+k_{t}\right) U+\left(c_{0} s+k_{g i}\right) U \\
& X_{L}=-\left(c_{0} s+k_{g i}\right) U+\left(m_{u} s^{2}+c_{0} s+k_{g i}\right) U
\end{aligned}
$$

Substituting $X_{\mathbf{u}}$ and $X_{L}$ from Eqs. (4.18) and (4.19) into Eq. (4.16) yields:

$$
G_{p}(s)=\frac{-\left(m_{u}+m_{L}\right) s^{2}-c_{t} s-k_{t}}{\Delta}
$$

The open-loop transfer function $G_{1}(s)$ of the input $f_{1}(t)$, can be expressed as:

$$
G_{1}(s)=\frac{X_{u}(s)-X_{L}(s)}{F_{1}(s)}
$$

Considering input $F_{1}$, one can set $U=F_{2}=0$ and all the initial conditions equal to zero in Eq. (4.14) and get $X_{u}$ and $X_{L}$ as a function of $F_{1} . X_{\mathbf{u}}$ and $X_{L}$ can then be substituted in to Eq. $(4.21)$ and $G_{1}(s)$ can be obtained as:

$$
G_{1}(s)=\frac{m_{L} s^{2}+c_{t} s+k_{t}}{\Delta}
$$


In a similar way, the open-loop transfer function $G_{2}(s)$ of the input $f_{2}(t)$, can be expressed as:

$$
G_{2}(s)=\frac{X_{u}(s)-X_{L}(s)}{F_{2}(s)}
$$

Considering input $F_{2}$, one can set $U=F_{1}=0$ and all the initial conditions equal to zero in Eq. (4.14) and derive $X_{u}$ and $X_{L}$ as a function of $F_{2} . X_{u}$ and $X_{L}$ can subsequently be substituted into Eq. (4.23) and finally $G_{2}(s)$ can be expressed as:

$$
G_{2}(s)=\frac{-m_{\mathcal{u}} s^{2}}{\Delta}
$$

The transfer functions $H_{1}(s)$ and $H_{2}(s)$ in Fig (4.1) can be described as:

$$
\begin{aligned}
& H_{1}(s)=\frac{G_{1}(s)}{G_{p}(s)} \\
& H_{2}(s)=\frac{G_{2}(s)}{G_{p}(s)}
\end{aligned}
$$

In order to obtain zero-input response of the system, one can set $U=F_{1}=F_{2}=0$ in Eq. (4.14) and get $X_{u}-X_{L}$ as:

$$
X_{u}(s)-X_{L}(s)=\frac{\left[m_{u}\left(s x_{0}+v_{0}\right)\right]\left(m_{L} s^{2}+c_{t} s+k_{t}\right)}{\Delta}-\frac{\left[m_{L}\left(s x_{0}+v_{0}\right)+c_{t} x_{0}\right] m_{u} s^{2}}{\Delta}
$$

Eq. (4.27) can be simplified as:

$$
X_{u}(s)-X_{L}(s)=\frac{\left(m_{u} v_{0}\right)\left(c_{t} s+k_{t}\right)+m_{u} x_{0} k_{t} s}{\Delta}
$$

Taking the inverse Laplace of Eq. (4.28), one can get zero-input response, $n(t)$, as:

$$
x_{u}(t)-x_{L}(t)=n(t)=a_{1} e^{b_{1} t}+a_{2} e^{b_{2} t}+a_{3} e^{b_{3} t}+a_{4} e^{b_{4} t}+a_{5} e^{b_{5} t}
$$

where $a_{i} e^{b_{i} t}$ are exponential functions and $a_{i}$ and $b_{i}$ are constant values. The method used to calculate these values is given in Appendix C. 
Considering the above-mentioned transfer functions and the zero-input response, the output of the system, $x_{u}-x_{L}$ or $x_{s}$, due to the inputs $u, f_{1}, f_{2}$ and initial conditions can be given by:

$X_{s}(s)=X_{u}(s)-X_{L}(s)=\underbrace{G_{p}(s) U(s)+G_{1}(s) F_{1}(s)+G_{2}(s) F_{2}(s)}_{\text {Zero-state response }}+\underbrace{\frac{\left(m_{u} v_{0}\right)\left(c_{t} s+k_{t}\right)}{\Delta}}_{\text {Zero-input response }}$

Eq. (4.30) shows that the output of the system is partly excited by the inputs $u, f_{1}, f_{2}$ and partly excited by the initial condition $v_{0}$ which is the sink speed of the landing gear.

Taking Laplace transform of Eq. (4.3), one can obtain the transfer function equation of the controller, $C(s)$, as:

$$
C(s)=K_{p}+\frac{K_{i}}{s}+K_{d} s=\frac{K_{d} s^{2}+K_{p} s+K_{i}}{s}
$$

Since the use of the PID algorithm for control does not guarantee optimal control of the system, we need to verify if the system is implementable. In order for a control system to be implementable, every closed-loop transfer function of the system should be proper and the system needs to be totally stable. Improper transfer functions are difficult to build in practice and amplify high-frequency noise. It can be noted that if the system is not stable, it will burn out or disintegrate.

A transfer function is called proper if the degree of the nominator is less than or equal to the degree of the denominator. A system is said to be totally stable if the closedloop transfer function of every possible input-output of the system is stable.

In order to verify the well-posedness (every closed-loop transfer function to be proper) and stability of the landing gear control system, one can get the closed loop transfer functions from $r$ to $x_{s}, G_{o}$, from $f_{1}$ to $x_{s}, G_{x_{s} f_{1}}$, from $f_{2}$ to $x_{s}, G_{x_{s} f_{2}}$, and from $n$ to $x_{s}$, $G_{x_{s} n}$, as: 


$$
\begin{aligned}
& G_{o}(s)=\frac{X_{s}}{R}=\frac{C(s) G_{p}(s)}{1+C(s) G_{p}(s)} \\
& G_{x_{s} f_{1}}(s)=\frac{X_{s}}{F_{1}}=\frac{H_{1}(s) G_{p}(s)}{1+C(s) G_{p}(s)} \\
& G_{x_{s} f_{2}}(s)=\frac{X_{s}}{F_{2}}=\frac{H_{2}(s) G_{p}(s)}{1+C(s) G_{p}(s)} \\
& G_{x_{s} n}(s)=\frac{X_{s}}{N}=\frac{G_{p}(s)}{1+C(s) G_{p}(s)}
\end{aligned}
$$

Substituting $C(s), G_{p}(s), H_{1}(s)$ and $H_{2}(s)$ into the above-mentioned equations, one can conclude that the resulting system is well-posed. In order for the system to be totally stable, every pole of the above-mentioned closed-loop transfer functions should have a negative real part or, equivalently, lay inside the open half s-plane. Routh test method can be used to determine the range of control parameters $\left(K_{p}, K_{p}\right.$ and $\left.K_{p}\right)$ in which the system is stable [36]. Using Routh test method, one can determine the stability without solving for the roots of the denominator.

Using the block diagram of the control system shown in Fig (4.1) and the obtained transfer function equations, a program is written in MATLAB to attain the controller gains and subsequently formulate the controller.

The controller gains are calculated as:

$K_{p}=915000, K_{i}=430500, K_{d}=107150$

Calculation shows that these parameters are within the stability range.

\subsection{Controlled Performance}

In this section, proposed block diagram of the landing gear system is simulated using MATLAB SIMULINK and the PID controller is formulated using MATLAB programming and consequently the optimized proportional, derivative and integral gains 
of the PID controller are obtained. Acceleration, velocity, displacement, damping force and the damping energy of the shock strut are then presented for the control system. Finally the desired current input is presented. It should be noted that the input coil current is limited to $2.0 \mathrm{~A}$.

Figs 4.5 - 4.11 compare the results of closed -loop system using PID controller with those of open-loop system in which there is no current applied and the landing gear operates as a passive system. Simulation is run within the time range of $0 \leq t \leq 0.2$ and sink velocity is assumed to be $v=3.2 \mathrm{~m} / \mathrm{s}$ in these figures.

Fig 4.5 shows the shock strut force versus time. It can be clearly seen from Fig 4.5 that initially the damping force in the strut is very high compared to the spring force. However, this later reduces to very small value (essentially zero). As it can be seen, the gas spring force is reduced by employing the PID controller. However the total shock strut force is increased. Since the damping force is the difference between the total force and gas spring force, one can conclude that the damping force is increased which is shown in Fig 4.5. Therefore more energy can be extracted from the damper while using the control system. Since the total shock strut force has been increased, it is required to ensure that the total force in control system does not exceed the maximum axial load that shock strut can carry without buckling ${ }^{3}$.

The maximum axial load or critical load, $F_{\text {max }}$, of the shock strut can be calculated using Euler formula as:

$$
F_{\max }=\frac{\pi^{2} E I}{k^{2} L_{r}^{2}}
$$

\footnotetext{
${ }^{3}$ buckling is a mode of failur and described as a sudden failure of a structural member subjected to high compressive stresses.
} 
where $E$ is the Young's modulus and determined as $E=211 \mathrm{Gpa}$ for iron rod, $I$ is the area moment of inertia and calculated as $I=0.00042345 \mathrm{~m}^{4}, L_{r}$ is the rod length at full compression which is given as $L_{r}=0.405 \mathrm{~m}$ and $\mathrm{k}$ is rod effective length factor which is given as $k=0.5$ for a rod with both ends fixed.

Substituting the above mentioned parameters into Eq. (4.36), one can calculate $F_{\max }$ as $F_{\max }=213,900,000 \mathrm{~N}$. As it can be seen from Fig 4.5, the maximum shock strut force in control system is shown as $F_{a}=80000 \mathrm{~N}$ which is far less than calculated $F_{\max }$. Therefore, MR shock strut can be implemented in the modeled landing gear system without inducing any buckling.

As it can be seen from Fig 4.6, the total shock strut force and consequently the damping force is increased. For energy estimation, the area enclosed between the total shock strut force and the gas spring force can be expressed as:

$$
E=\int_{0}^{S} F_{p} d x_{s}
$$

where $\mathrm{E}$ is the energy dissipated, $S$ is the total stroke of the system, $x_{s}$ is the strut displacement and $F_{p}$ is the overall damping force of the system which is the difference between the total shock strut and the gas spring force. 


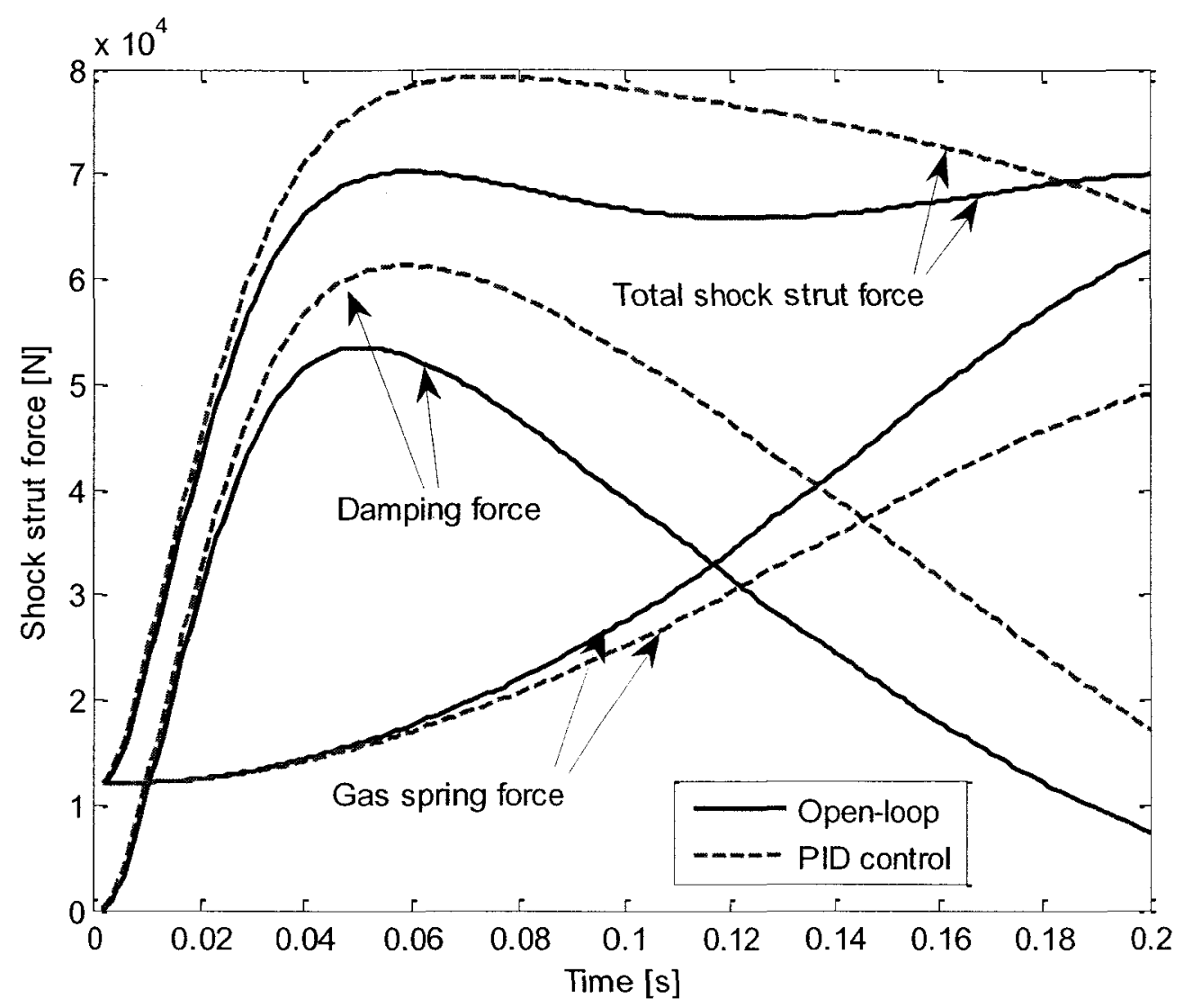

Fig 4.5 Time history of shock strut force in open-loop and control system, $v=3.2 \mathrm{~m} / \mathrm{s}$.

The energy dissipated by the shock strut in open-loop, $E_{1}$, and control closed-loop system, $E_{2}$, and their ratio, $\frac{E_{1}}{E_{2}}$, are found as:

$$
\frac{E_{1}}{E_{2}}=\frac{11500 \mathrm{~J}}{13300 \mathrm{~J}}=86 \%
$$

Eq. (4.38) shows that the energy dissipated through shock strut in the open-loop system is $86 \%$ of that dissipated in the MR damper in control closed-loop. Therefore, it can be noted that MR fluids improve the efficiency of the shock strut by $16.3 \%$. The dissipated energy versus time is shown in Fig 4.7. As it can be seen for time less than $0.06 \mathrm{~s}$, the same amount of energy is dissipated through the shock strut in both systems however as the time increases, the difference between the two dissipated energies increases. 


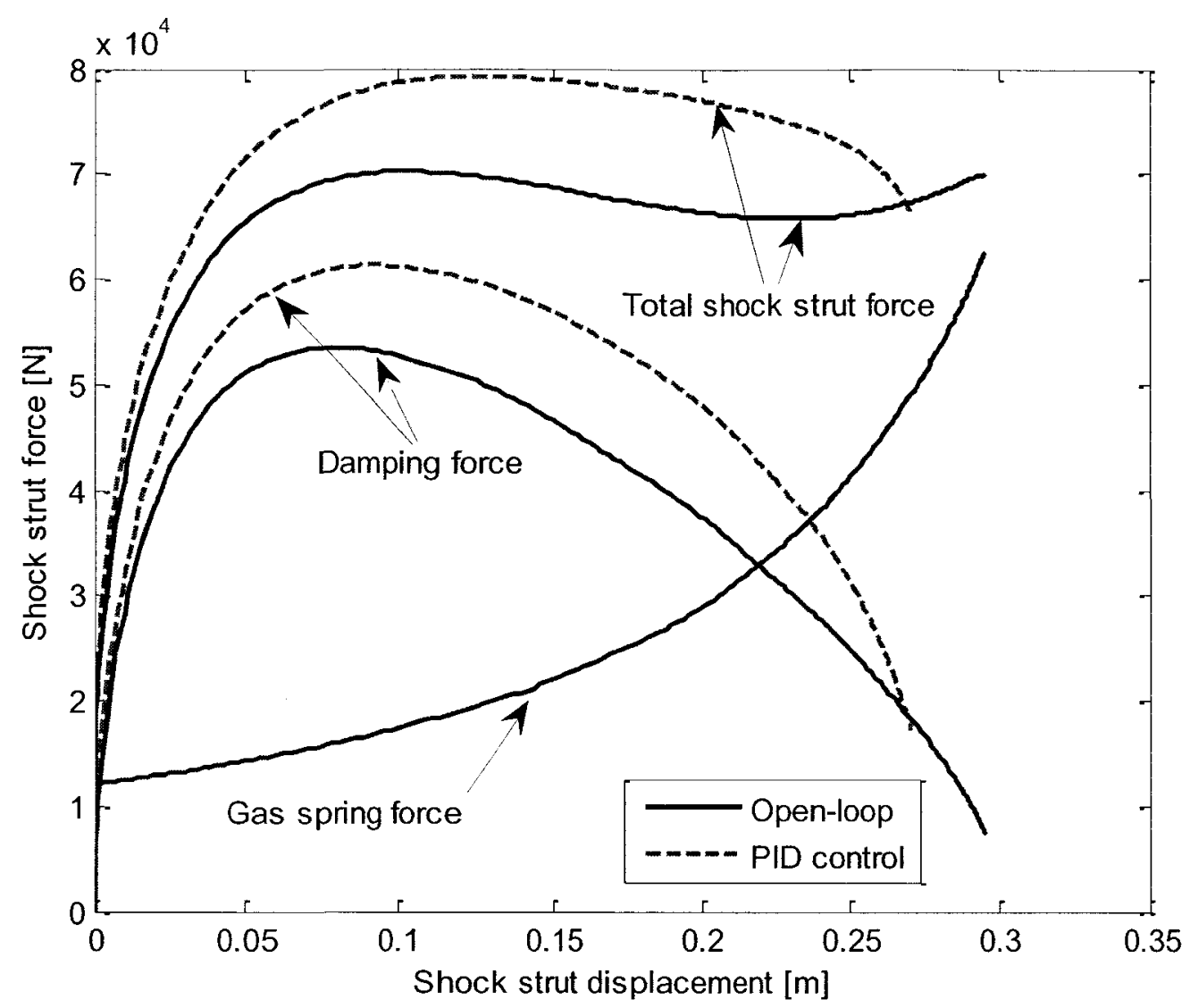

Fig 4.6 Shock strut force vs. shock strut displacement in open-loop and control system, $\mathrm{v}=3.2 \mathrm{~m} / \mathrm{s}$.

Fig 4.8 shows the lower and upper mass displacement in both open and closedloop systems. As it can be seen, the lower mass displacement or tire deflection is increased by utilizing the PID controller. 


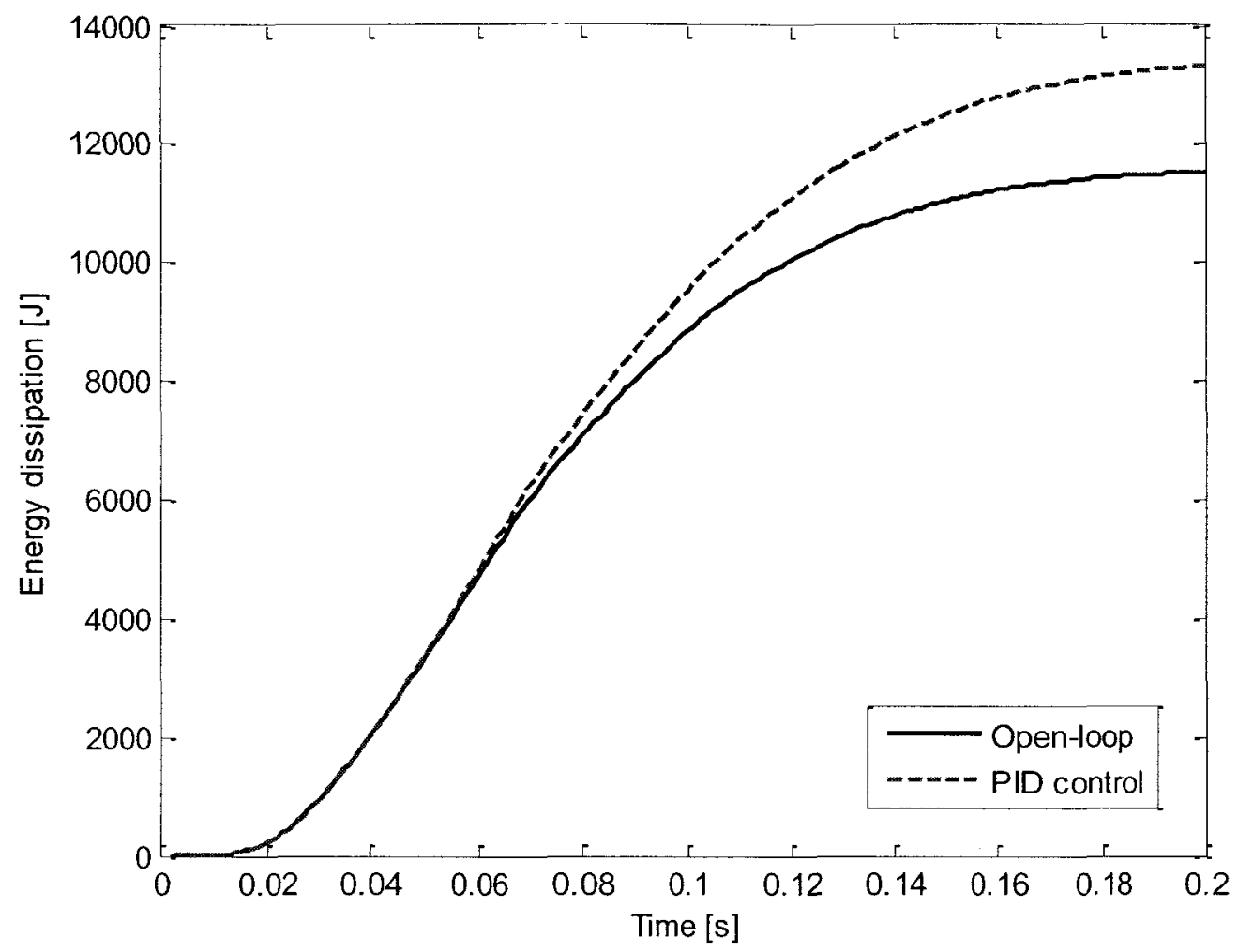

Fig 4.7 Time history of energy dissipation in open-loop and control system, $v=3.2 \mathrm{~m} / \mathrm{s}$.

As discussed before, maximum tire deflection for the tire used in this work is $0.09 \mathrm{~m}$. This requirement is satisfied in the formulated control system as shown in Fig 4.8. The result also shows that the upper mass or fuselage displacement is reduced. Lower and upper mass velocity versus time is shown in Fig 4.9. Upper mass velocity is slightly reduced however, the lower mass velocity is increased before time $t=0.11 \mathrm{~s}$ and decreased when $t>0.11 s$. 

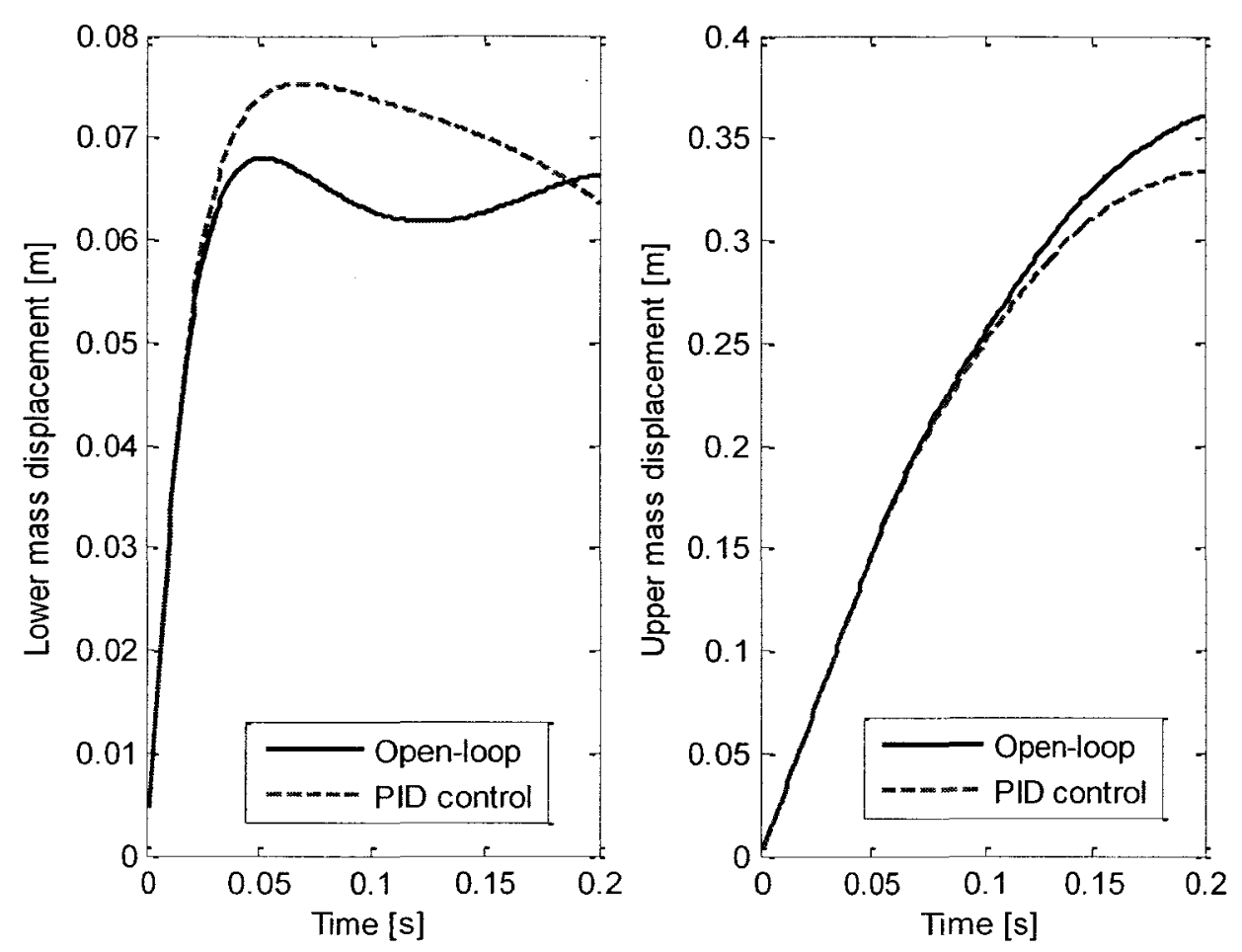

Fig 4.8 Time history of lower and upper mass displacement in open-loop and control system, $v=3.2 \mathrm{~m} / \mathrm{s}$.
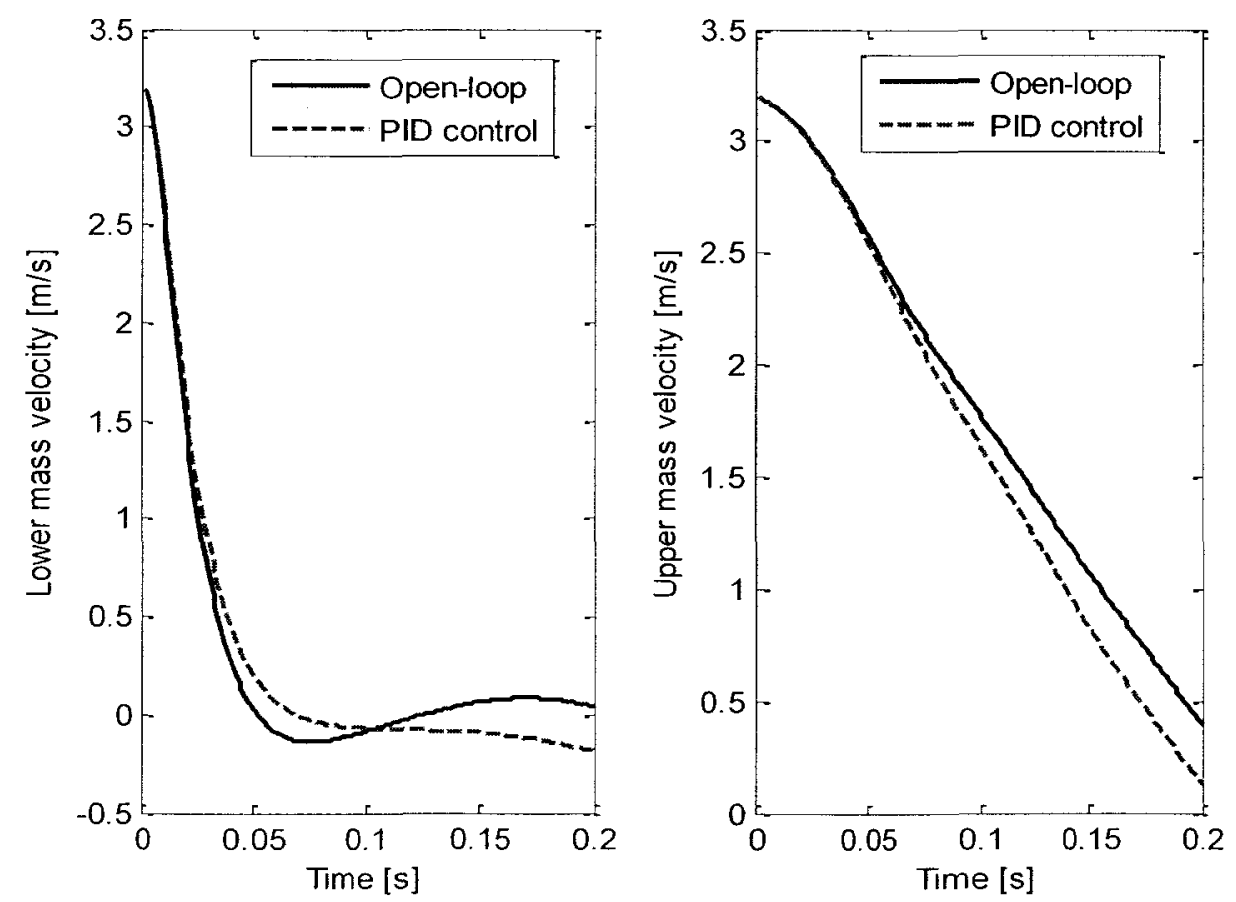

Fig 4.9 Time history of lower and upper mass velocity in control and open-loop system, $\mathrm{v}=3.2 \mathrm{~m} / \mathrm{s}$. 
Fig 4.10 shows the lower and upper mass acceleration factor versus time. As it can be seen peak value of the acceleration of the lower mass is significantly reduced by employing the PID controller to the MR landing gear system. However, the acceleration of the upper mass is slightly increased. As shown earlier (Fig 2.8), the touchdown occurs in less than $0.3 \mathrm{~s}$. The primary purpose of formulation of the PID controller for the selected landing gear system is to prevent hard landing by minimizing the acceleration of the shock strut and consequently acceleration of the lower mass during impact. This strategy does not consider the ride comfort of the aircraft and consequently the acceleration of the upper mass. Therefore ride quality of the aircraft might be fairly deteriorated due to increases in acceleration of the upper mass. In order to prevent hard landing and consequently prevent structural damages, the pilot needs to control stability of the aircraft in a very short duration of impact. It should be noted that drive stability and ride comfort are the criteria which conflict each other while controlling the vibration of the landing gear [37].

The shock strut displacement and acceleration factor are shown in Fig 4.11. As observed in Fig 4.11, the shock strut is in compression phase within the simulation time which is $t=0.2 \mathrm{~s}$. As can be seen, the displacement is reduced and is within the acceptable range of $x_{s}<0.38 \mathrm{~m}$. Fig 4.11 also shows that the first peak of the shock strut acceleration is significantly reduced from $10 \mathrm{~g}$ to $9 \mathrm{~g}$ which means $11 \%$ attenuation in acceleration. Therefore the vibration due to the landing impact and consequently dynamic stress on the fuselage are significantly attenuated by employing the PID controller. 


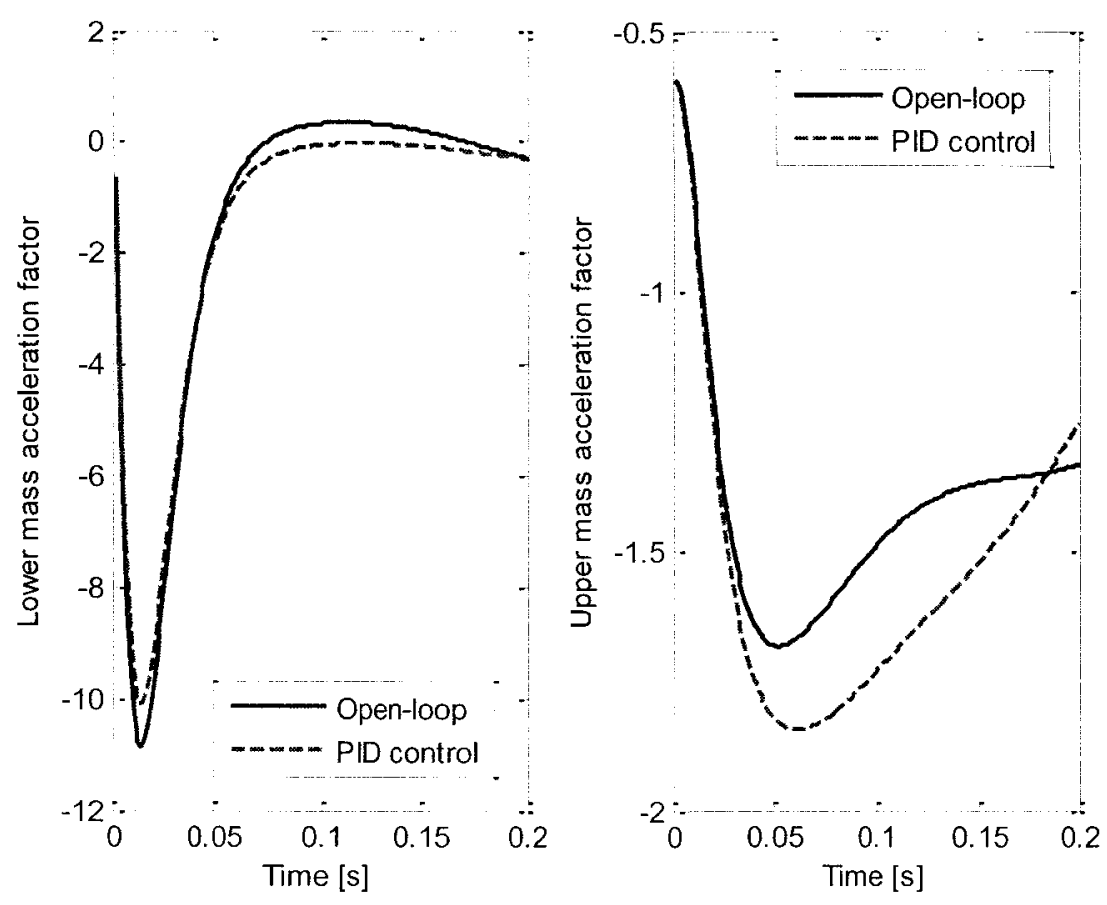

Fig 4.10 Time history of lower and upper mass acceleration in open-loop and control system, $v=10.5 \mathrm{ft} / \mathrm{s}$.
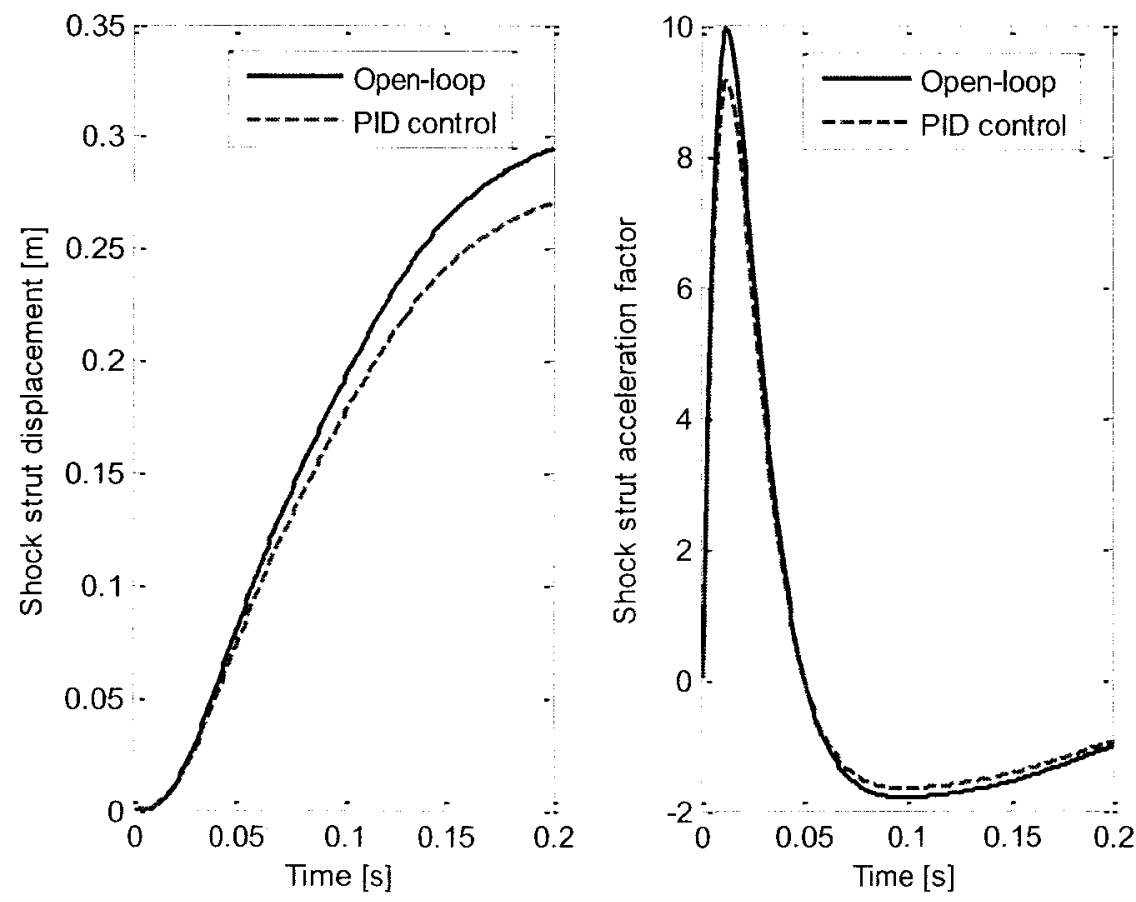

Fig 4.11 Time history of shock strut displacement and acceleration in open-loop and control system, $v=3.2 \mathrm{~m} / \mathrm{s}$. 
One can substitute the desired MR damping force and desired shock strut velocity, attained from the controller, into Eq. (3.33) and consequently obtain the desired yield stress. The desired yield stress values can then be placed in Eq. (3.39) to obtain the inverse command current.

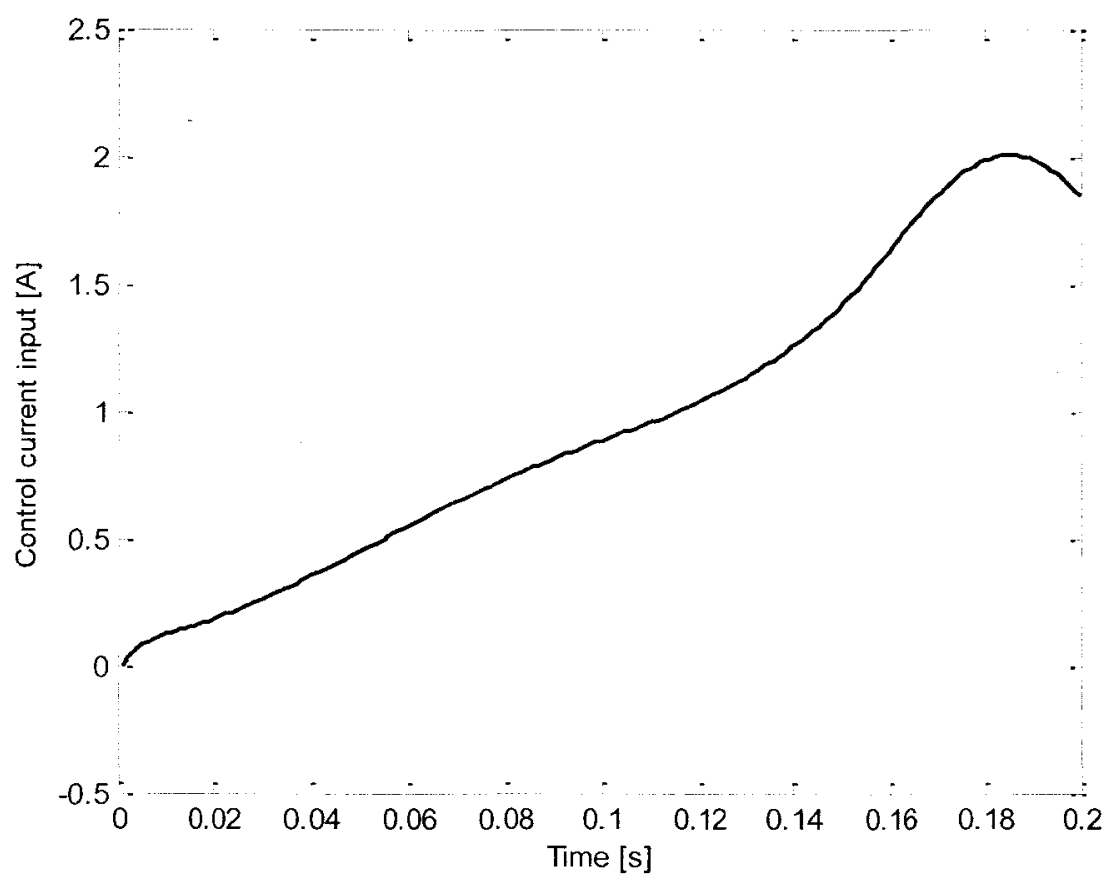

Fig 4.12 Time history of control current input, $v=3.2 \mathrm{~m} / \mathrm{s}$.

Fig 4.12 presents the control current input for the formulated control system. As observed in Fig 4.12, the current is increased steadily as the time passes until $t=0.185 \mathrm{~s}$ and decreases after that. As can be seen in Figs 4.8 and 4.11 , when the current is at its maximum level at $t=0.185 \mathrm{~s}$, the tire is coming back to its original shape and the shock strut is in compression phase.

Figs $4.13-4.19$ present control performance of the MR landing gear system under PID controller with sink velocity of $v=3.7 \mathrm{~m} / \mathrm{s}(12 \mathrm{ft} / \mathrm{s})$. Comparing these figures with those presented earlier for the sink velocity of $v=3.2 \mathrm{~m} / \mathrm{s}$ assists us to study the 
effect of sink speed increase on aircraft impact. This parameter is considered as the most important factor in the severity of the landing impact [35].

Fig 4.13 shows the shock strut force versus time. Comparing Fig 4.5 with Fig 4.13, one can conclude that the damping force and gas spring force is increased in the system with higher sink speed. Fig 4.14 shows the shock strut force versus shock strut displacement. Comparing Fig 4.6 with Fig 4.14, the difference between shock strut force in open loop system and PID controller is decreased in the system with higher sink speed.

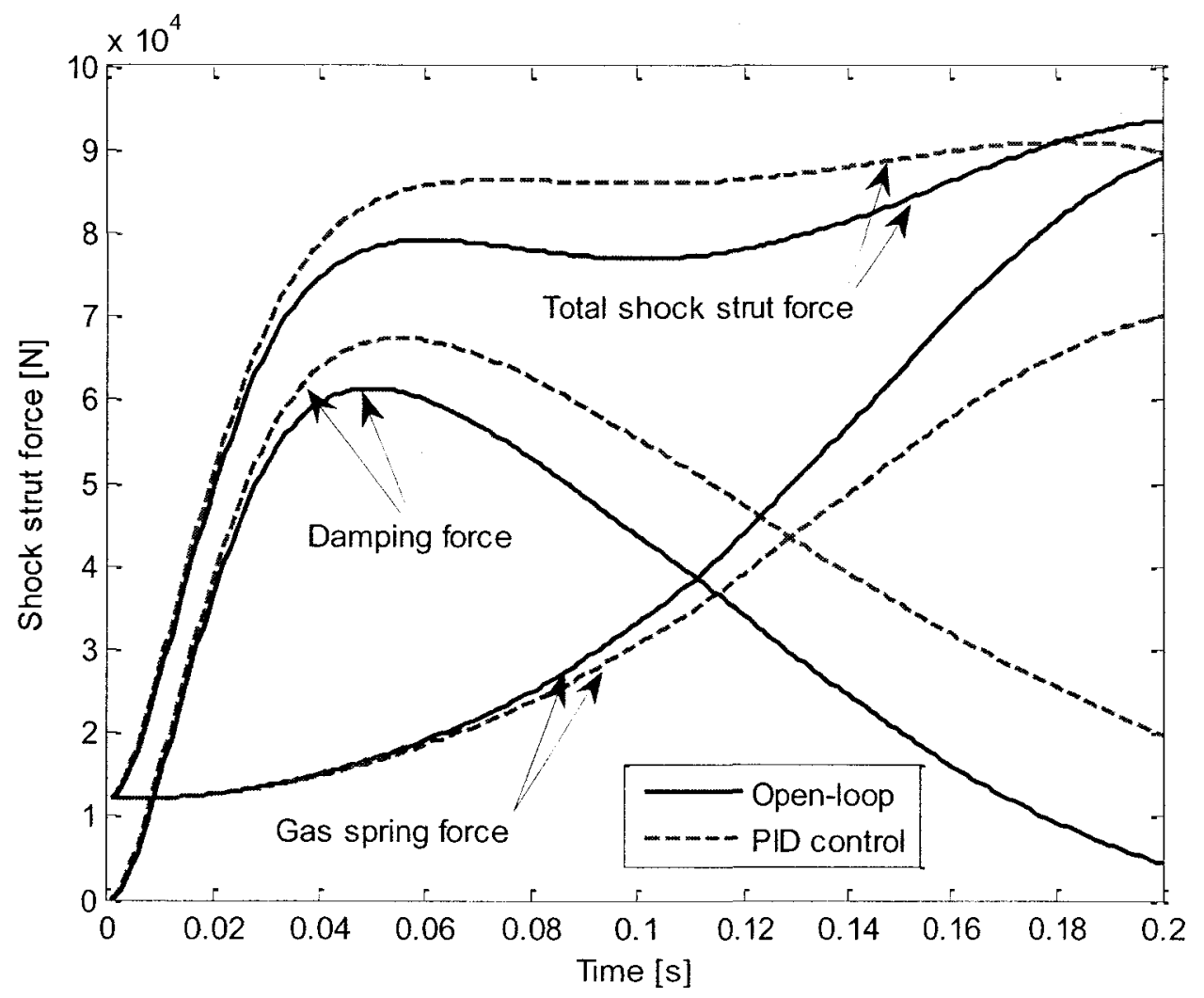

Fig 4.13 Time history of shock strut force in open-loop and control system, $v=3.7 \mathrm{~m} / \mathrm{s}$. 


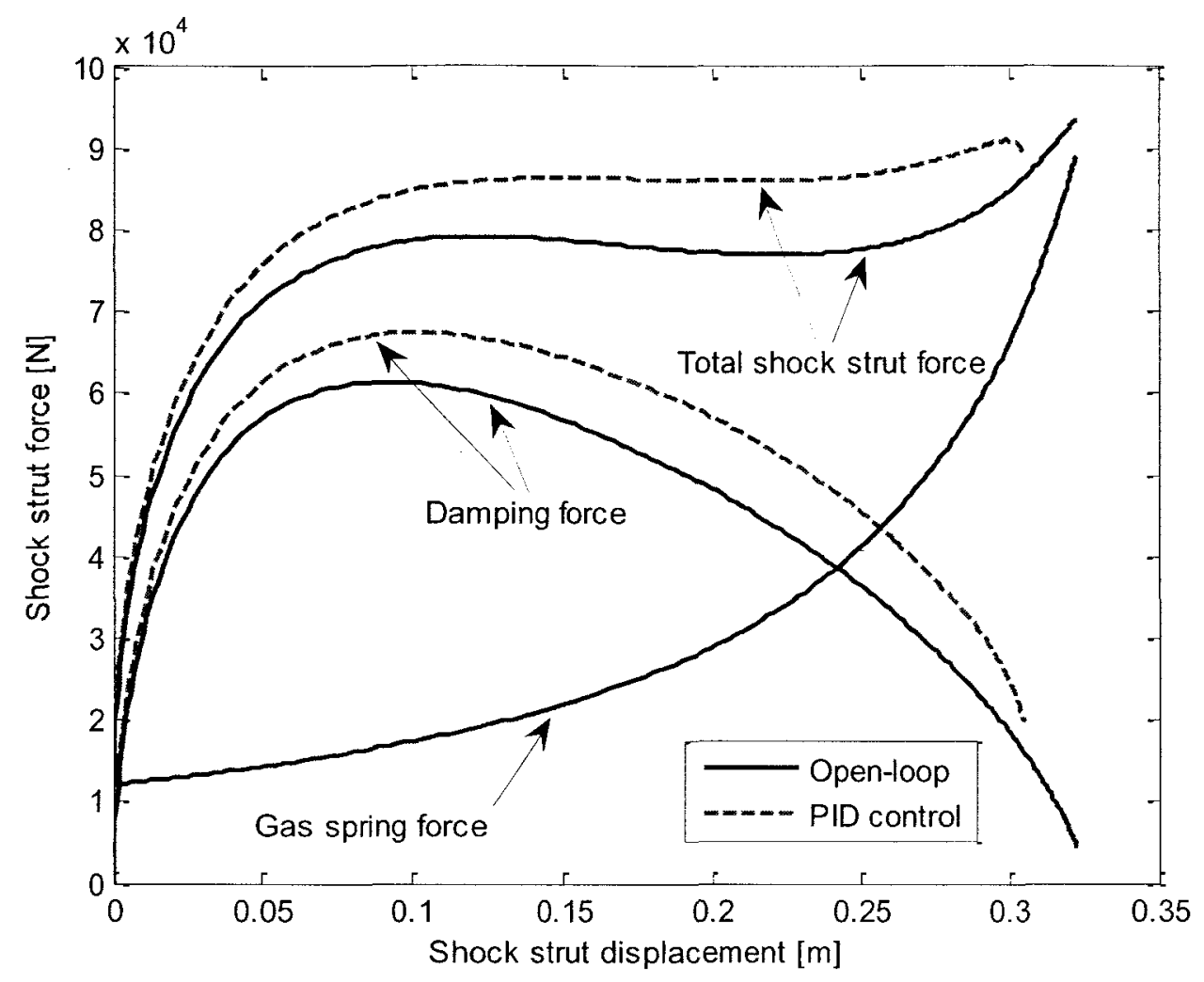

Fig 4.14 Shock strut force vs. shock strut displacement in open-loop and control system, $\mathrm{v}=3.7 \mathrm{~m} / \mathrm{s}$.

As observed in Fig 4.15, the dissipated energy is significantly increased because the sink velocity is higher than that of Fig 4.7. Applying Eq. (4.36) for maximum energies in Fig 4.15 shows that the energy dissipated through shock strut in the open-loop system is $89 \%$ of that dissipated in the MR damper in closed control loop. Therefore, it can be noted that MR fluids improve the efficiency of the shock strut by $12.3 \%$ which is far less than that for sink velocity of $3.2 \mathrm{~m} / \mathrm{s}$. 


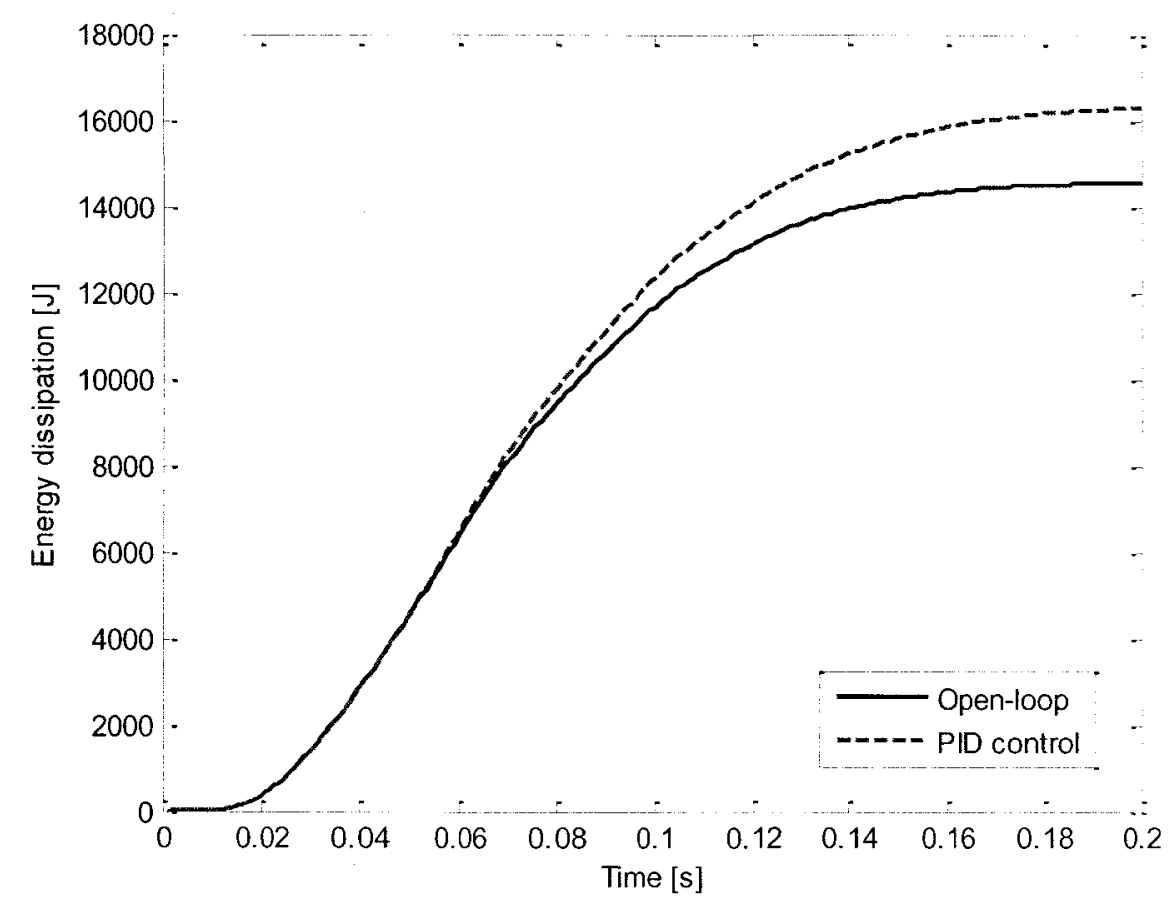

Fig 4.15 Time history of energy dissipation in open-loop and control system, $v=3.7 \mathrm{~m} / \mathrm{s}$.

As it can be seen from Figs $4.16-4.18$, the lower mass and upper mass displacement, velocity and acceleration factor are significantly increased for sink velocity of $v=3.7 \mathrm{~m} / \mathrm{s}$. As discussed before, maximum tire deflection for the tire used in this work is $0.09 \mathrm{~m}$. This requirement is satisfied in the formulated control system as shown in Fig 4.16. 

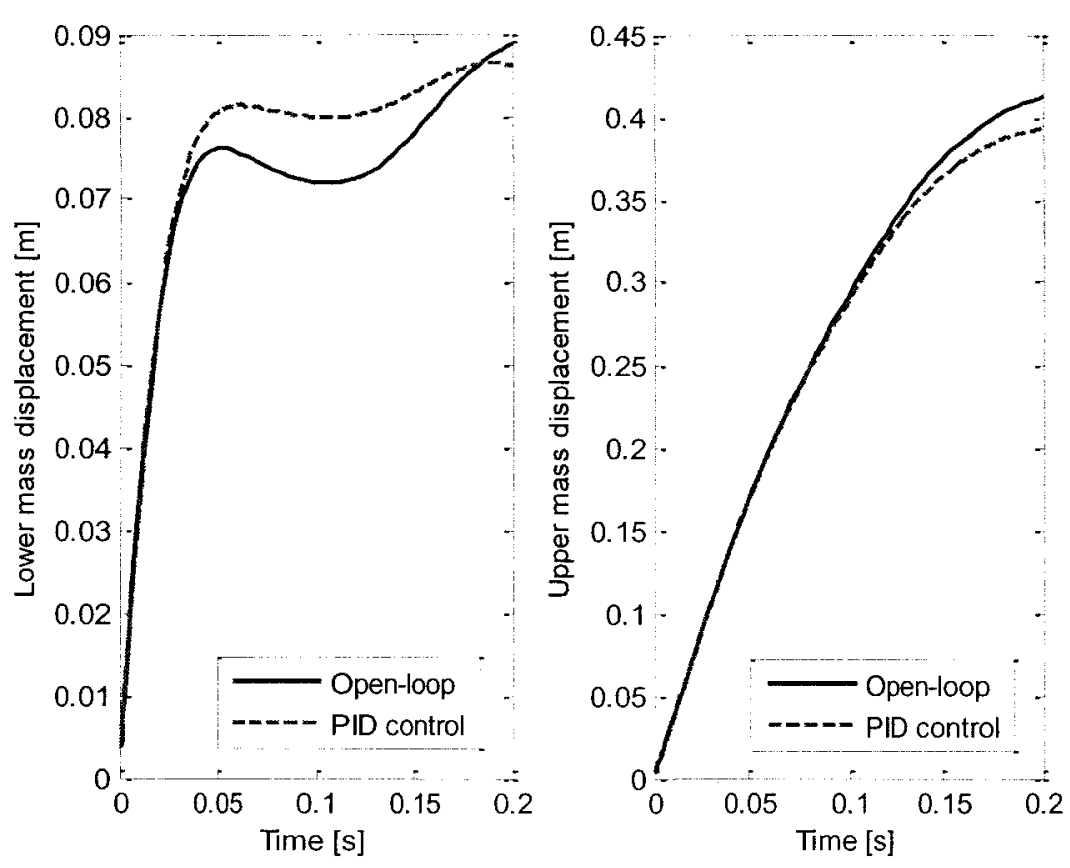

Fig 4.16 Time history of lower and upper mass displacement in open-loop and control system, $\mathrm{v}=3.7 \mathrm{~m} / \mathrm{s}$.
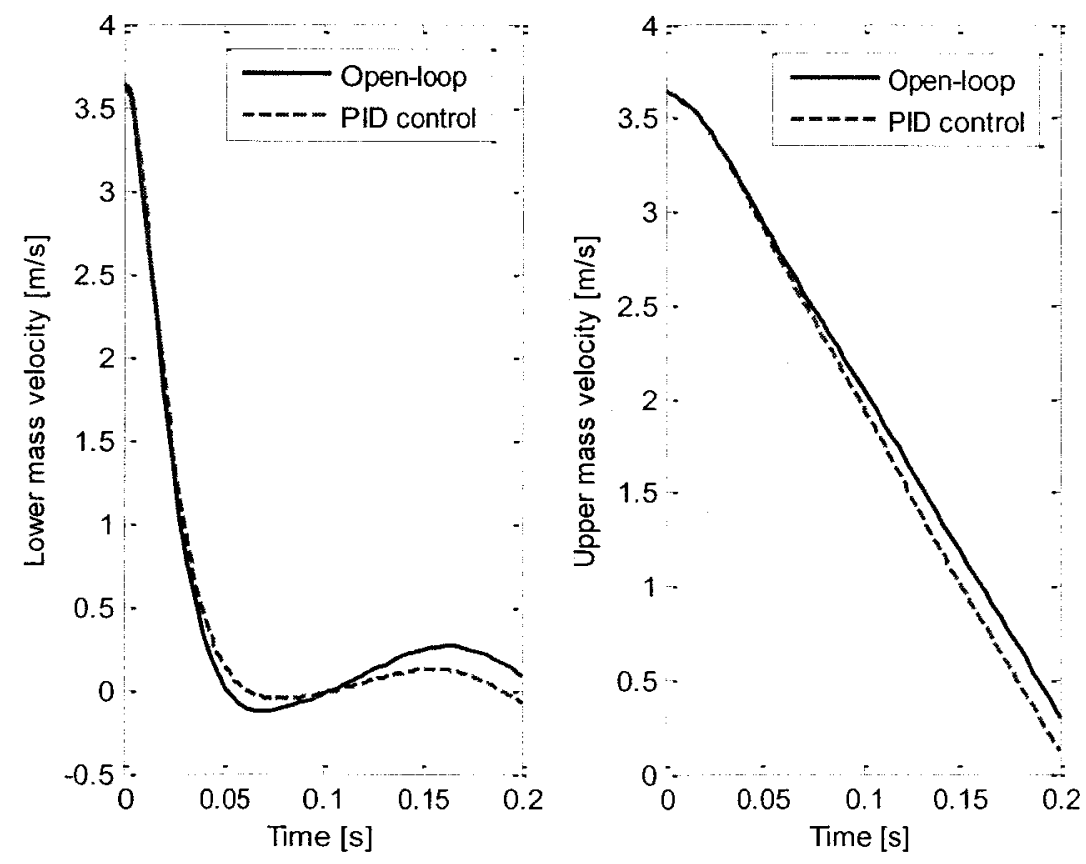

Fig 4.17 Time history of lower and upper mass velocity in control and open-loop system, $\mathrm{v}=3.7 \mathrm{~m} / \mathrm{s}$. 

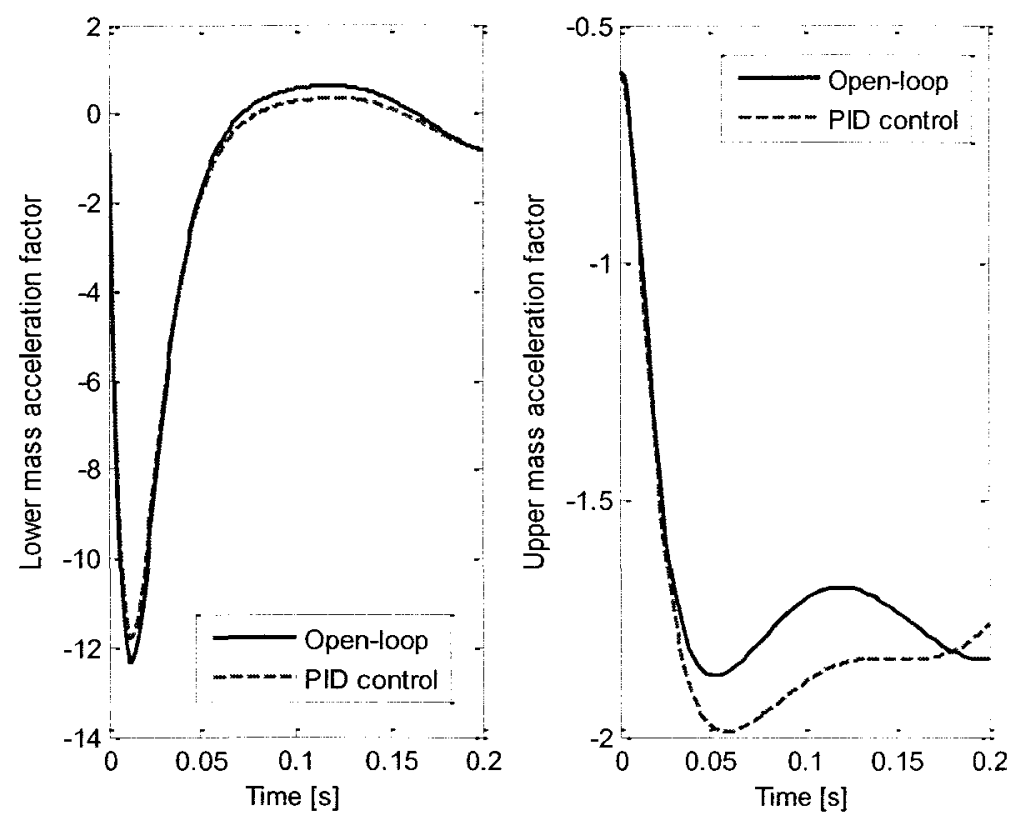

Fig 4.18 Time history of lower and upper mass acceleration in open-loop and control system, $\mathrm{v}=3.7 \mathrm{~m} / \mathrm{s}$.

The shock strut displacement and acceleration factor are also shown in Fig 4.19. As it can be seen, the shock strut displacement is increased and is within the acceptable range of $x_{s}<0.38 \mathrm{~m}$. The result also shows that the first peak of the shock strut acceleration is significantly reduced from $11.5 \mathrm{~g}$ in open-loop system to $10.8 \mathrm{~g}$ in control system which means $7 \%$ attenuation in acceleration. Therefore, it can be concluded that the attenuation percentage is decreased from $11 \%$ (in the system with sink velocity of $10.5 \mathrm{tf} / \mathrm{s}$ shown in Fig 4.11 ) to $7 \%$ (in the system with sink velocity of $12 \mathrm{ft} / \mathrm{s}$ shown in Fig 4.19).

Fig 4.20 presents the control current input for the formulated control system. As observed, the current is increased as the time passes until $t=0.13 \mathrm{~s}$ and decreases after that. 

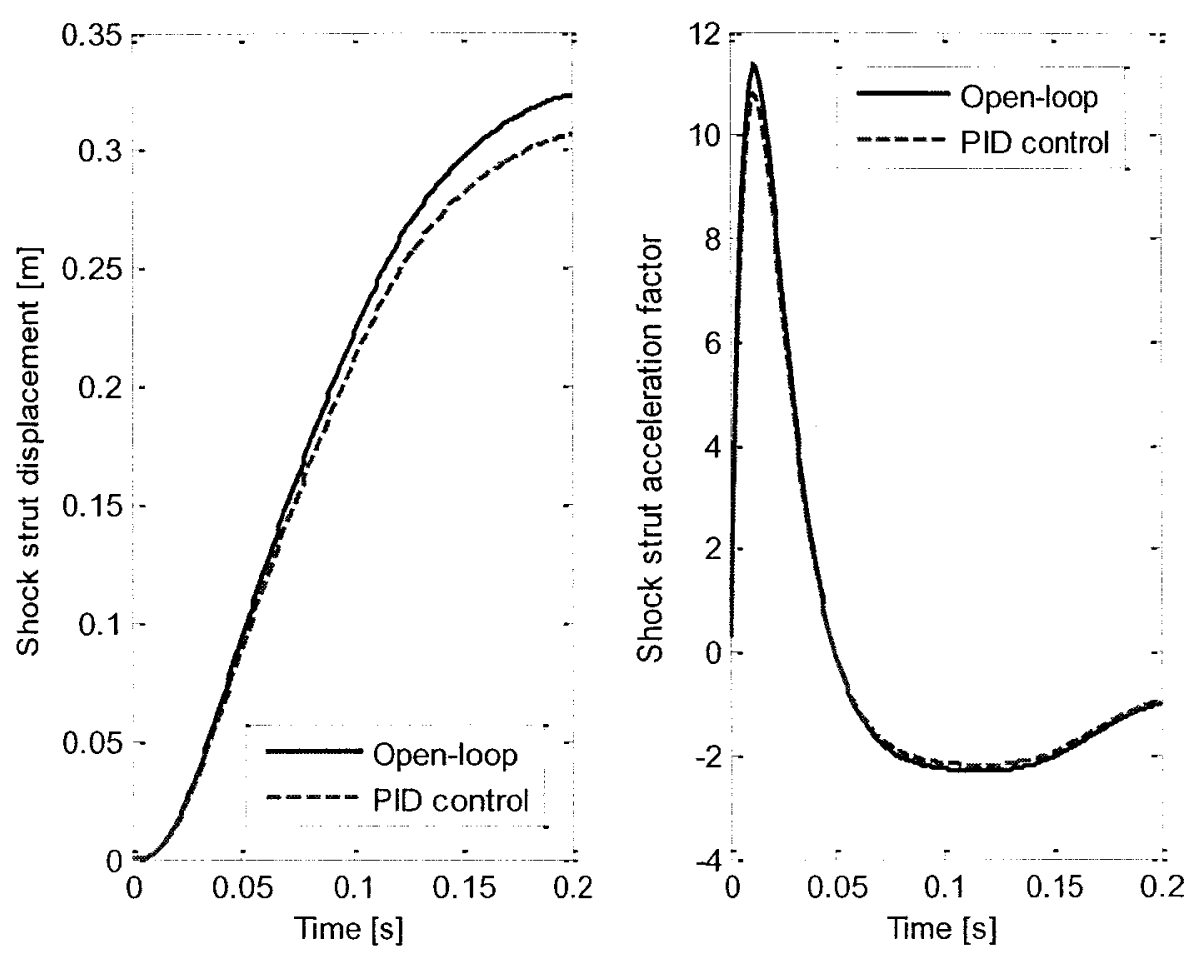

Fig 4.19 Time history of shock strut displacement and acceleration in open-loop and control system, $v=3.7 \mathrm{~m} / \mathrm{s}$.

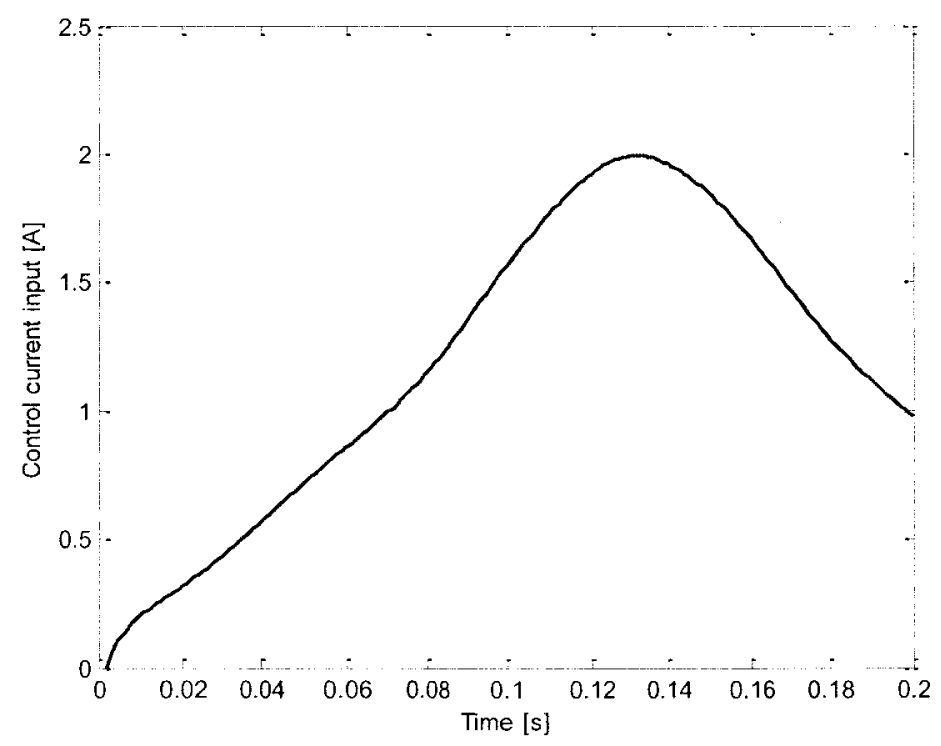

Fig 4.20 Time history of control current input, $v=3.7 \mathrm{~m} / \mathrm{s}$. 


\subsection{Summery}

A proportional-integral-derivative (PID) controller was formulated for the selected landing gear system. First the design requirements were determined and block diagram of the control system was proposed. The transfer function equations of the system were then formulated using the proposed block diagram. The control system was simulated and acceleration, velocity, displacement, damping force and the damping energy of the shock strut were presented. Desired damping force was calculated and was substituted in inverse Buckingham equation, in order to obtain desired applied current. The control current input was presented.

It was demonstrated that shock strut displacement and acceleration were significantly attenuated during impact by employing a PID controller to the MR landing gear system. 


\section{CHAPTER 5}

\section{CONCLUSIONS AND FUTURE RECOMMENDATIONS}

Modeling and analysis of a MR damper for a landing gear system used in aircraft was presented. Landing gear of a Navy A6-Intruder aircraft was used for modeling and simulation. A physical model of the shock strut was introduced and a lump mass based mathematical model of the landing gear upon the governing equations were derived and solved. Landing impact was simulated, a detailed description of the simulation was given and the results were discussed and validated. A PID controller was further formulated to reduce the acceleration encountered during landing impact. The simulations carried out for certain landing condition led to the conclusion that implementation of MR damping systems in conjunction with an appropriate control scheme would reduce the consequences related to condition that according to the present model are classified as hard landing.

It has been demonstrated that the area between the gas spring force and the total force, which represents the dissipated energy during impact, is increased by employing a PID controller to the MR landing gear system and consequently the efficiency is increased. The simulations carried out for certain landing condition lead to the conclusion that implementation of MR damping systems in conjunction with the PID control scheme increases the damping force and consequently reduces the vibration due to landing impact.

It has also been demonstrated that shock strut displacement and acceleration are significantly attenuated by employing a PID controller to the MR landing gear system. 
In the future, the proposed MR shock strut prototype can be made and its performances can be validated in the lab. The model of the MR damper can be improved based on temperature of operation. The hysteresis in the damper and the role of that in energy absorption can be evaluated.

The existing model can be extended to an elastic mass for the structure of the aircraft and consequently, simulations of various cases can be performed. A non-linear controller can also be formulated for the existing model and the results can be compared with those of the PID controller. 


\section{CONTRIBUTIONS}

The major contributions of the thesis are provided below:

1. A mathematical model of a passive landing gear system of a Navy aircraft is developed. The landing gear components are modeled and the forces associated with the passive shock strut are formulated. The shock strut's nonlinear stiffness, which is identified by gas exponent, is also studied.

2. The passive shock strut is fitted with a MR valve in order to redesign the MR shock strut. The MR shock strut model is consequently proposed which can properly express the magneto-rheological behavior of the damper. This model is based on Batterbee et al. [3] hysteresis model. Finally the associated forces of the MR shock strut are formulated.

3. A two-DOF, lump mass based model of the MR landing gear system is theoretically constructed and the governing equations are derived. The inverse model of the MR shock strut relating MR yield stress to the MR shock strut force and strut velocity is also formulated.

4. Passive and MR landing gear models are simulated and the results are demonstrated for different current excitation, sink velocity and orifice height. The effect of orifice height on the shock strut force is investigated in order to optimize the height.

5. The block diagram of the landing gear system is proposed and the transfer function equations of the system are formulated. Using the block diagram and the 
transfer function equations, a PID controller is further formulated to reduce the acceleration encountered during landing impact. 


\section{REFERENCES}

1. Howe, D., Aircraft loading and structural layout. AIAA education series. 2004: AIAA.

2. Kruger, W., et al., Aircraft landing gear dynamics: simulation and control. Vehicle System Dynamics, 1997. 28(2-3): p. 119-58.

3. Batterbee, D.C., et al., Magnetorheological landing gear: 1. a design methodology. Smart Materials and Structures, 2007. 16(6): p. 2429-40.

4. Norman, S.C., Aircraft Landing Gear Design: Principles and Practices, ed. E. Series. 1988, Washington, DC: AIAA.

5. Ross, I. and R. Edson, Electronic control for an electrohydraulic active control aircraft landing gear. NASA CR-3113. 1979.

6. Daniels, N.J., A Method for Landing Gear Modeling and Simulation with Experimental Validation. NASA CR-201601, 1996.

7. Lucas G. Horta, R.H.D., and Veloria Modeling and Validation of a Navy A6Intruder Actively Controlled Landing Gear System. NASA 1999.

8. Ghiringhelli, G.L., Testing of a semi-active landing gear control for ageneral aviation aircraft. Journal of Aircraft, 2000. 37(4): p. 606-616.

9. Choi, Y.-T. and N.M. Wereley, Vibration control of a landing gear system featuring electrorheological/magnetorheological fluids. Journal of Aircraft, 2003. 40(3): p. 432-439.

10. Milwitzky, B.C., Francis E., Analysis of Landing-Gear Behavior. 1953, NASA. 
11. Wereley, N.M. and L. Pang, Nondimensional analysis of semi-active electrorheological and magneto-rheological dampers using approximate parallel plate models. Smart materials and structures, 2000. 7: p. 732-743.

12. Rabinow, J., The magnetic fluid clutch. AIEE Transactions, 1948. 67: p. 13081315.

13. Winslow, W.M., Induced vibration of suspension. Applied physics, 1949. 20: p. 1137-1140.

14. Wang, E.R., Synthesis and Analysis of Semi-active Control Algorithms for a Magneto-Rheological Damper for Vehicle Suspension. 2005, Concordia: Montreal. p. 274.

15. Carlson, J.D. Controllable fluids in 2000 status - of ER and MR fluid technology. in Proceedings of 7th International Conference on New Actuators - ACTUATOR 2000, 19-21 June 2000. 2000. Bremen, Germany: MESSE BREMEN GMBH.

16. Spencer, B.F., et al., Phenomenological Model of a Magnetorheological damper. Engineering Mechanics, 1997. 123(3): p. 230-238.

17. Dominguez, A., R. Sedaghati, and I. Stiharu, A new dynamic hysteresis model for magnetorheological dampers. Smart Materials and Structures, 2006. 15(5): p. 1179-89.

18. Xiaojie, W. and F. Gordaninejad, Flow analysis of field-controllable, electro- and magneto-rheological fluids using Herschel-Bulkley model. Journal of Intelligent Material Systems and Structures, 1999. 10(Copyright 2000, IEE): p. 601-8.

19. Wilkinson, W.L., Non-Newtonian Fluids. 1960, London: Elsevier. 
20. Stanway, R., J.L. Sproston, and N.G. Stevens, non-linear modeling of an electrorheological vibration damper. Journal of Electrostatics, 1987. 20(Compendex): p. 167-184.

21. Gamota, D.R. and F.E. Filisko, Dynamic mechanical studies of electrorheological materials: moderate frequencies. Journal of Rheology, 1991. 35(Copyright 1991, IEE): p. 399-425.

22. Rakheja, S. and S. Sankar, Vibration and shock isolation performance of a semiactive 'on-off damper. Transactions of the ASME. Journal of Vibration, Acoustics, Stress, and Reliability in Design, 1985. 107(4): p. 398-403.

23. Lee, H.-S. and S.-B. Choi, Control and response characteristics of a magnetorheological fluid damper for passenger vehicles. Journal of Intelligent Material Systems and Structures, 2000. 11(Compendex): p. 80-87.

24. Choi, S.-B., et al., Control and response characteristics of a magneto-rheological fluid damper for passenger vehicles. Proceedings of SPIE - The International Society for Optical Engineering, 2000. 3985: p. 438-443.

25. Lam, A.H.F. and L. Wei-Hsin, Semi-active control of automotive suspension systems with magneto-rheological dampers. International Journal of Vehicle Design, 2003. 33(1-3): p. 50-75.

26. Batterbee, D.C., et al., Magnetorheological landing gear: 2. Validation using experimental data. Smart Materials and Structures, 2007. 16(6): p. 2441-52.

27. Lou, Z., et al., Electrorheologically controlled landing gear. Aerospace Engineering (Warrendale, Pennsylvania), 1993. 13(6): p. 17-22. 
28. Berg, C.D. and P.E. Wellstead. The application of a smart landing gear oleo incorporating electrorheological fluid. 1998. Bristol, UK: IOP Publishing.

29. Ghiringhelli G.L., G.S., Semi-Active Landing Gear Control Design Using a Multibody Code, in Proceedings of the International Forum on Aeroelasticity and Structural Dynamics. 2003: Amsterdam.

30. Daniels, J.N., A Method for Landing Gear Modeling and Simulation With Experimental Validation. NASA CR-201601. 1996.

31. Horta, L.G., R.H. Daugherty, and Veloria, Modeling and Validation of a Navy A6-Intruder Actively Controlled Landing Gear System. NASA 1999.

32. Milwitzky, B. and F.E. Cook, Analysis of Landing-Gear Behavior, in NASA. 1953.

33. Besinger, F.H., D. Cebon, and D.J. Cole, Force control of a semi-active damper. Vehicle System Dynamics, 1995. 24(Copyright 1995, IEE): p. 695-723.

34. Seung-Jin, H., P. Kihong, and P. Sung-Ho, Performance and design consideration for continuously controlled semi-active suspension systems. International Journal of Vehicle Design, 2000. 23(Copyright 2000, IEE): p. 376-89.

35. Firoozrai, A., Study of Aircraft Structure during Landing Impact. 2008, Concordia: Montreal. p. 97.

36. Dorf, R.C. and R.H. Bishop, Modern control systems. 2000, NJ, USA: PrenticeHall, Inc. . 831.

37. Lee, D.Y., et al., Performance Evaluation on Vibration Control of MR Landing Gear. Journal of Physics, 2009. 149(1). 


\section{APPENDICES}

\section{APPENDIX A: Development of the Pressure Drop across the Active Length of the Orifice}

To derive Buckingham equation or consequently the pressure drop across the active length of the orifice, we assume non-Newtonian time-independent fluids between stationary parallel plates which are separated by distance $D_{m}$ as shown in Fig A.1. The plates are assumed to be infinite in the $z$ direction, with no variation of any fluid property in this direction. As previously discussed, flow is also assumed to be laminar. No slip is assumed at the wall. To start with, presume a cubic element with width of $y$ and length of $L$ and depth of $a$ as shown in Fig A.1, where variable $y$ changes from 0 to $D_{m}$.

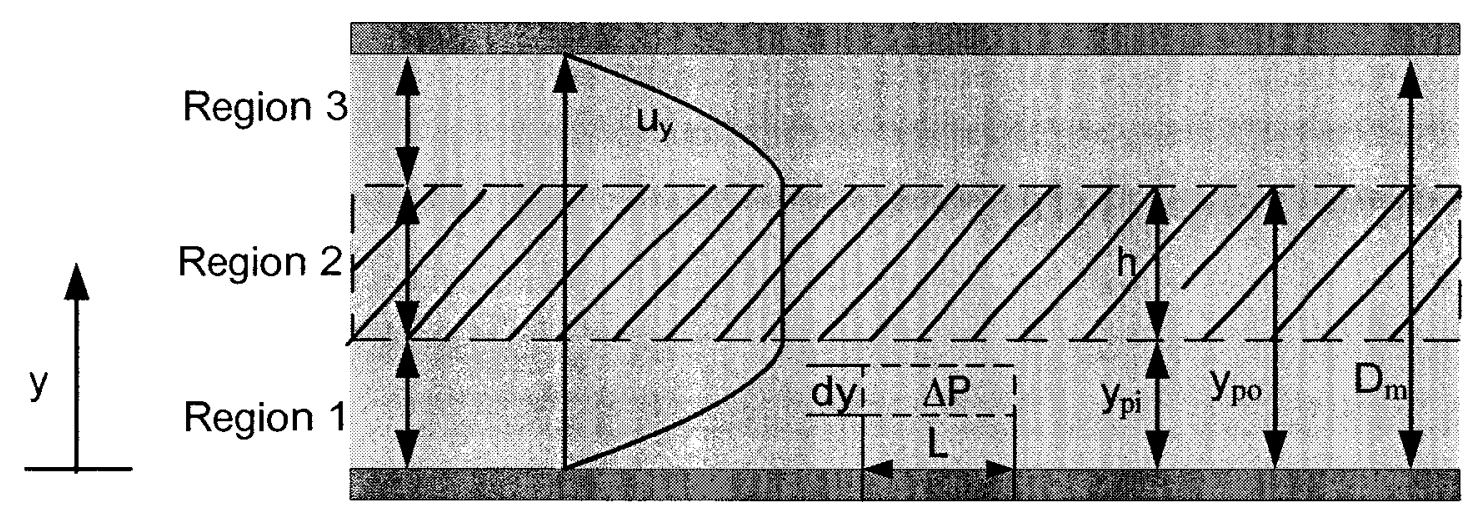

Fig A.1 Laminar flow between stationary parallel plates. 
The balance of forces on the above-mentioned element gives:

$$
\frac{d \tau}{d y}=\frac{\Delta \mathrm{P}}{L}
$$

where $\tau$ is the shear stress on the border of the element and $\Delta \mathrm{P}$ is the pressure drop across the length of the element as shown in Fig A.1. As it was shown in Eq. $(2,10)$, when $\left|\tau_{y}\right|<|\tau|$ then the shear rate is non-zero and can be described by the following equation:

$$
\tau=\tau_{y} \operatorname{sgn}(u)+\mu_{p} \frac{d u}{d y}
$$

One can substitute $\tau$ from Eq. (A.2) into Eq. (A.1) and obtain the velocity of the flow, $u$, by direct integration. Thus:

$$
u=\frac{\Delta \mathrm{P}}{2 \mu_{p} L} y^{2}+c_{1} y+c_{2}
$$

where $c_{1}$ and $c_{2}$ are constant values and can be found by using boundary conditions.

As it can be seen from Fig A.1, the flow gap is divided into three regions where the regions 1 and 3 present the post-yield condition $\left(\tau>\tau_{y}\right)$ and region 2 presents the pre-yield condition $\left(\tau<\tau_{y}\right.$ ) of the Bingham plastic flow. The velocity in region 1,2 and 3 can be shown by $u_{1}, u_{2}$ and $u_{3}$ respectively.

The boundary conditions for region 1 are $u_{1}(0)=0$ and $u_{1}^{\prime}\left(y_{p i}\right)=0$. Therefore the velocity profile can be expressed as:

$$
u_{1}=\frac{\Delta \mathrm{P}}{2 \mu_{p} L}\left(y^{2}-2 y_{p i} y\right)
$$

Since velocity is constant in region 2 , one can conclude that:

$$
u_{2}=u_{1}\left(y_{p i}\right)=-\frac{\Delta \mathrm{P}}{2 \mu_{p} L} y_{p i}^{2}
$$


The boundary conditions for region 3 are $u_{3}\left(D_{m}\right)=0$ and $u_{3}{ }^{\prime}\left(y_{p o}\right)=0$. Therefore the velocity profile can be expressed as:

$$
u_{3}=\frac{\Delta \mathrm{P}}{2 \mu_{p} L}\left[y^{2}-D_{m}^{2}+2 y_{p o}\left(D_{m}-y\right)\right]
$$

Integrating Eq. (A.2), one can obtain shear stress equation for region 2 as:

$$
\tau=\frac{y \Delta \mathbf{P}}{L}+c_{3}
$$

where $c_{3}$ is a constant value. The boundary conditions $\tau\left(y_{p i}\right)=\tau_{y}$ and $\tau\left(y_{p o}\right)=\tau_{y}$ yield to the following equation:

$$
y_{p o}-y_{p i}=\frac{2 L \tau_{y}}{|\Delta \mathrm{P}|}=h
$$

Considering Fig (A.1), one can write:

$$
y_{p o}+y_{p i}=D_{m}
$$

Using system of Equations (Eq. (A.8) and Eq. (A.9)), one can solve for $y_{p o}$ and $y_{p i}$ as:

$$
y_{p i}=\frac{D_{m}-h}{2}
$$

and

$$
y_{p o}=\frac{D_{m}+h}{2}
$$

Further, the flow rate, $Q$, through the orifice can be provided as:

$$
Q=\int_{0}^{D_{m}} u(y) a d y
$$

The volumetric flow rate in the Eq. (A.9) can be written as the combination of the volumetric flow rate for region 1,2 and 3 as:

$$
Q=a \int_{0}^{y_{p i}} u_{1}(y) d y+a \int_{y_{p i}}^{y_{p o}} u_{2}(y) a d y+a \int_{y_{p 0}}^{D_{m}} u_{3}(y) a d y
$$


Substituting $u_{1}, u_{2}$ and $u_{3}$ from Eqs (A.4), (A.5) and (A.6), respectively, into Eq (A.14) one can obtain:

$Q=-\frac{\mathrm{a} \Delta \mathrm{P}}{2 \mu_{p L} L}\left[\left(\frac{2 y_{p i}{ }^{3}}{3}\right)+\left(y_{p i}{ }^{2} y_{p o}-y_{p i}{ }^{3}\right)+\left(-\frac{2 y_{p 0}{ }^{3}}{3}+\frac{2 D_{m}{ }^{3}}{3}-2 D_{m}{ }^{2} y_{p o}+2 D_{m} y_{p 0}{ }^{2}\right)\right]$

One can substitute $y_{p i}$ and $y_{p o}$ from Eqs. (A.8) and (A.9) into Eq. (A.15) and get:

$$
4\left(\frac{L}{D_{m} \Delta P}\right)^{3} \tau_{y}^{3}-3\left(\frac{L}{D_{m} \Delta P}\right) \tau_{y}+\left(1-\frac{12 \mu_{p} L Q}{a D_{m}{ }^{3} \Delta P}\right)=0
$$

Eq. (A.16) is called Buckingham equation which can be written for the active length of the orifice as it contains non-Newtonian fluids. Substituting $L=l_{m r}$ and $\Delta P=\Delta P_{m r}$ in Eq. (A.18), one can get:

$$
4\left(\frac{l_{m r}}{D_{m} \Delta P_{m r}}\right)^{3} \tau_{y}{ }^{3}-3\left(\frac{l_{m r}}{D_{m} \Delta P_{m r}}\right) \tau_{y}+\left(1-\frac{12 \mu_{p} l_{m r} Q}{a D_{m}{ }^{3} \Delta P_{m r}}\right)=0
$$

Therefore, $\Delta P_{m r}$ is achieved in terms of $Q$ and $\tau_{y}$. 


\section{APPENDIX B: Calculation of the Gas Pressure and Volume at Full Extension}

Loads at fully extended, static and compressed positions are first calculated using compression ratios ${ }^{4}$. This process starts with deciding on the value of the compression ratios. According to the aircraft manufacturers' code of standard, the following ratios are used for large aircrafts [4]:

Static to extended: $4 / 1$

Compressed to static: $3 / 1$

Since A6 Intruder is considered as a large aircraft, the above-mentioned ratios are used in our calculation. Having the load at static position, $R_{1}$, which is equal to strut load at maximum gross weight and calculated in tire modeling section, one can calculate loads at fully extended and compressed positions as

Load extended: $R_{e}=1 / 4 \times 10864.34=2716.1 \mathrm{lb}$

Load Static: $\mathrm{R}_{1}=10864.34 \mathrm{lb}$

Load compressed $=R_{c}=3 \times 10864.34=32593 \mathrm{lb}$

Static pressure, $P_{g s}$, can be calculated by dividing the static load, $\mathrm{R}_{1}$, by the upper chamber area, $A_{u}$, as

$$
P_{g s}=\frac{R_{1}}{A_{u}}=\frac{10864.34 \mathrm{lb}}{28.2743 \mathrm{in}^{2}}=384.2479 p s i
$$

Using compression ratios, the fully extended pressure, $P_{g e}$, and the compressed pressure, $P_{g c}$, can be estimated as

$$
P_{g e}=1 / 4 \times P_{g s}=1 / 4 \times 384.2479 p s i=96.0620 p s i=662324.17 \text { Pas }
$$

\footnotetext{
${ }^{4}$ Compression ratio is the ratio of the pressure at one point like fully compressed position divided by the pressure at another point such as fully extended position.
} 


$$
P_{g c}=3 \times P_{g s}=3 \times 384.2479 p s i=1152.7 p s i
$$

The displacement $D$ is defined as the product of the total stroke, $S$, and the lower chamber area, $A_{u}$

$$
D=S . A_{u}=15 \text { in } \times 28.2743 \mathrm{in}^{2}=424.1145 \mathrm{in}^{3}
$$

Gas volumes at static extension, $V_{\mathrm{gs}}$, full extension, $V_{g e}$, and compressed position, $V_{g c}$, can be calculated applying polytropic gas law for a closed system:

$$
P_{g s} V_{g s}{ }^{n}=P_{g e} V_{g e}{ }^{n}=P_{g c} V_{g c}{ }^{n}=C
$$

where $C$ is a constant and $n$ is the polytropic exponent which was assumed to be $n=$ 1.35 in Chapter 2.

Substituting for $V_{g c}=V_{g e}-\mathrm{D}$ in the Eq. (A.23), one can solve for $V_{g e}$ as:

$$
V_{g e}{ }^{n}=\frac{P_{g c}\left(V_{g e}-\mathrm{D}\right)^{n}}{P_{g e}}=\frac{1152.7\left(V_{g e}-424.1145\right)^{1.35}}{96.0620}
$$

Thus, $V_{g e}$ can be calculated as:

$$
V_{g e}=473.58 \mathrm{in}^{3}=0.0074 \mathrm{~m}^{3}
$$




\section{APPENDIX C: Zero-Input Response}

The response of linear systems can always be expressed as a combination of zeroinput response and zero-state response. In this section general properties of the zero-input response of the proposed control system are illustrated. The response of the proposed control system due to nonzero initial state was given in Eq. (4.27) as:

$$
X_{u}(s)-X_{L}(s)=\frac{\left(m_{u} v_{0}\right)\left(c_{t} s+k_{t}\right)+m_{u} x_{0} k_{t} s}{\Delta}
$$

where $\Delta$ was expressed in Eq. (4.14) as:

$$
\Delta=\left(m_{u} s^{2}+c_{0} s+k_{g i}\right)\left(m_{L} s^{2}+s\left(c_{0}+c_{t}\right)+k_{g i}+k_{t}\right)-\left(c_{0} s+k_{g i}\right)\left(c_{0} s+k_{g i}\right)
$$

Substituting $\Delta$ from Eq. (C.2) into Eq. (C.1), one can expand Eq. (C.1) as:

$$
X_{u}(s)-X_{L}(s)=\frac{a_{1}}{s-b_{1}}+\frac{a_{2}}{s-b_{2}}+\frac{a_{3}}{s-b_{3}}+\frac{a_{4}}{s-b_{4}}+\frac{a_{5}}{s-b_{5}}
$$

where $a_{i}$ and $b_{i}$ are complex numbers and are calculated in table (C.1) for a landing gear system with the sink velocity of $v_{0}=4.3 \mathrm{ft} / \mathrm{s}$.

Table C.1 Calculation of the constants $\boldsymbol{a}_{\boldsymbol{i}}$ and $\boldsymbol{b}_{\boldsymbol{i}}$

\begin{tabular}{|c|c|}
\hline$a_{i}$ & $b_{i}$ \\
\hline $8606.293+5437.405 i$ & $-61.559+73.135 i$ \\
\hline $8606.293-5437.405 i$ & $-61.559-73.135 i$ \\
\hline$-8606.293-137678.640 i$ & $-0.996+6.674 i$ \\
\hline$-8606.293+137678.640 i$ & $-0.996-6.674 i$ \\
\hline
\end{tabular}

As it can be seen from Eq. (C.3), $b_{i}$ are the four roots of the denominator of Eq.

(C.1) or equivalently the four roots of the $\Delta$. These roots are defined as the modes of the system which govern the form of the zero-input response. 
The application of inverse Laplace transform to Eq. (C.3) yields:

$$
x_{u}(t)-x_{L}(t)=n(t)=a_{1} e^{b_{1} t}+a_{2} e^{b_{2} t}+a_{3} e^{b_{3} t}+a_{4} e^{b_{4} t}
$$

where $n(t)$ is defined as the zero-input response and $a_{i} e^{b_{i} t}$ is exponential function. 